\title{
WITHIN AND BEYOND IMMUNOMODULATORY STRATEGIES \\ AGAINST AUTOIMMUNE DIABETES: ANTIGEN-SPECIFIC TOLERANCE AND ENDOTHELIAL REGENERATION
}

\author{
A Dissertation \\ Presented to \\ The Faculty of the Graduate School \\ University of Missouri
}

\begin{abstract}
In partial fulfillment
Of the requirements for the Degree

Doctor of Philosophy
\end{abstract}

\begin{abstract}
By
Xiaoxiao Wan

Dr. Habib Zaghouani, Mentor \& Dissertation Advisor
\end{abstract}

May - 2013 
The undersigned, appointed by the dean of the Graduate School, have examined the dissertation entitled

\section{WITHIN AND BEYOND IMMUNOMODULATORY STRATEGIES AGAINST AUTOIMMUNE DIABETES: ANTIGEN-SPECIFIC TOLERANCE AND ENDOTHELIAL REGENERATION}

presented by Xiaoxiao Wan

a candidate for the degree of Doctor of Philosophy and hereby certify that, in their opinion, it is worthy of acceptance.

Dr. Habib Zaghouani

Dr. Helen Mullen

Dr. Craig Franklin

Dr. David Lee

Dr. Ulus Atasoy 


\section{ACKNOWLEDGEMENTS}

Throughout my graduate career, many people have helped and supported me. First, I would like to thank my parents, who have to tolerate being away from their only child but never complained a little bit. They always tell me that no matter what I may get or lose, they will be there for me. Their words, care, and sacrifice are the source of the power that encourages me to forge my way to where I am.

I want to express my gratitude to my advisor and mentor, Habib Zaghouani. Six years ago, he gave me a life-time opportunity that started all of this. He made me understand how difficult it would be for me to achieve anything. He told me to seize every possible chance, cherish what I have, and never stop working even when I fall. It is his constant challenge that makes me think, practice and try my best. It is his generous support that makes me believe that I can achieve even more.

I owe a special thanks to Betul Guloglu. It is very fortunate for me to have a chance to learn from her since the beginning of my graduate study. Whenever I have a scientific problem, I consult with her and she always offers great ideas and solutions without holding anything back. Her honesty, integrity, thinking, and skills have a great impact on me from which I will benefit for a very long time. A big thank you, as well, goes to Danielle Tartar for working side by side with me and helping me out within and outside the lab. 
I also appreciate the support provided by my committee members, who not only gave great feedback on my projects, but also challenged me to become a better scientist: Dr. David Lee, Dr. Helen Mullen, Dr. Craig Franklin, and Dr. Ulus Atasoy. Your guidance was invaluable. I also want to thank all Zaghouani lab members, past and present, who have at one point or another shared this journey and provided support, including: Renu Jain, Jason Ellis, Cara Haymaker, Jason Cascio, SeungHi Yahng, Christine Hoeman, Amie Van Morlan, Mermagya Dhakal, Linda Rowland, Marie-Therese Khaillarah, Weirong Chen, Mindy Miller and the numerous undergrads and summer students that have passed through.

A big thank you to the office staff of Jana, Karen, Shelly, and Kathy. They are the glue that keeps the department together - without them none of this would be possible. 


\section{TABLE OF CONTENTS}

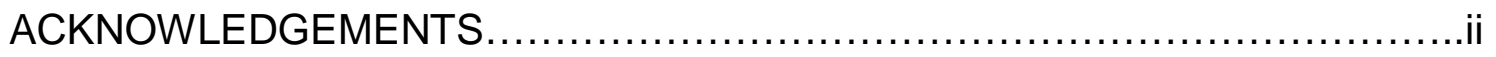

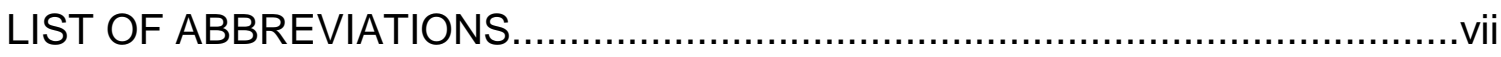

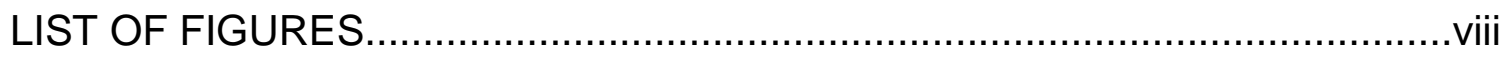

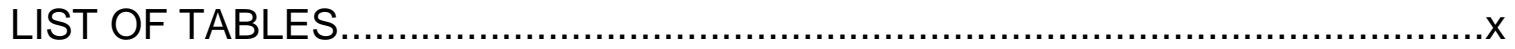

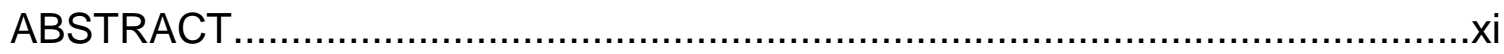

CHAPTER I: LITERATURE REVIEW

1. Antigen targets in autoimmune diabetes.............................

2. Initiation and progression of autoimmune diabetes...................8

3. Antigen-specific treatment in type 1 diabetes........................22

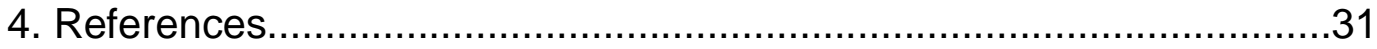

CHAPTER II: MECHANISMS UNDERLYING ANTIGEN-SPECIFIC TOLERANCE OF STABLE AND CONVERTIBLE TH17 CELLS DURING SUPPRESSION OF AUTOIMMUNE

1. ABSTRACT 46

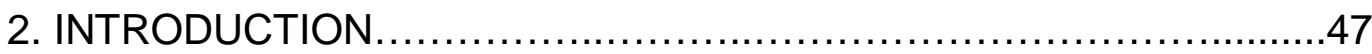

3. RESEARCH DESIGN AND METHODS $\ldots \ldots \ldots \ldots \ldots \ldots \ldots \ldots \ldots \ldots \ldots \ldots$

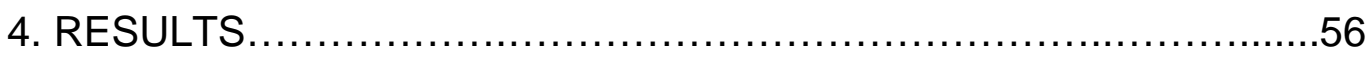

a. Environmental IL-12 is essential for Th17 cells to convert into Th1cells and efficiently induce T1D in NOD.scid mice. .56 
b. Tolerance of the converted Th1 cells accounts for suppression of T1D induced by Th17 cell transfer .60

c. Treatment with Ig-p79 interferes with CXCR3 expression on converted Th1 cells.

d. Downregulation of CXCR3 expression on regular Th1 cells after treatment with Ig-p79....... 68

e. Overexpression of CXCR3 on Th17 cells nullifies tolerance......71

f. Th17 cells are unable to undergo Th1 conversion upon transfer into NOD mice and require depletion of Tregs to transfer diabetes to the host .73

g. Treatment with Ig-p79 suppresses both islet pathology and clinical diabetes induced by stable Th17 cells .77

h. Apoptosis of stables Th17 cells represents the mechanism of the tolerance induced by treatment with $\lg -\mathrm{p} 79$ .77 j. Ig-p79-induced apoptosis is specific for Th17 but not Th1 cells..80

5. DISCUSSION .83

6. ACKNOWLEDGEMENTS .87

7. REFERENCES .88

CHAPTER III: RECOVERY FROM OVERT TYPE 1 DIABETES ENSUES WHEN IMMUNE TOLERANCE AND $\beta$-CELL FORMATION ARE COUPLED WITH REGENERATION OF ENDOTHELIAL CELLS IN THE PANCREATIC ISLETS

1. ABSTRACT 


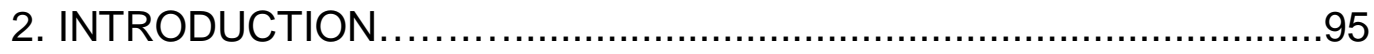

3. RESEARCH DESIGN AND METHODS .............................98

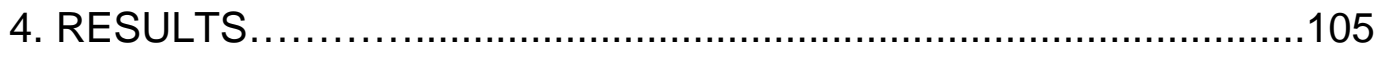

a. Ig-GAD2-driven immune modulation is not sufficient to overcome

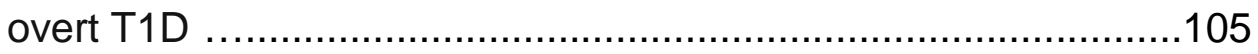

b. Transfer of BM cells alongside Ig-GAD2 treatment overcomes

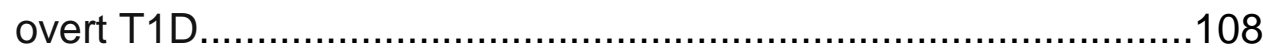

c. BM transfer promotes $\beta$-cell restoration without affecting immune tolerance.

d. Donor BM-derived cells contribute to disease remission via indirect

mechanisms 114

e. Treatment with Ig-GAD2+BM results in concomitant restoration of both $\beta$ and endothelial cells in the islet of pancreas .117

f. Donor BM gave rise to islet endothelial cells. 123

g. Transfer of purified BM EPCs sustained reversal of T1D during treatment with Ig-GAD2 125

5. DISCUSSION. 129

6. ACKNOWLEDGEMENTS .133

7. REFERENCES. 134

VITA 141 


\section{LIST OF ABBREVIATIONS}

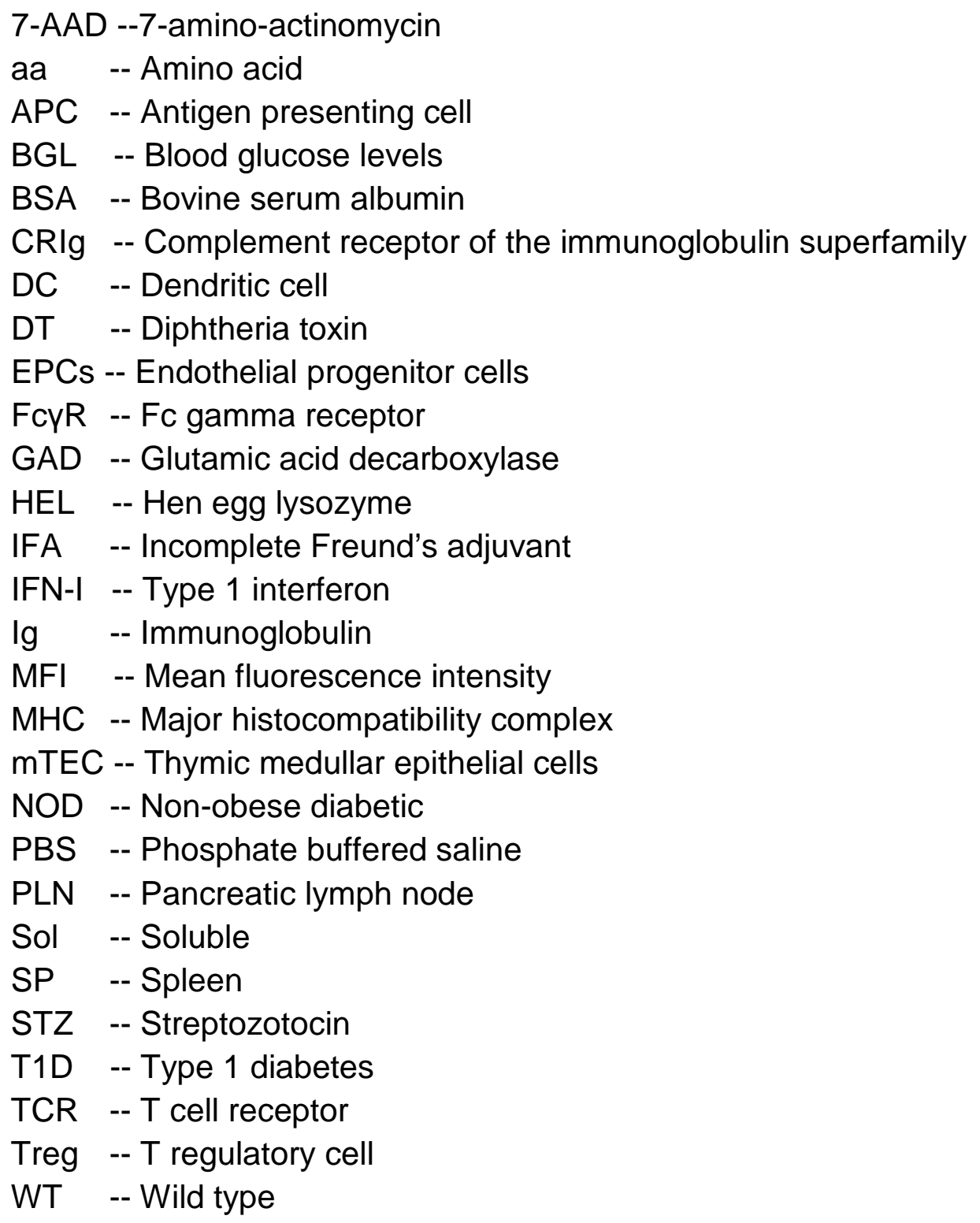




\section{LIST OF FIGURES}

\section{CHAPTER I}

Figure 1. A leading hypothesis of the formation of T1D autoimmunity. 21

\section{CHAPTER II}

Figure 1. Sorted Th1 and Th17 cells display high degree of purity...... .56

Figure 2. Th17 cells undergo cell conversion to sustain development of T1D in NOD.scid mice .59

Figure 3. Treatment with Ig-p79 retained the Th17-derived Th1 cells in the spleen and impaired their trafficking into pancreas.

Figure 4. Treatment with Ig-p79 interferes with CXCR3 expression on converted

Th1 cells 66

Figure 5. Converted Th1 cells display equivalent proliferative and survival attributes in the spleen and pancreas of Ig-p79-versus Ig-HEL- treated NOD.scid mice. 68

Figure 6. Polarized, like converted Th1 cells, down-regulate CXCR3 upon treatment of the NOD.scid host with $\lg -\mathrm{p} 79$ 70

Figure 7. Over-expression of CXCR3 in plastic Th17 cells confers resistance to converted Th1 cells against Ig-p79-induced tolerance. 72 Figure 8. Ig-p79 ameliorates islet histopathology and clinical diabetes caused by transfer of Th17 cells into NOD mice .75

Figure 9. Apoptosis of stable Th17 cells represents the mechanism underlying amelioration of clinical and histopathological diabetes by $\lg -\mathrm{p} 79$. 
Figure 10. Polarized Th1 cells transferred into NOD mice down-regulate CXCR3 expression upon treatment with Ig-p79

.82

\section{CHAPTER III}

Figure 1. Ig-GAD2 treatment could not overcome overt T1D despite induction of immune tolerance 107

Figure 2. Healthy donor BM cells transferred during immune modulation restore normoglycemia in diabetic mice.

Figure 3. Mice recipient of BM transfer during treatment with Ig-GAD2 display increased insulin-producing pancreatic $\beta$-cells

Figure 4. Insulin producing- $\beta$ cells in Ig-GAD2+BM-treated mice are not derived from donor cells 116

Figure 5. Decline of blood and pancreatic endothelial cells during progression to diabetes. 118

Figure 6 . Restoration of endothelial cells parallels with $\beta$-cell regeneration.....120 Figure 7. Enhanced production of angiogenic factors during restoration of normoglycemia. 122

Figure 8. Donor bone marrow gives rise to pancreatic endothelial cells during suppression of diabetes. 124

Figure 9. Microdissection of insulin ${ }^{+}$or $\mathrm{PECAM}^{+}$cells..... 125

Figure 10. Transfer of endothelial cell progenitors during treatment with Ig-GAD2 sustains $\beta$ cell regeneration and restores normoglycemia. 


\section{LIST OF TABLES}

\section{CHAPTER I}

Table 1. Major antigen targets in type 1 diabetes................................... 


\section{ABSTRACT}

Type 1 diabetes (T1D) is a chronic disorder in which the cells of the immune system mediate selective destruction of the insulin-producing $\beta$-cells in the islets of Langerhans in the pancreas. CD4 ${ }^{+}$effector T cells, including Th1 and Th17 cells, are crucial mediators during disease development. Therefore, therapeutic strategies against T1D should target both $\mathrm{T}$ cell subtypes. The mechanisms underlying the control of Th1 cells are well-defined, but those operating modulation of Th17 cells remain largely unknown due to the fact that Th17 cells are plastic and can drive the disease as convertible (Th17 to Th1) or stable T cells. To overcome these limitations, a tolerance induction model was developed to analyze the mechanisms underlying modulation of plastic Th17 cells. Indeed, upon induction of tolerance, convertible (Th17 to Th1) cells displayed downregulation of the chemokine receptor CXCR3 that was associated with diminished T-bet expression, leading to retention of the cells in the spleen and inhibition of trafficking to the pancreas. In contrast, stable Th17 cells downregulated ROR $\gamma$ t but increased FasL expression and died by apoptosis under the same antigen-specific tolerance. Thus, the final signature transcription factor shapes the mechanism of tolerance in plastic Th17 cells. These findings suggest that effective strategies against T1D will require regimens that could drive both mechanisms of tolerance to overcome the disease.

A core feature of autoimmune diabetes is the loss of the majority of insulinproducing $\beta$ cells. Therefore, reversal of overt T1D requires restoration of $\beta$-cell mass in addition to effective control of islet inflammation. It has been established 
that $\beta$-cell turnover relies on self-replication of pre-existing $\beta$-cells; however, the diabetic state is tightly associated with a striking decrease of the islet endothelial cells, leading to poor $\beta$-cell survival and function. Given that the endothelial progenitor cells (EPCs) reside in the bone marrow and the number of EPCs significantly decreased in human and mice with T1D, we devised a combination treatment regimen in which bone marrow transfer was coupled with an antigenspecific tolerance therapy, and tested it against overt T1D. Indeed, transfer of whole bone marrow or fractioned EPCs gave rise to islet endothelial cells, which facilitated regeneration of endogenous $\beta$-cells and normalization of glucose levels. Therefore, this work provides a new avenue in design of future therapies against T1D by emphasizing the importance of re-establishing a functional microvascular network and the symbiotic relationship between endothelial and $\beta$ cells in the islet of Langerhans. 
CHAPTER I

\section{LITERATURE REVIEW}




\section{ANTIGEN TARGETS IN AUTOIMMUNE DIABETES}

Type 1 diabetes (T1D) is caused by immune-mediated selective destruction of the insulin-producing $\beta$ cells in the pancreatic islets of Langerhans. The majority of the immune cells that infiltrate into the islets are T lymphocytes recognizing $\beta$ cell derived peptide antigens (Lieberman and DiLorenzo, 2003). Therefore, comprehensive understanding of the disease pathogenesis would require thorough characterization of the antigen types and their corresponding T cells. Herein, recent findings regarding identified antigenic targets involved in T1D are summarized in this section.

The presence of autoantibodies is an important indicator for prediction of T1D onset in human subjects (Orban et al., 2009). Approaches using autoantibodies for immunoprecipitation allowed for identification of various autoantigens involved in T1D, such as preproinsulin/insulin, glutamic acid decarboxylase (GAD), insulinoma antigen-2 (IA-2), and islet-specific glucose-6-phosphatase catalytic subunit-related protein (IGRP). A vast number of studies aiming at characterizing the structure and function of the islet antigens have suggested a prominent role of the insulin and GAD antigens in the priming and augmentation of $T$ cell autoreactivities. Therefore, this section will mainly discuss insulin and GAD antigens as well as their cognate $\mathrm{T}$ cells. Other autoantigens, which were extensively reviewed elsewhere (Arvan et al., 2012; Roep and Peakman, 2012), will not be a major focus in this section. 


\section{A. Insulin}

Recent findings have suggested that the mean level of autoantibodies against insulin correlates with the age of the first presentation of T1D in susceptible children (Steck et al., 2011). In addition, insulin autoantibodies were detected before the onset of T1D and were used to predict the development of the disease (Gottlieb and Eisenbarth, 2002). In the non obese diabetic (NOD) mouse model, the presence of insulin autoantibodies is detected between 4 and 8 weeks of age, a time point preceding evident insulitis. Collectively, these findings suggest that insulin is one of the major antigens involved in the initiation of the disease.

The prominent role of the insulin reactivity in T1D pathogenesis is supported by several lines of studies. Manipulation of the insulin promoter by variable number of tandem repeats polymorphism or mutations resulted in reduced insulin expression in the thymus, leading to a breakdown of insulin self-tolerance (Bennett et al., 1995; Vafiadis et al., 1997). NOD mice express two genes coding preproinsulin, insulin 1 and insulin 2. Insulin 1 is exclusively expressed in the islet whereas insulin 2 is expressed both in the thymus and the islet. Genetic ablation of insulin 1 in NOD mice diminished T1D onset, while a complete knockout of insulin 2 accelerated the disease (Moriyama et al., 2003; Thebault-Baumont et al., 2003). These results support the notion that autoreactive $T$ cells recognizing insulin 1-coding protein antigens are able to escape thymic purging and respond to the local antigens in the islet. Furthermore, a recent study revealed that the expression of insulin 2 by thymic medullar epithelial cells (mTECs) is critical for sustaining self-tolerance to insulin reactive $T$ cells. In fact, selective deletion of 
insulin 2 in mTECs of insulin $1^{-1-}$ C57BL/6 mice induced robust diabetes (Fan et al., 2009), suggesting a potentially strong reactivity of $T$ cells to insulin 2-coding antigens in the islet when the central surveillance machinery is defective.

The antigenic property of the insulin protein antigen is predominantly represented by the B: $9-23$ epitope. NOD mice with an ablation of both insulin 1 and insulin 2 but expressing a bioactive insulin gene encoding a mutant B: 9-23 epitope are diabetes-resistant (Nakayama et al., 2005). These findings suggest that B: 9-23 autoreactivity may be up-stream of other pathogenic $\mathrm{T}$ cell responses. Importantly, the mouse B: 9-23 sequence is identical to the human counterpart, and T cells from patients with a recent onset of T1D also recognized this epitope. In NOD mice, a group of unique diabetogenic T cells recognizing the free B: 9-23 peptide but not the same peptide fragment processed from the insulin protein has been identified (Mohan et al., 2010). This finding provides a leading hypothesis regarding the formation of insulin autoreactivity in NOD mice, which will be discussed in detail in the second section of this chapter. In addition, the prominent role of the B: $9-23$ peptide is highlighted by its therapeutic potential in antigen-specific strategies against T1D in human and NOD mice (ClementeCasares et al., 2012), which will be elaborated in the third section of this chapter.

\section{B. Glutamic acid decarboxylase}

Identification of GAD as an autoantigen in T1D can be traced back to studies using immunoprecipitation assays, in which solubilized rat islets were incubated with sera from newly diagnosed T1D patients. Indeed, autoantibodies in the sera 
pulled down a $64 \mathrm{KD}$ protein (Baekkeskov et al., 1982), which was identified as GAD in a subsequent study (Baekkeskov et al., 1990). Based on these findings, a system for detection of autoantibodies against GAD65 was developed (Grubin et al., 1994).

There are several unique characteristics of GAD65-associated antigens relative to other islet antigens, including insulin. First, GAD antigens are not associated with the dense core of the insulin secretory granules (Sorenson et al., 1991), and are synthesized in the $\beta$-cell cytosol rather than the ER (Uchizono et al., 2007; Wicksteed et al., 2007). Second, GAD antigens may be more likely involved in the advanced disease stages compared to the insulin antigens, which are associated with the initial stages of the disease (Chao et al., 1999). Furthermore, unlike depletion of insulin 1 in NOD mice, GAD65 knockout NOD mice were not protected from the disease (Yamamoto et al., 2004). However, diabetes was diminished in a NOD mouse model with inhibition of GAD65 expression in the islet by anti-sense RNA (Jun et al., 2002). These results suggested a regulatory rather than pathogenic role of GAD65-reactive T cells in the periphery. In fact, transfer of spleen cells from NOD.GAD65 ${ }^{-/}$mice to NOD.scid recipients significantly delayed the disease onset relative to the transfer of NOD.GAD65 $5^{+/+}$ cells (Kanazawa et al., 2009). To date, most of the $T$ cell clones recognizing different GAD65-derived peptides displayed inhibitory effects against diabetogenic responses, which will be discussed in detail in the third section of this chapter. 


\section{Concluding remarks}

Although the list of the autoantigens involved in T1D is ever growing (Table 1), the precise nature and identity of the target antigens still remain to be determined. The paucity of this information is due to the vast diversity of the antigen repertoire and the temporal distribution of the antigens during different disease stages (so called epitope spreading). Other technical limitations, such as the lack of $1-A^{97}$ expression on $\beta$-cells and the low number of the primary $\beta$-cells for in vitro examination, made it difficult to identify the natural peptides bound to I$A^{97}$. A previous study employed insulinoma cell lines expressing $1-A^{97}$ to identify their MHC-peptidome (Suri et al., 2008). Using this approach, T cells directed to various proteins of the secretory granules, such as chromogranin and secretogranin, have been identified (Suri et al., 2008). One caveat of this strategy is that it may only be able to identify epitopes with a high affinity to I-A ${ }^{97}$. To circumvent this limitation, the same group developed a computational program to predict the peptides bound to $\mathrm{I}-\mathrm{A}^{97}$ as well as those to the human $\mathrm{MHCll}$ molecule HLA-DQ8 (Chang et al., 2007). Further examination of the functional activities of the corresponding $T$ cells would undoubtedly further our understanding of the T cell-driven events during T1D pathogenesis. 
Table 1. Major antigen targets in type 1 diabetes.

\begin{tabular}{|c|c|c|c|c|c|c|}
\hline \multirow[b]{2}{*}{ Autoantigen } & \multirow{2}{*}{$\begin{array}{c}\text { Tissue } \\
\text { distribution }\end{array}$} & \multicolumn{2}{|c|}{ Mice } & \multicolumn{2}{|c|}{ Men } & \multirow[b]{2}{*}{ Comments } \\
\hline & & AutoAbs & T cells & AutoAbs & T cells & \\
\hline Preproinsulin & $\beta$ cells, thymus & Yes & CD4 & Yes & $\begin{array}{l}\text { CD4, D8, } \\
\text { aTregs }\end{array}$ & $\begin{array}{l}\text { AAb affinity matters; CD8 T } \\
\text { cells lyse } \beta \text { cells in a } \\
\text { glucose-dependent manner; } \\
\text { genetically determined } \\
\text { variation in gene expression } \\
\text { in } \beta \text { cells vs. thymus }\end{array}$ \\
\hline $\begin{array}{l}\text { Glutamic } \\
\text { decarboxylase } 65 \\
\text { (GAD65) }\end{array}$ & $\begin{array}{l}\text { Islet cells, adrenal } \\
\text { gland, CNS, } \\
\text { neurons, testis, } \\
\text { ovary }\end{array}$ & No & CD4 & Yes & $\mathrm{CD} 4, \mathrm{CD} 8$ & $\begin{array}{l}\text { Not expressed in mouse } \beta \text { cells; } \\
\text { AAb associated with } \\
\text { HLA-DR3-DQ2 }\end{array}$ \\
\hline GAD67 & Islet cells, neurons & No & CD4 & Yes & CD4 & Not expressed in human $\beta$ cells \\
\hline $\begin{array}{l}\text { Tyrosine } \\
\text { phosphatase like } \\
\text { autoantigen or } \\
\text { insulinoma } \\
\text { antigen-2 (IA-2; } \\
\text { ICA512, PTPRN) }\end{array}$ & Islets & Yes & $\mathrm{CD} 4$ & Yes & $\mathrm{CD} 4, \mathrm{CD} 8$ & $\begin{array}{l}\text { AAb associated with } \\
\text { DR4-DQ8; alternative splice } \\
\text { variation; truncated variant: } \\
\text { ICA512 }\end{array}$ \\
\hline $\begin{array}{l}\text { IA-2 } \beta \text { (Phogrin, } \\
\text { PTPRN2) }\end{array}$ & Islets & No & CD4 & Yes & $\mathrm{CD} 4$ & \\
\hline $\begin{array}{l}\text { Islet cell antigen-69 } \\
\quad \text { (ICA69) }\end{array}$ & $\begin{array}{l}\text { Pancreas, heart, } \\
\text { and brain }\end{array}$ & No & No & Yes & $\mathrm{CD} 4$ & $\begin{array}{l}\text { Inverse correlation between } \\
\text { AAb and T-cell responses; } \\
\text { AAb associated with } \\
\text { HLA-DR4, T-cell responses } \\
\text { with -DR3 }\end{array}$ \\
\hline $\begin{array}{l}\text { Zinc transporter-8 } \\
\quad(\mathrm{ZnT})\end{array}$ & $\beta$ cells & & & & & Polymorphic \\
\hline Chromogranin A & $\begin{array}{l}\text { Neuroendocrine } \\
\text { cells }\end{array}$ & No & CD4 & No & $?$ & \\
\hline $\begin{array}{l}38 \mathrm{kDa} \text { granule } \\
\text { antigen }\end{array}$ & $\begin{array}{l}\text { Neuroendocrine } \\
\text { cells }\end{array}$ & No & $?$ & Yes & Yes & \\
\hline Peripherin & Neurons & No & CD4 & $?$ & $?$ & $\begin{array}{l}\text { No evidence of differential } \\
\text { recognition in human type } 1 \\
\text { diabetes }\end{array}$ \\
\hline $\begin{array}{l}\text { Islet amyloid } \\
\text { polypeptide } \\
\text { (ppIAPP) }\end{array}$ & Islets & No & $\mathrm{CD} 4$ & No & CD8 & $\begin{array}{l}\text { Immune responses not specific } \\
\text { for diabetes }\end{array}$ \\
\hline $\begin{array}{l}\text { Carboxypeptidase } \\
\text { H/E }\end{array}$ & $\begin{array}{l}\text { Neuroendocrine } \\
\text { cells; adrenals }\end{array}$ & No & No & Yes & No & \\
\hline $\begin{array}{l}\text { Heat shock protein } \\
\quad 60(\mathrm{hsp} 60)\end{array}$ & $\begin{array}{l}\text { Ubiquitous } \\
\text { (mitochondria) }\end{array}$ & No & CD4 & No & $\mathrm{CD} 4$ & $\begin{array}{l}\text { Immune responses not disease } \\
\text { specific }\end{array}$ \\
\hline $\begin{array}{l}\text { IGRP; islet-specific } \\
\text { glucose-6- } \\
\text { phosphatase } \\
\text { catalytic subunit- } \\
\text { related protein }\end{array}$ & Islets & No & CD8 & No & CD8 & Alternative splice variation \\
\hline Sulfatide & Ubiquitous & No & No & Yes & $?$ & Anti-inflammatory properties \\
\hline Ganglioside & Ubiquitous & No & No & Yes & $?$ & \\
\hline
\end{tabular}

Adapted from Roep et al., 2012 


\section{INITIATION AND PROGRESSION OF AUTOIMMUNE DIABETES}

Autoimmune diseases, including T1D, are driven by intertwined cellular and molecular pathways incorporating genetic predisposition, environmental triggers and breakdown of self-tolerance (Atkinson, 2012). Autoimmune diabetes involves destruction of insulin-producing $\beta$-cells by immune attacks mainly mediated by $\mathrm{CD}^{+}$and $\mathrm{CD}^{+} \mathrm{T}$ cells. In human and the NOD mouse model, the immune insults (so called insulitis) in the islets of Langerhans are observed long time before the ultimate critical loss of $\beta$-cell mass that leads to hyperglycemia (Jeker et al., 2012). In this regard, the disease can be generally divided into two stages: 1. Initiation of immune attacks that is somehow chronic, benign and controlled. 2 . Progression of destructive insulitis that overcomes the regulatory mechanisms and specifically destroys pancreatic $\beta$-cells. In the human context, genetic predisposition (Steck and Rewers, 2011) and environmental triggers (Knip and Simell, 2012) would undoubtedly play an important role in T1D pathogenesis, and a better understanding of these factors would provide insights into disease prediagnosis and prevention. However, the NOD mice, which share identical genetic materials and very similar, if not the same, housing environment, would be invaluable tools for analyses of immunological events that initiate, culminate and finally demolish $\beta$-cells. Herein, the recent findings regarding the initiation and propagation of autoimmune diabetes, including the potential environmental triggers and the critical immunological events, are summarized. 


\section{A. Environmental triggers}

It has been viewed that pathogen infections are important environmental factors that can influence the disease course by altering immune function and/or directly acting on $\beta$-cells. For example, local inflammation can induce $\beta$-cell death, leading to a pronounced release of $\beta$-cell antigens, which may accelerate the priming of autoreactive T cells (Filippi and von Herrath, 2008). Molecular mimicry and cross-presentation of viral epitopes may initiate and enhance $\mathrm{T}$ cell responses. Nevertheless, the altered function of APCs by pathogen infections permits antigen presentation to self-reactive $\mathrm{T}$ cells in an inflammatory rather than a tolerogenic condition. The role of viral triggers in T1D is further supported by the fact that the IFIH1 gene involved in anti-viral immunity has been associated with a decrease of disease risk (Nejentsev et al., 2009), and that enteroviruses have been isolated from patients with a recent onset of T1D (Filippi and von Herrath, 2008). However, it should be noted that the type and timing of the viral infection might protect or accelerate the disease development (Filippi and von Herrath, 2008). In fact, it is believed that a lower hygiene standard is associated with a lower incidence of diabetes. In support of this notion is the fact that Western countries generally have a higher diabetes incidence (Filippi and von Herrath, 2008). Therefore, certain pathogen infections may protect T1D by shaping the host immune responses. For example, NOD mice infected by Schistosoma mansoni were protected against diabetes with a shift of the Th1 to Th2 responses, a mechanism also observed in various protective antigenspecific treatments (Zaccone et al., 2003). In addition, Salmonella typhimurium 
infection reduced disease incidence possibly through influencing dendritic cells and T cell trafficking to the pancreas (Raine et al., 2006). Notably, the same type of bacteria can be detrimental or protective in different autoimmune diseases depending on the type of the immune response driving the disease. The most relative evidence is two studies showing that the intestinal segmented filamentous bacteria protected against T1D (Kriegel et al., 2011), but exacerbated rheumatoid arthritis (Wu et al., 2010). Therefore, anti-viral immunity should be viewed as an integrated part of the autoimmune responses. In this regard, interesting questions could be raised, such as whether exhaustion of CD8 T cells during chronic viral infection would dampen the pathogenic function of the $\beta$-cell-reactive T cells or whether the APCs bearing viral antigens could migrate into thymus and affect the selection of the autoreactive $T$ cells. Nevertheless, more analyses are needed to further define the role of pathogen infections in triggering autoimmune diabetes, and the answer would probably never be definite because of the broad diversity of the pathogens types and the related $\mathrm{T}$ cell responses.

It is understandable that pathogen infection is not indispensible in triggering T1D simply because not every individual would have the same chance for exposure. In fact, endogenous triggers, especially the commensal triggers have gained considerable attention and provide a new avenue for understanding how the interaction between the gut microbiota and the immune system would influence the course of autoimmune diabetes. The fact that initiation of cell infiltration into the islets occurs at the week of weaning in NOD mice indicates that alterations in 
gut microbiota may be a part of the early events during T1D pathogenesis. Indeed, the reciprocal role between gut microbiota and the immune system and its influence in the development of T1D has been highlighted by a study showing that germ free female NOD mice displayed an accelerated disease onset compared with those housed under SPF conditions (Wen et al., 2008). In addition, removal of the commensal bacteria permitted a robust disease development in the diabetes-resistant male mice (Wen et al., 2008). These results suggest a critical role of the intestinal microbiota in alleviating the disease progression. Furthermore, MyD88-deficient mice, which are normally protected from T1D, developed robust disease under germ free conditions (Wen et al., 2008). These results suggest that the intimate interaction between commensal microbiota and innate immune cells plays an important role in modulation of $\mathrm{T}$ cell priming because removal of commensal microbiota nullified MyD88dependence of the innate cells for priming T cells. However, whether commensal ablation results in pronounced MyD88-independent pathway or aberrant APC functions is not clear. Furthermore, colonization of a consortium of bacterial species to germ free MyD88 $8^{-/-}$mice significantly attenuated the disease, and the MyD88 $^{-1-}$ mice displayed specific changes in the composition of commensal microbiota (Wen et al., 2008). These data clearly provided a new perspective in the pathogenesis of T1D, although the precise mechanism of induction of local tolerance by the microbiota remains to be elucidated.

Importantly, children that develop T1D also possess a different microbiome compared with the control children (Giongo et al., 2011). In addition, human 
diabetic subjects displayed upregulation of zonulin, a protein associated with increased intestine permeability (Sapone et al., 2006), suggesting that that loss of the intestine barrier function may lead to a switch from tolerance to activation in response to gut non-self antigens. As such, gut antigens and/or APCs bearing gut antigens may circulate to pancreas or the draining lymph nodes, leading to priming of $\beta$-cell reactive $T$ cells. However, evidence regarding how $\beta$-cell reactive $T$ cells would recognize gut non-self antigens still lacks. In addition, it has been established that $\beta$-cell reactive $T$ cells express gut-specific homing receptors (Paronen et al., 1997), and the same molecules can home to both pancreas and gastrointestinal tract (Vaarala, 2000). Because the pancreatic draining lymph node (PLN) is a preferred site for cell trafficking from the peritoneal cavity, it is possible that the inflammatory state of the gut environment could affect the activation state of APCs in the pancreatic lymph nodes. Another connection between pancreas and the gut environment is the omentum, which may serve as a site for $\mathrm{T}$ cell response to trapped peritoneal antigens (RangelMoreno et al., 2009). These findings clearly suggested a potential role of the gut microenvironment in regulation of the immune responses in pancreas. However, important and intriguing questions remained to be answered with more powerful analytic tools. For example, it is not clear whether female NOD mice that eventually develop diabetes would display increased intestinal permeability at an early age relative to those who share the same cage but are resistant to clinical diabetes or whether the loss of the gut barrier function is due to intrinsic factors, 
such as changes in the composition of commensal microbiota, or needed to be triggered by a pathogen infection.

\section{B. Initial immunological events in T1D}

The most important genetic determinant of T1D incidence in human and mice is the major histocompatibility complex (MHC). Furthermore, the fact that disease concordance between monozygotic twins is about $50 \%$ suggests a critical role of the immune system in determining the outcome of the disease independently of genetic and environmental triggers. For example, islet resident dendritic cells (DCs) are heavily loaded with $\beta$-cell-derived peptide antigens under a physiological condition, and neither $\beta$-cell death nor local inflammation affected the presentation of the peptide/MHC (pMHC) complex to the T cells. Thus, it is likely that these islet DCs migrate to the draining lymph nodes where they present antigens to circulating T cells (Calderon et al., 2008). However, it is not clear that whether islet antigens can be directly released to the draining lymph node and captured by the PLN DCs. In this regard, a model that can specifically label and track islet DCs would be valuable in determining the initial site of the T cell priming and the environmental cues, if any, driving the migration of DCs. However, this would be very difficult due to a lack of congenic marker for islet

DCs because they seem to have a typical immature phenotype despite a relatively high expression of B7-1 (Calderon et al., 2008).

Another strategy to dissect the initial events in T1D is to monitor the islet transcriptional profiling throughout the disease pathogenesis. A study focusing on 
the transition of innocuous to destructive insulitis demonstrated that the expression of natural killer (NK)-cell-specific genes and the percentage of these cells increased in the more aggressive diabetogenic TCR transgenic strain (Poirot et al., 2004). In addition, entry of antigen-specific T cells into the islet was observed as early as $24 \mathrm{~h}$ after intravenous transfer and was associated with upregulation of chemokines and adhesion molecules, which is needed for subsequent entry of non-specific T cells (Calderon et al., 2011). Furthermore, the entry of antigen-specific $T$ cells induced rapid changes in the expression of a group of interferon-inducible genes in the islets (Calderon et al., 2011). Indeed, upregulation of type I interferon (IFN-I)-inducible genes was observed in the PLN at the 4 and 6 weeks of age in both NOD and NOD.BDC2.5 TCR transgenic mice, and blockade of IFNa receptor 1 in 2 or 3 -week old mice significantly delayed disease onset ( $\mathrm{Li}$ et al., 2008). More importantly, a study used reliable islet isolation techniques and transcriptional profiling assays to examine the gene expression changes in the islets throughout the disease pathogenesis in NOD mice (Carrero et al., 2013). This study pinpointed a unique IFN-I signature in the islets of all the NOD female mice at 4-6 weeks of age, a time point preceding T cell activation (Carrero et al., 2013). However, the causative association between upregulation of IFN-I and entry of T cells is not known.

The early entry of $\mathrm{CD}^{+} \mathrm{T}$ cells is one of the most important events during the initial steps of T1D pathogenesis. It is believed the first entry of T cells should be $\beta$-cell-antigen specific, but the actual specificity of these $T$ cells is not known. Insulin is considered one of the initiating autoantigens, and it has been shown 
that the islet DCs bearing antigens derived from secretary granules containing insulin protein or peptides (Mohan et al., 2010). Two types of insulin-reactive T cells have been identified: the type A T cells recognize both insulin protein and/or the B: 9-23 peptide, while the type B T cells only recognize soluble B: 9-23 peptide when offered exogenously (Mohan et al., 2010). Therefore, the type A T cells are readily being negatively selected in the thymus in that the thymic epithelial cells express insulin protein. However, the type B T cells are able to escape thymic purging, and respond to a low concentration of the insulin peptide antigen in the islets (Mohan et al., 2010; Mohan and Unanue, 2012). The free peptide antigen is indeed available in the $\beta$-cell secretory granules and the local DCs are able to capture these granules. Therefore, these type B T cells are likely among the first entry of the T cells that infiltrate into the islet. Analysis of these unique diabetogenic $\mathrm{T}$ cells using a TCR transgenic mouse model would certainly further our understanding of the initial T cell-driven events in T1D.

\section{Transition from insulitis to $\beta$-cell destruction}

A mysterious and key question in the field of T1D is how the initial benign immune insults progress into destructive insulitis that eventually results in hyperglycemia. In the clinical perspective, this is of great importance due to the difficulty for prediction and prevention of the disease at a very early stage. Therefore, perhaps a better and more practical way to rescue the vulnerable $\beta$ cells is to block the progression of invasive insulitis. The fact that every NOD mouse, regardless of female or male, develops insulitis but varies in the 
incidence of clinical diabetes provides a good starting point for this line of researches. The question then has become if we have a cage of 10 young female NOD mice, can we do a simple experiment to predict which 6-8 will develop hyperglycemia at 20 or 30 -week old of age? A recent study utilized magnetic resonance imaging (MRI) to scan the pancreatic region of female NOD mice at the prediabetic stage and found that the mice that eventually developed clinical disease had a significantly higher T2 value as early as 6-week old (Fu et al., 2012). Thus, it appears that the occurrence of clinical diabetes has already been determined in a relatively early stage rather than a late outcome after a long term fight between pathogenic and regulatory elements. More specifically, it is possible that some early pathogenic events have precipitated and need to overcome the defensive mechanisms to drive the clinical disease, which means that, there is no need for a secondary hit, such as a pathogen infection, or late development of certain pathogenic cells for determinism of diabetes incidence. In support of this, this study performed microarray analyses to screen and compare the changes of gene expression in the pancreatic islets between diabetes-prone and -resistant mice. Indeed, these assays revealed an upregulation of the complement receptor of the immunoglobulin superfamily (CRIg) in the latter group (Fu et al., 2012). The authors subsequently confirmed the protein upregulation of CRIg on islet macrophages and demonstrated that inhibition of CRIg in 3-week old mice accelerated disease onset (Fu et al., 2012). It should be noted that CRIg is among a group of upregulated genes in the diabetes-resistant NOD mice, which are potentially protective genes of diabetes (Fu et al., 2012). 
Therefore, thorough characterization of these genes should provide valuable insights into the critical elements attenuating disease incidence. Indeed, the authors suggested that many of these genes are associated with macrophage functions, which may dampen $T$ cell responses by timely clearance of apoptotic $\beta$-cell debris. A more desired result would be to have some "biomarkers" that readily distinguish the diabetes-prone and -resistant NOD mice.

The chronic nature of progression to destructive insulitis suggests a dynamic involvement of different cell infiltrates and epitopes. It is debatable that whether non-antigen-specific $T$ cells can enter the islet, but it is entirely possible that $T$ cells recognizing different $\beta$-cell-derived epitopes are primed and recruited into the islet at different disease stages. This process involves shedding of different autoantigens and/or modification of preexisting epitopes, the so called "neoantigens" (Marrack and Kappler, 2012). Some evidence suggested a post translational modification of self-antigens in other autoimmune diseases (Abadie et al., 2011; Vossenaar et al., 2003), but in the context of T1D, an elegant study pointed out that unique binding of distinct peptide registers to $1-A^{97}$ may be of a more prominent role in triggering diabetogenic responses (Mohan et al., 2011).

It is conceivable that a breakdown of tolerogenic mechanisms is one important factor driving progressive insulitic lesions. In fact, a number of studies have suggested that the loss of Treg function is a critical mediator in the disease progression (Bettini and Vignali, 2009), and this is associated with lack of IL-2 or defects in IL-2R signaling (Long et al., 2010; Tang et al., 2008). Furthermore, the decreased level of IL-2 and defective Treg function were associated with IL-2 
single nucleotide polymorphism (SNP) within the Idd3 susceptibility locus in NOD mice (Yamanouchi et al., 2007). In addition, Tregs may be instable under inflammatory conditions (lose FoxP3 expression), and acquire a pathogenic phenotype (Zhou et al., 2009). However, these studies were challenged by other findings indicating that Tregs in the islets of NOD mice are able to suppress pathogenic $T$ cells. For example, Tregs isolated from islet infiltrates were actively involved in modulation of diabetogenic $T$ cell responses, but failed to regulate initial T cell recruitment to the islets (Chen et al., 2005). Another study used a conditional depletion mouse model for $\mathrm{FoxP}^{+}$Tregs, in which diphtheria toxin (DT) receptor is driven by the FoxP3 promoter (FoxP3.DTR) and injection of DT permits selective killing of $\mathrm{FoxP}^{+}$cells. The depletion of Tregs in NOD.BDC2.5 TCR transgenic mice resulted in diabetes occurrence in all the mice within 40 days (Feuerer et al., 2009). Furthermore, another study using an inducible fatemapping system to monitor Treg plasticity supported a notable stability rather than conversion of the committed FoxP3 ${ }^{+}$Tregs (Rubtsov et al., 2010). Therefore, Tregs in NOD mice appear to be able to contain pathogenic responses, but may not be sufficient at certain disease stages or in particular cellular microenvironments. Dissecting this paradox would require temporal and spatial Treg depletion experiments. Another important implication is that the essence of autoimmunity in T1D largely lies in the initiation and augmentation of pathogenic T cell responses, which is critically mediated by interaction between escaped thymic autoimmune emigrants with peptide-I- $\mathrm{A}^{\mathrm{g7}}$ complex, rather than intrinsic defects in central and peripheral tolerance mechanisms. 


\section{Concluding remarks}

Treating autoimmune diabetes is of great importance, but predicting or preventing the disease may be even more crucial for understanding and overcoming T1D autoimmunity. The initiation of the disease involves intriguing aspects as to the timing and the site for the beginning of $\mathrm{T}$ cell priming and the earliest changes in the islet of Langerhans. A recent study suggested that every NOD female mouse develops a signature of IFN-I in the islets at 4-week old of age, which precedes detectable activation of T cells (Carrero et al., 2013). This finding provides an essential starting point and a future framework for dissecting the initial immune events during T1D pathogenesis, especially since the presence of IFN-I is not related to viral infection or genetic predisposition and is unique to NOD mice (Carrero et al., 2013). On the other hand, the progression to destructive insulitis is another checkpoint for preventing the disease before critical loss of $\beta$-cell mass. This stage involves a complex network of interactions between pathogenic and regulatory elements. Despite the fact that the intrinsic defensive mechanisms in NOD mice may be defective in certain aspects, emerging evidence rather suggests a functional negative selection machinery and Treg function in NOD mice (Mingueneau et al., 2012). These studies highlighted the importance of the findings focused on analyses of the formation of the diabetogenic $T$ cell responses based on the peptide-I- $A^{97}$ complex (Calderon and Unanue, 2012; Mohan and Unanue, 2012; Mohan and Unanue, 2013). Indeed, a more favorable explanation (Figure 1) of T1D autoimmunity in NOD mice is that a group of the type B T cells, which only recognizes free peptides but not those from processing of the protein antigen, are not selected in the thymus 
and are able to respond to a low concentration of the peptide antigens in the islets (Mohan et al., 2010; Mohan et al., 2011; Mohan and Unanue, 2012). Further scrutinization of these unique $T$ cells would be the key to comprehend the $\mathrm{T}$ cell-driven events during initiation and propagation of autoimmune diabetes. 


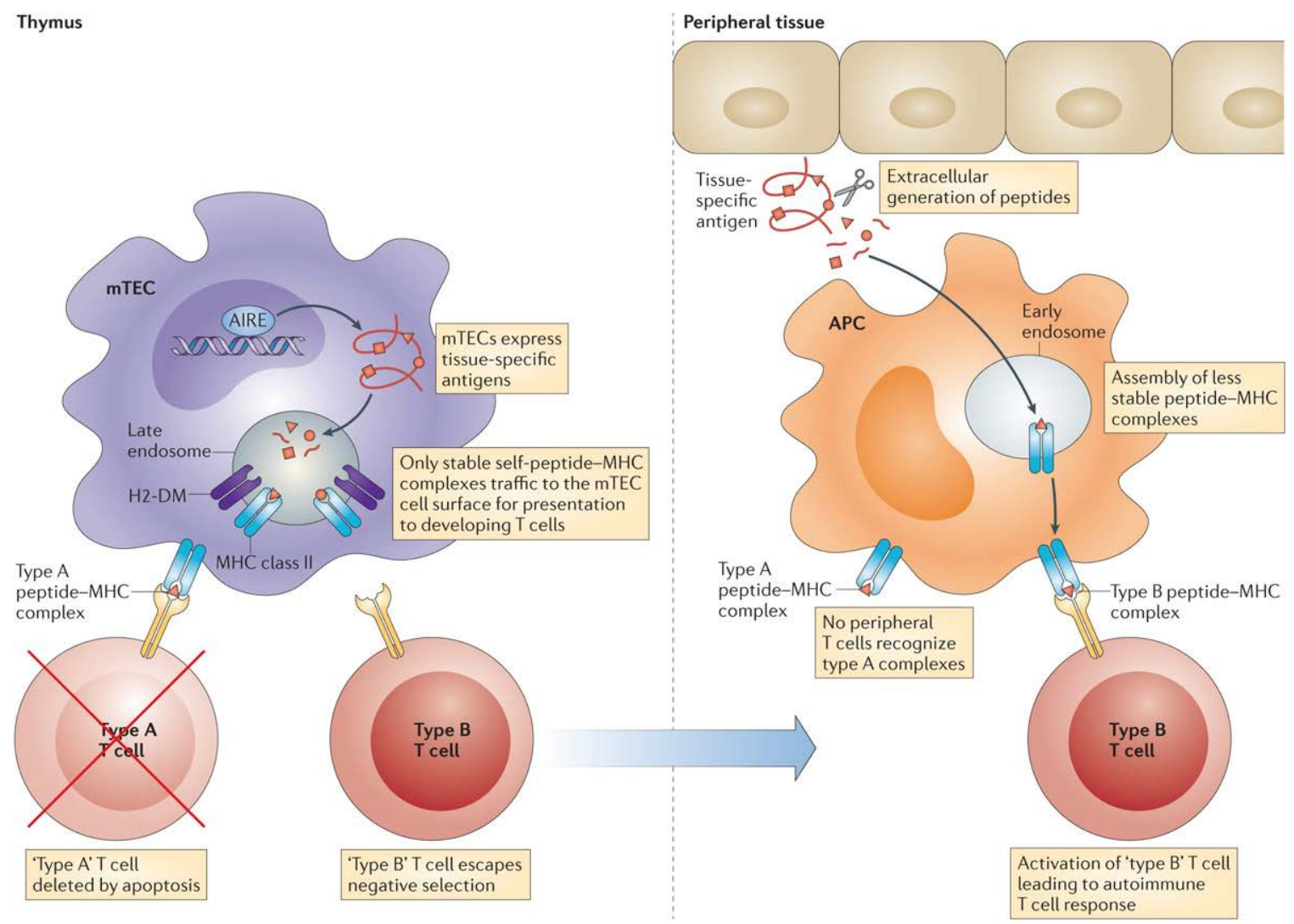

Adapted from Mohan et al., 2012

Figure 1. A leading hypothesis of the formation of T1D autoimmunity. The deletion of autoreactive T cells in the medullary cortex is mediated by medullary thymic epithelial cells (mTECs). mTECs express a variety of tissue-specific antigens and endogenously process peptides derived from these antigens and present them to developing T cells. This process is highly effective in the deletion of conventional self-reactive $\mathrm{T}$ cell. However, owing to the constraints of processing protein antigens and the relatively low abundance of any given antigen, self-reactive T cells that show 'type B' peptide specificities may routinely escape negative selection. These type B $T$ cells have the potential to be activated by APCs in the periphery, and this may result in autoimmune $\mathrm{T}$ cell responses. AIRE, autoimmune regulator. 


\section{ANTIGEN-SPECIFIC TREATMENT IN TYPE 1 DIABETES}

Immunotherapies aiming at re-establishing self-tolerance to insulin-producing $\beta$ cells have been extensively studied. The majority of these therapies are designed to deplete and/or inactivate pathogenic $\mathrm{T}$ cells with or without activation/expansion of the regulatory T cells (Atkinson and Eisenbarth, 2001; Bluestone et al., 2010; Luo et al., 2010). In general, T-cell targeting therapies can be categorized into broad-based and antigen-specific strategies. The broadbased therapies, especially the anti-CD3 monoclonal antibodies have shown efficacy in normalization of hyperglycemia in NOD mice and in preservation of Cpeptide responses in human patients (Chatenoud and Bluestone, 2007; Chatenoud et al., 1997; Chatenoud et al., 1994; Herold et al., 2005; Herold et al., 2002; Keymeulen et al., 2005). However, these therapies are associated with safety issues by potentially compromising the normal function of the immune system against pathogen infections. In this regard, antigen-specific therapies that particularly target $\beta$-cell antigen-reactive T cells are more desired (Luo et al., 2010). Due to the fact that different antigens, timing, routes and disease models are employed, varied effects of the therapies are observed in animal T1D models and human patients. Herein, the recent findings of the antigen-specific treatment in T1D are summarized in this section.

\section{A. GAD treatment}

To date, the most studied autoantigens in T1D are insulin and glutamic acid decarboxylase (GAD). The mouse and human islets differentially express two 
isoforms of GAD (Bu et al., 1992; Christgau et al., 1991; Erlander et al., 1991), with the former predominantly expressing GAD67 (67KD) (Faulkner-Jones et al., 1993), while the latter only expressing GAD65 (65KD) (Karlsen et al., 1992). GAD-reactive T cells are detected in NOD mice (Elliott et al., 1994; Kaufman et al., 1993; Tisch et al., 1993) and human patients (Endl et al., 1997; Honeyman et al., 1993; Panina-Bordignon et al., 1995; Rudy et al., 1995). Prevention of GAD expression in the pancreatic islets by antisense GAD RNA blocked T1D onset in NOD mice (Yoon et al., 1999). These results suggested that GAD is a prevalent antigen in T1D and prompted the studies aiming at inducing tolerance of GADspecific T cells (Kaufman et al., 1993; Ramiya et al., 1997; Tisch et al., 1999). In fact, administration of GAD through different routes in NOD mice resulted in antidiabetogenic effects, and the protection is associated with a shift of Th1 to Th2 response and elevated serum IgG1 levels (Carter et al., 2006; Ma et al., 1997; Tian et al., 1996). Furthermore, vaccination of alum-formulated GAD (GAD-alum) in recently diagnosed T1D patients significantly delayed the loss of the C-peptide response (Agardh et al., 2005; Ludvigsson et al., 2008). Isolated PBMCs from those given GAD-alum had an increased mRNA level of FoxP3 and TGF $\beta$ gene expression as well as IFNy, TNFa, IL-6, IL-17, IL-5 and IL-13 cytokine secretion (Ludvigsson et al., 2008). Although the treatment did not change the insulin requirement, the effects of GAD-related therapies in regulation of the immune system and improvement of the metabolic control are of note.

Efforts in inducing GAD-specific T cell tolerance have been further extended to study individual peptides derived from GAD. Individual administration of GAD65 
peptides spanning aa 217-236 (p217), 247-265 (p247), 290-309 (p290) and 524-543 (p524) emulsified in incomplete Freund's adjuvant (IFA) effectively resulted in disease prevention in 4-week NOD mice, but only the combination of p217 and p290 inhibited insulitis and diabetes development in 12-week NOD mice (Carter et al., 2006). Furthermore, the disease protection was absent in IL4-deficient mice (Carter et al., 2006). These findings suggest that GAD specific epitopes differ in their ability to induce regulatory Th2 response and that induction of disease protection in advanced disease stages is more likely to be dependent on certain GAD epitopes. Tolerogenic effects of other GAD peptidesbased treatment involved the IFNY/IL-10-producing type 1 regulatory (Tr1) cells as exemplified by the GAD 206-220 (p206) and 221-235 (p221) cells. Tetramer isolated p206 or p221 antigen-specific cells from immunized mice secreted IFNY and IL-10 and failed to induce diabetes upon transfer to NOD.scid recipients (Chen et al., 2003). Furthermore, these cells were able to delay diabetes onset when co-transferred with diabetogenic spleen cells and the suppressive ability of the p206 or p221 cells is directly correlated with their IFNy and/or IL-10 production (Chen et al., 2003). The regulatory function of the p206 cells has been further examined using the p206 TCR transgenic mice (Kim et al., 2004). Consistent with the tetramer-isolated cells, the TCR transgenic p206 cells produced IFNy and IL-10 and inhibited transfer of diabetes (Kim et al., 2004). Interestingly, the p206 TCR transgenic mice lack insulitis and diabetes development even after crossing with mice over-expressing human GAD65 in the pancreas (Kim et al., 2004). Therefore, the inhibitory nature of the p206 cells is 
not due to low presence of GAD in NOD mouse and increase of the local antigen does not convert these cells into a pathogenic phenotype. Furthermore, unstimulated p206 cells were not able to suppress transfer of diabetes, indicating that in vivo stimulation could enhance the ability of the p206 cells to downmodulate pathogenic responses. In fact, p206 cells isolated from mice immunized with IFA/p206 displayed higher proliferative index than those from IFA-immunized mice (Kim et al., 2004), suggesting that administration of p206 peptide under an uninflammatory condition was able to stimulate the p206 cells in vivo and amplify their suppressive functions. Based on these findings, our laboratory has genetically incorporated the aa sequence of p206 into an Ig backbone and tested the resulting Ig-p206 (referred to as Ig-GAD2) against T1D in multiple disease stages (Jain et al., 2008). Notably, Ig-GAD2 was able to normalize blood glucose levels $(B G L)$ in hyperglycemic mice $(B G L=160-250$ $\mathrm{mg} / \mathrm{dl}$ ), but failed to prevent disease onset in young NOD mice before occurrence of insulitis (Jain et al., 2008). This is possibly due to the late reactivity of the p206-specific T cells in NOD mice. Interestingly, the protective effect of Ig-GAD2 is associated with reduced IL-17 producing cells in the pancreas and periphery (Jain et al., 2008). These findings bode well with another study showing that administration of anti-IL-17 neutralizing antibodies in 10-wk old NOD mice suppressed insulitis and diabetes despite the fact that the role of Th17 cells in T1D remains obscure and debatable (Emamaullee et al., 2009).

Different routes for administration of GAD peptides have been evaluated, among which the nasal or oral delivery shows values in practice and efficacy. Nasal or 
oral administration of GAD 524-543 followed by injection of CFA in the footpad induced T cells producing IL-4, IL-10 and TGF and delayed diabetes transfer (Maron et al., 1999). Furthermore, intranasal delivery of GAD 247-266, GAD 509-527, and GAD 524-543 delayed islet graft rejection possibly through enhanced IL-10 production (Ravanan et al., 2007).

The safety of Alum-GAD has been tested in patients in a preclinical trial that showed non-detectable adverse effects in patients after injection with GAD with or without adjuvants (Plesner et al., 1998; Uibo and Lernmark, 2008). Subsequently, a phase II trial demonstrated that a $20 \mu \mathrm{g}$ dose of alum-GAD was able to preserve C-peptide responses over a 24-week monitoring period accompanied by a increased $\mathrm{CD} 4^{+} \mathrm{CD} 25^{+} / \mathrm{CD} 4^{+} \mathrm{CD} 25^{-}$ratio (Agardh et al., 2005). Although the role of Tregs in the regulation of the pathogenic responses has been further supported by the increased FoxP3 and TGF $\beta$ gene expression in the PMBCs of patients 30 weeks after the first alum-GAD treatment, these patients also had increased levels of GAD autoantibody as well as expression of both proinflammatory and inhibitory cytokines (Ma et al., 1997). It is not surprising that GAD treatment displays a multifactorial regulation of the immune system; however, this adds difficulty to further distinction of the "beneficial" or "detrimental" responses. Indeed, frustrating results exist in that GAD treatment has not meet the primary expectation for reduction of insulin reliance in patients or reversal of T1D in NOD mice. Therefore, essential preclinical work is required for evaluating the choice of specific peptide treatment, the route of administration, antigen formulation, dosing and other factors. 


\section{B. Insulin treatment}

Despite the fact that insulin is the most prominent autoantigen in T1D pathogenesis, the insulin-specific treatments are somewhat less effective than GAD treatments especially in human patients. As the major hormone regulator of glucose homeostasis produced by pancreatic $\beta$-cells, insulin is the first autoantigen described in human patients (Palmer et al., 1983). Autoantibodies specific for both insulin and its precursor preproinsulin can be detected in patients with a recent onset of T1D (Kuglin et al., 1988; Yu et al., 2000). In 8week old NOD mice, presence of insulin autoantibody is associated with high disease incidence (Yu et al., 2000). Most insulin reactive $\mathrm{CD}^{+}{ }^{+}$cells in NOD mice recognize the segment of the insulin B chain composed of residues 9-23. Existing and emerging evidence suggests that insulin-reactive $T$ cells may be the major initiator of the islet infiltration given that local islet antigen presenting cells are physiologically heavily loaded with B:9-23 peptide regardless of $\beta$-cell death and inflammation (Lieberman and DiLorenzo, 2003; Mohan et al., 2010; Nakayama et al., 2005).

Therefore, targeting insulin-reactive T cells has been extensively studied in order to determine the proper routes or dosing for preventing or curing T1D. To date, oral, nasal, parenteral and intravenous routes have shown efficacy in preventing the disease in NOD mice (Aspord and Thivolet, 2002; Atkinson et al., 1990; Harrison et al., 1996; Hutchings and Cooke, 1995; Sai et al., 1996; Zhang et al., 1991). It also has been shown that adjuvants such as cholera toxin could enhance the effectiveness of insulin treatment (Aspord and Thivolet, 2002; 
Bergerot et al., 1997; Harrison et al., 1996). Interestingly, there is a B chain dependence of the insulin treatment because immunizing NOD mice with insulin B chain in IFA but not the A chain protected against T1D (Coon et al., 1999; Muir et al., 1995). Therefore, selection of the insulin epitope together with timing and routes of administration has been the major focus of insulin vaccination therapies, and different combination of these factors generated both disease protective and promoting results (Chen et al., 2001; Hutchings and Cooke, 1995). For example, subcutaneous delivery of proinsulin B24-C33 at 18 days of age promoted diabetes in NOD mice, while the intranasal route delayed onset of T1D (Chen et al., 2001). Therefore, the intranasal route appears to favor a tolerogenic response. This is further supported by other studies using proinsulin B24-C33, B24-C32, and insulin B: 9-23 peptide, which all displayed inhibition of diabetogenic responses (Daniel and Wegmann, 1996a; Daniel and Wegmann, 1996b; Martinez et al., 2003). Interestingly, expansion of a group of antigenspecific $\mathrm{CD}^{+}{ }^{+} \mathrm{FOPP}^{+}$regulatory T cells producing IL-10 and TGF $\beta$ was observed when intranasal delivery of proinsulin B24-C33 was synergized with anti-CD3 monoclonal antibody treatment (Bresson et al., 2006). In contrast, the subcutaneous route generated mixed results as to disease protection or promotion. Immunizing 4-week old NOD mice with insulin-1 B: 9-23 peptide accelerated disease development, but immunization with insulin-2 B: 9-23 peptide conferred disease protection (Devendra et al., 2004). Thus, the selection of appropriate peptide segments appears to be an important issue for design of insulin therapies. In addition, the effectiveness of the treatment is also disease 
stage dependent. For example, immunization of prediabetic NOD mice with insulin B 9-23 with IFA was able to delay diabetes onset but failed to reverse established hyperglycemia (Daniel and Wegmann, 1996a; Fousteri et al., 2010; Hutchings and Cooke, 1995; Muir et al., 1995). This is perhaps because insulin is one of the earliest autoantigen present in the islet or pancreatic lymph node that may prime the first wave of $T$ cell attack. Similar with GAD therapies, insulinrelated treatment is also associated with expansion of CD4+CD25+ Tregs and production of the immunoregulatory cytokines, such as IFNY and IL-10 (Fousteri et al., 2010).

To date, insulin treatment in human context has yielded disappointing results. Although insulin therapies did not cause detectable adverse effects and indeed downregulated insulin-specific $T$ cell responses, they failed to prevent disease onset or delay $\beta$-cell damage (Harrison et al., 2004). Importantly, it seems that this is not due to the choice of dosing or routes of administration because different combination of these factors had similar results (Chaillous et al., 2000; Fourlanos et al., 2011; Nanto-Salonen et al., 2008; Orban et al., 2010; Pozzilli et al., 2000; Skyler et al., 2008; Skyler et al., 2005). Again, because little is known about the activity of insulin-reactive T cells in humans, one would envision that improvement of insulin treatment should largely rely on a more profound understanding of the insulin T cell autoreactivity. 


\section{Concluding remarks}

To summarize, both GAD and insulin therapies have shown their effectiveness in modulating the immune system, which may lead to disease prevention or protection. However, it should be noted that although $\beta$-cell loss and the eventual hyperglycemia are initiated by the immune attacks in the islet, reversal of such processes requires approaches beyond control of inflammation. Specifically, strategies facilitating restoration of insulin production of $\beta$-cells and/or recovery of the actual $\beta$-cell mass may be needed and combined with anti-inflammation therapies. Above all, the lack of success of the antigen-specific treatment in clinical trials suggests an urgent need for a clearer understanding of the initial and progressive immune events leading to $\beta$-cell failure. In this sense, humanized NOD mice may be of great value (Brehm et al., 2012). These efforts together with continuous optimization of the dosing and routes should eventually provide satisfactory translation of animal work to human T1D subjects. 


\section{REFERENCES}

Abadie, V., L.M. Sollid, L.B. Barreiro, and B. Jabri. 2011. Integration of genetic and immunological insights into a model of celiac disease pathogenesis. Annual review of immunology 29:493-525.

Agardh, C.D., C.M. Cilio, A. Lethagen, K. Lynch, R.D. Leslie, M. Palmer, R.A. Harris, J.A. Robertson, and A. Lernmark. 2005. Clinical evidence for the safety of GAD65 immunomodulation in adult-onset autoimmune diabetes. Journal of diabetes and its complications 19:238-246.

Arvan, P., M. Pietropaolo, D. Ostrov, and C.J. Rhodes. 2012. Islet autoantigens: structure, function, localization, and regulation. Cold Spring Harbor perspectives in medicine 2 :

Aspord, C., and C. Thivolet. 2002. Nasal administration of CTB-insulin induces active tolerance against autoimmune diabetes in non-obese diabetic (NOD) mice. Clin Exp Immunol 130:204-211.

Atkinson, M.A. 2012. The pathogenesis and natural history of type 1 diabetes. Cold Spring Harbor perspectives in medicine 2:

Atkinson, M.A., and G.S. Eisenbarth. 2001. Type 1 diabetes: new perspectives on disease pathogenesis and treatment. Lancet 358:221-229.

Atkinson, M.A., N.K. Maclaren, and R. Luchetta. 1990. Insulitis and diabetes in NOD mice reduced by prophylactic insulin therapy. Diabetes 39:933-937.

Baekkeskov, S., H.J. Aanstoot, S. Christgau, A. Reetz, M. Solimena, M. Cascalho, F. Folli, H. Richter-Olesen, and P. De Camilli. 1990. Identification of the $64 \mathrm{~K}$ autoantigen in insulin-dependent diabetes as the GABA-synthesizing enzyme glutamic acid decarboxylase. Nature 347:151-156.

Baekkeskov, S., J.H. Nielsen, B. Marner, T. Bilde, J. Ludvigsson, and A. Lernmark. 1982. Autoantibodies in newly diagnosed diabetic children immunoprecipitate human pancreatic islet cell proteins. Nature 298:167169.

Bennett, S.T., A.M. Lucassen, S.C. Gough, E.E. Powell, D.E. Undlien, L.E. Pritchard, M.E. Merriman, Y. Kawaguchi, M.J. Dronsfield, F. Pociot, and et al. 1995. Susceptibility to human type 1 diabetes at IDDM2 is determined by tandem repeat variation at the insulin gene minisatellite locus. Nature genetics 9:284-292. 
Bergerot, I., C. Ploix, J. Petersen, V. Moulin, C. Rask, N. Fabien, M. Lindblad, A. Mayer, C. Czerkinsky, J. Holmgren, and C. Thivolet. 1997. A cholera toxoid-insulin conjugate as an oral vaccine against spontaneous autoimmune diabetes. Proc Natl Acad Sci U S A 94:4610-4614.

Bettini, M., and D.A. Vignali. 2009. Regulatory T cells and inhibitory cytokines in autoimmunity. Current opinion in immunology 21:612-618.

Bluestone, J.A., K. Herold, and G. Eisenbarth. 2010. Genetics, pathogenesis and clinical interventions in type 1 diabetes. Nature 464:1293-1300.

Brehm, M.A., A.C. Powers, L.D. Shultz, and D.L. Greiner. 2012. Advancing animal models of human type 1 diabetes by engraftment of functional human tissues in immunodeficient mice. Cold Spring Harbor perspectives in medicine 2:a007757.

Bresson, D., L. Togher, E. Rodrigo, Y. Chen, J.A. Bluestone, K.C. Herold, and M. von Herrath. 2006. Anti-CD3 and nasal proinsulin combination therapy enhances remission from recent-onset autoimmune diabetes by inducing Tregs. J Clin Invest 116:1371-1381.

Bu, D.F., M.G. Erlander, B.C. Hitz, N.J. Tillakaratne, D.L. Kaufman, C.B. Wagner-McPherson, G.A. Evans, and A.J. Tobin. 1992. Two human glutamate decarboxylases, 65-kDa GAD and 67-kDa GAD, are each encoded by a single gene. Proc Natl Acad Sci U S A 89:2115-2119.

Calderon, B., J.A. Carrero, M.J. Miller, and E.R. Unanue. 2011. Entry of diabetogenic $T$ cells into islets induces changes that lead to amplification of the cellular response. Proceedings of the National Academy of Sciences of the United States of America 108:1567-1572.

Calderon, B., A. Suri, M.J. Miller, and E.R. Unanue. 2008. Dendritic cells in islets of Langerhans constitutively present beta cell-derived peptides bound to their class II MHC molecules. Proceedings of the National Academy of Sciences of the United States of America 105:6121-6126.

Calderon, B., and E.R. Unanue. 2012. Antigen presentation events in autoimmune diabetes. Current opinion in immunology 24:119-128.

Carrero, J.A., B. Calderon, F. Towfic, M.N. Artyomov, and E.R. Unanue. 2013. Defining the Transcriptional and Cellular Landscape of Type 1 Diabetes in the NOD Mouse. PloS one 8:e59701.

Carter, J.E., 3rd, J. Yu, N.W. Choi, J. Hough, D. Henderson, D. He, and W.H. Langridge. 2006. Bacterial and plant enterotoxin B subunit-autoantigen 
fusion proteins suppress diabetes insulitis. Molecular biotechnology 32:115.

Chaillous, L., H. Lefevre, C. Thivolet, C. Boitard, N. Lahlou, C. Atlan-Gepner, B. Bouhanick, A. Mogenet, M. Nicolino, J.C. Carel, P. Lecomte, R. Marechaud, P. Bougneres, B. Charbonnel, and P. Sai. 2000. Oral insulin administration and residual beta-cell function in recent-onset type 1 diabetes: a multicentre randomised controlled trial. Diabete Insuline Orale group. Lancet 356:545-549.

Chang, K.Y., A. Suri, and E.R. Unanue. 2007. Predicting peptides bound to I-Ag7 class II histocompatibility molecules using a novel expectationmaximization alignment algorithm. Proteomics 7:367-377.

Chao, C.C., H.K. Sytwu, E.L. Chen, J. Toma, and H.O. McDevitt. 1999. The role of MHC class II molecules in susceptibility to type I diabetes: identification of peptide epitopes and characterization of the $\mathrm{T}$ cell repertoire. Proceedings of the National Academy of Sciences of the United States of America 96:9299-9304.

Chatenoud, L., and J.A. Bluestone. 2007. CD3-specific antibodies: a portal to the treatment of autoimmunity. Nat Rev Immunol 7:622-632.

Chatenoud, L., J. Primo, and J.F. Bach. 1997. CD3 antibody-induced dominant self tolerance in overtly diabetic NOD mice. J Immunol 158:2947-2954.

Chatenoud, L., E. Thervet, J. Primo, and J.F. Bach. 1994. Anti-CD3 antibody induces long-term remission of overt autoimmunity in nonobese diabetic mice. Proc Natl Acad Sci U S A 91:123-127.

Chen, C., W.H. Lee, P. Yun, P. Snow, and C.P. Liu. 2003. Induction of autoantigen-specific Th2 and Tr1 regulatory $T$ cells and modulation of autoimmune diabetes. J Immunol 171:733-744.

Chen, W., I. Bergerot, J.F. Elliott, L.C. Harrison, N. Abiru, G.S. Eisenbarth, and T.L. Delovitch. 2001. Evidence that a peptide spanning the B-C junction of proinsulin is an early Autoantigen epitope in the pathogenesis of type 1 diabetes. J Immunol 167:4926-4935.

Chen, Z., A.E. Herman, M. Matos, D. Mathis, and C. Benoist. 2005. Where CD4+CD25+ $T$ reg cells impinge on autoimmune diabetes. The Journal of experimental medicine 202:1387-1397.

Christgau, S., H. Schierbeck, H.J. Aanstoot, L. Aagaard, K. Begley, H. Kofod, K. Hejnaes, and S. Baekkeskov. 1991. Pancreatic beta cells express two autoantigenic forms of glutamic acid decarboxylase, a $65-\mathrm{kDa}$ hydrophilic 
form and a 64-kDa amphiphilic form which can be both membrane-bound and soluble. J Biol Chem 266:23516.

Clemente-Casares, X., S. Tsai, C. Huang, and P. Santamaria. 2012. Antigenspecific therapeutic approaches in Type 1 diabetes. Cold Spring Harbor perspectives in medicine 2:a007773.

Coon, B., L.L. An, J.L. Whitton, and M.G. von Herrath. 1999. DNA immunization to prevent autoimmune diabetes. J Clin Invest 104:189-194.

Daniel, D., and D.R. Wegmann. 1996a. Intranasal administration of insulin peptide B: $9-23$ protects NOD mice from diabetes. Ann $N$ Y Acad Sci 778:371-372.

Daniel, D., and D.R. Wegmann. 1996b. Protection of nonobese diabetic mice from diabetes by intranasal or subcutaneous administration of insulin peptide B-(9-23). Proc Natl Acad Sci U S A 93:956-960.

Devendra, D., J. Paronen, E. Liu, H. Moriyama, D. Miao, L. Yu, and G.S. Eisenbarth. 2004. Differential immune induction with subcutaneous versus oral administration of a diabetogenic insulin peptide in the NOD mouse. Ann N Y Acad Sci 1029:328-330.

Elliott, J.F., H.Y. Qin, S. Bhatti, D.K. Smith, R.K. Singh, T. Dillon, J. Lauzon, and B. Singh. 1994. Immunization with the larger isoform of mouse glutamic acid decarboxylase (GAD67) prevents autoimmune diabetes in NOD mice. Diabetes 43:1494-1499.

Emamaullee, J.A., J. Davis, S. Merani, C. Toso, J.F. Elliott, A. Thiesen, and A.M. Shapiro. 2009. Inhibition of Th17 cells regulates autoimmune diabetes in NOD mice. Diabetes 58:1302-1311.

Endl, J., H. Otto, G. Jung, B. Dreisbusch, F. Donie, P. Stahl, R. Elbracht, G. Schmitz, E. Meinl, M. Hummel, A.G. Ziegler, R. Wank, and D.J. Schendel. 1997. Identification of naturally processed $T$ cell epitopes from glutamic acid decarboxylase presented in the context of HLA-DR alleles by $T$ lymphocytes of recent onset IDDM patients. J Clin Invest 99:2405-2415.

Erlander, M.G., N.J. Tillakaratne, S. Feldblum, N. Patel, and A.J. Tobin. 1991. Two genes encode distinct glutamate decarboxylases. Neuron 7:91-100.

Fan, Y., W.A. Rudert, M. Grupillo, J. He, G. Sisino, and M. Trucco. 2009. Thymus-specific deletion of insulin induces autoimmune diabetes. The EMBO journal 28:2812-2824. 
Faulkner-Jones, B.E., D.S. Cram, J. Kun, and L.C. Harrison. 1993. Localization and quantitation of expression of two glutamate decarboxylase genes in pancreatic beta-cells and other peripheral tissues of mouse and rat. Endocrinology 133:2962-2972.

Feuerer, M., Y. Shen, D.R. Littman, C. Benoist, and D. Mathis. 2009. How punctual ablation of regulatory $\mathrm{T}$ cells unleashes an autoimmune lesion within the pancreatic islets. Immunity 31:654-664.

Filippi, C.M., and M.G. von Herrath. 2008. Viral trigger for type 1 diabetes: pros and cons. Diabetes 57:2863-2871.

Fourlanos, S., C. Perry, S.A. Gellert, E. Martinuzzi, R. Mallone, J. Butler, P.G. Colman, and L.C. Harrison. 2011. Evidence that nasal insulin induces immune tolerance to insulin in adults with autoimmune diabetes. Diabetes 60:1237-1245.

Fousteri, G., J.R. Chan, Y. Zheng, C. Whiting, A. Dave, D. Bresson, M. Croft, and M. von Herrath. 2010. Virtual optimization of nasal insulin therapy predicts immunization frequency to be crucial for diabetes protection. Diabetes 59:3148-3158.

Fu, W., G. Wojtkiewicz, R. Weissleder, C. Benoist, and D. Mathis. 2012. Early window of diabetes determinism in NOD mice, dependent on the complement receptor CRIg, identified by noninvasive imaging. Nature immunology 13:361-368.

Giongo, A., K.A. Gano, D.B. Crabb, N. Mukherjee, L.L. Novelo, G. Casella, J.C. Drew, J. Ilonen, M. Knip, H. Hyoty, R. Veijola, T. Simell, O. Simell, J. Neu, C.H. Wasserfall, D. Schatz, M.A. Atkinson, and E.W. Triplett. 2011. Toward defining the autoimmune microbiome for type 1 diabetes. The ISME journal 5:82-91.

Gottlieb, P.A., and G.S. Eisenbarth. 2002. Insulin-specific tolerance in diabetes. Clinical immunology 102:2-11.

Grubin, C.E., T. Daniels, B. Toivola, M. Landin-Olsson, W.A. Hagopian, L. Li, A.E. Karlsen, E. Boel, B. Michelsen, and A. Lernmark. 1994. A novel radioligand binding assay to determine diagnostic accuracy of isoformspecific glutamic acid decarboxylase antibodies in childhood IDDM. Diabetologia 37:344-350.

Harrison, L.C., M. Dempsey-Collier, D.R. Kramer, and K. Takahashi. 1996. Aerosol insulin induces regulatory CD8 gamma delta $T$ cells that prevent murine insulin-dependent diabetes. J Exp Med 184:2167-2174. 
Harrison, L.C., M.C. Honeyman, C.E. Steele, N.L. Stone, E. Sarugeri, E. Bonifacio, J.J. Couper, and P.G. Colman. 2004. Pancreatic beta-cell function and immune responses to insulin after administration of intranasal insulin to humans at risk for type 1 diabetes. Diabetes care 27:2348-2355.

Herold, K.C., S.E. Gitelman, U. Masharani, W. Hagopian, B. Bisikirska, D. Donaldson, K. Rother, B. Diamond, D.M. Harlan, and J.A. Bluestone. 2005. A single course of anti-CD3 monoclonal antibody hOKT3gamma1(Ala-Ala) results in improvement in C-peptide responses and clinical parameters for at least 2 years after onset of type 1 diabetes. Diabetes 54:1763-1769.

Herold, K.C., W. Hagopian, J.A. Auger, E. Poumian-Ruiz, L. Taylor, D. Donaldson, S.E. Gitelman, D.M. Harlan, D. Xu, R.A. Zivin, and J.A. Bluestone. 2002. Anti-CD3 monoclonal antibody in new-onset type 1 diabetes mellitus. N Engl J Med 346:1692-1698.

Honeyman, M.C., D.S. Cram, and L.C. Harrison. 1993. Glutamic acid decarboxylase 67-reactive T cells: a marker of insulin-dependent diabetes. J Exp Med 177:535-540.

Hutchings, P.R., and A. Cooke. 1995. Comparative study of the protective effect afforded by intravenous administration of bovine or ovine insulin to young NOD mice. Diabetes 44:906-910.

Jain, R., D.M. Tartar, R.K. Gregg, R.D. Divekar, J.J. Bell, H.H. Lee, P. Yu, J.S. Ellis, C.M. Hoeman, C.L. Franklin, and H. Zaghouani. 2008. Innocuous IFNgamma induced by adjuvant-free antigen restores normoglycemia in NOD mice through inhibition of IL-17 production. J Exp Med 205:207-218.

Jeker, L.T., H. Bour-Jordan, and J.A. Bluestone. 2012. Breakdown in peripheral tolerance in type 1 diabetes in mice and humans. Cold Spring Harbor perspectives in medicine 2:a007807.

Jun, H.S., L.Y. Khil, and J.W. Yoon. 2002. Role of glutamic acid decarboxylase in the pathogenesis of type 1 diabetes. Cellular and molecular life sciences : CMLS 59:1892-1901.

Kanazawa, Y., A. Shimada, Y. Oikawa, Y. Okubo, A. Tada, T. Imai, J. Miyazaki, and $\mathrm{H}$. Itoh. 2009. Induction of anti-whole GAD65 reactivity in vivo results in disease suppression in type 1 diabetes. Journal of autoimmunity 32:104-109.

Karlsen, A.E., W.A. Hagopian, J.S. Petersen, E. Boel, T. Dyrberg, C.E. Grubin, B.K. Michelsen, O.D. Madsen, and A. Lernmark. 1992. Recombinant glutamic acid decarboxylase (representing the single isoform expressed in 
human islets) detects IDDM-associated $64,000-\mathrm{M}(\mathrm{r})$ autoantibodies. Diabetes 41:1355-1359.

Kaufman, D.L., M. Clare-Salzler, J. Tian, T. Forsthuber, G.S. Ting, P. Robinson, M.A. Atkinson, E.E. Sercarz, A.J. Tobin, and P.V. Lehmann. 1993. Spontaneous loss of T-cell tolerance to glutamic acid decarboxylase in murine insulin-dependent diabetes. Nature 366:69-72.

Keymeulen, B., E. Vandemeulebroucke, A.G. Ziegler, C. Mathieu, L. Kaufman, G. Hale, F. Gorus, M. Goldman, M. Walter, S. Candon, L. Schandene, L. Crenier, C. De Block, J.M. Seigneurin, P. De Pauw, D. Pierard, I. Weets, P. Rebello, P. Bird, E. Berrie, M. Frewin, H. Waldmann, J.F. Bach, D. Pipeleers, and L. Chatenoud. 2005. Insulin needs after CD3-antibody therapy in new-onset type 1 diabetes. N Engl J Med 352:2598-2608.

Kim, S.K., K.V. Tarbell, M. Sanna, M. Vadeboncoeur, T. Warganich, M. Lee, M. Davis, and H.O. McDevitt. 2004. Prevention of type I diabetes transfer by glutamic acid decarboxylase 65 peptide 206-220-specific T cells. Proc Natl Acad Sci U S A 101:14204-14209.

Knip, M., and O. Simell. 2012. Environmental triggers of type 1 diabetes. Cold Spring Harbor perspectives in medicine 2:a007690.

Kriegel, M.A., E. Sefik, J.A. Hill, H.J. Wu, C. Benoist, and D. Mathis. 2011. Naturally transmitted segmented filamentous bacteria segregate with diabetes protection in nonobese diabetic mice. Proceedings of the National Academy of Sciences of the United States of America 108:11548-11553.

Kuglin, B., F.A. Gries, and H. Kolb. 1988. Evidence of IgG autoantibodies against human proinsulin in patients with IDDM before insulin treatment. Diabetes 37:130-132.

Li, Q., B. Xu, S.A. Michie, K.H. Rubins, R.D. Schreriber, and H.O. McDevitt. 2008. Interferon-alpha initiates type 1 diabetes in nonobese diabetic mice. Proceedings of the National Academy of Sciences of the United States of America 105:12439-12444.

Lieberman, S.M., and T.P. DiLorenzo. 2003. A comprehensive guide to antibody and T-cell responses in type 1 diabetes. Tissue antigens 62:359-377.

Long, S.A., K. Cerosaletti, P.L. Bollyky, M. Tatum, H. Shilling, S. Zhang, Z.Y. Zhang, C. Pihoker, S. Sanda, C. Greenbaum, and J.H. Buckner. 2010. Defects in IL-2R signaling contribute to diminished maintenance of FOXP3 expression in CD4(+)CD25(+) regulatory T-cells of type 1 diabetic subjects. Diabetes 59:407-415. 
Ludvigsson, J., M. Faresjo, M. Hjorth, S. Axelsson, M. Cheramy, M. Pihl, O. Vaarala, G. Forsander, S. Ivarsson, C. Johansson, A. Lindh, N.O. Nilsson, J. Aman, E. Ortqvist, P. Zerhouni, and R. Casas. 2008. GAD treatment and insulin secretion in recent-onset type 1 diabetes. $N$ Engl $\mathrm{J}$ Med 359:1909-1920.

Luo, X., K.C. Herold, and S.D. Miller. 2010. Immunotherapy of type 1 diabetes: where are we and where should we be going? Immunity 32:488-499.

Ma, S.W., D.L. Zhao, Z.Q. Yin, R. Mukherjee, B. Singh, H.Y. Qin, C.R. Stiller, and A.M. Jevnikar. 1997. Transgenic plants expressing autoantigens fed to mice to induce oral immune tolerance. Nat Med 3:793-796.

Maron, R., N.S. Melican, and H.L. Weiner. 1999. Regulatory Th2-type T cell lines against insulin and GAD peptides derived from orally- and nasally-treated NOD mice suppress diabetes. J Autoimmun 12:251-258.

Marrack, P., and J.W. Kappler. 2012. Do MHCll-presented neoantigens drive type 1 diabetes and other autoimmune diseases? Cold Spring Harbor perspectives in medicine 2:a007765.

Martinez, N.R., P. Augstein, A.K. Moustakas, G.K. Papadopoulos, S. Gregori, L. Adorini, D.C. Jackson, and L.C. Harrison. 2003. Disabling an integral CTL epitope allows suppression of autoimmune diabetes by intranasal proinsulin peptide. J Clin Invest 111:1365-1371.

Mingueneau, M., W. Jiang, M. Feuerer, D. Mathis, and C. Benoist. 2012. Thymic negative selection is functional in NOD mice. The Journal of experimental medicine 209:623-637.

Mohan, J.F., M.G. Levisetti, B. Calderon, J.W. Herzog, S.J. Petzold, and E.R. Unanue. 2010. Unique autoreactive $T$ cells recognize insulin peptides generated within the islets of Langerhans in autoimmune diabetes. Nat Immunol 11:350-354.

Mohan, J.F., S.J. Petzold, and E.R. Unanue. 2011. Register shifting of an insulin peptide-MHC complex allows diabetogenic $T$ cells to escape thymic deletion. The Journal of experimental medicine 208:2375-2383.

Mohan, J.F., and E.R. Unanue. 2012. Unconventional recognition of peptides by $\mathrm{T}$ cells and the implications for autoimmunity. Nature reviews. Immunology 12:721-728.

Mohan, J.F., and E.R. Unanue. 2013. A novel pathway of presentation by class II-MHC molecules involving peptides or denatured proteins important in autoimmunity. Molecular immunology 55:166-168. 
Moriyama, H., N. Abiru, J. Paronen, K. Sikora, E. Liu, D. Miao, D. Devendra, J. Beilke, R. Gianani, R.G. Gill, and G.S. Eisenbarth. 2003. Evidence for a primary islet autoantigen (preproinsulin 1) for insulitis and diabetes in the nonobese diabetic mouse. Proceedings of the National Academy of Sciences of the United States of America 100:10376-10381.

Muir, A., A. Peck, M. Clare-Salzler, Y.H. Song, J. Cornelius, R. Luchetta, J. Krischer, and N. Maclaren. 1995. Insulin immunization of nonobese diabetic mice induces a protective insulitis characterized by diminished intraislet interferon-gamma transcription. J Clin Invest 95:628-634.

Nakayama, M., N. Abiru, H. Moriyama, N. Babaya, E. Liu, D. Miao, L. Yu, D.R. Wegmann, J.C. Hutton, J.F. Elliott, and G.S. Eisenbarth. 2005. Prime role for an insulin epitope in the development of type 1 diabetes in NOD mice. Nature 435:220-223.

Nanto-Salonen, K., A. Kupila, S. Simell, H. Siljander, T. Salonsaari, A. Hekkala, S. Korhonen, R. Erkkola, J.I. Sipila, L. Haavisto, M. Siltala, J. Tuominen, J. Hakalax, H. Hyoty, J. Ilonen, R. Veijola, T. Simell, M. Knip, and O. Simell. 2008. Nasal insulin to prevent type 1 diabetes in children with HLA genotypes and autoantibodies conferring increased risk of disease: a double-blind, randomised controlled trial. Lancet 372:1746-1755.

Nejentsev, S., N. Walker, D. Riches, M. Egholm, and J.A. Todd. 2009. Rare variants of IFIH1, a gene implicated in antiviral responses, protect against type 1 diabetes. Science 324:387-389.

Orban, T., K. Farkas, H. Jalahej, J. Kis, A. Treszl, B. Falk, H. Reijonen, J. Wolfsdorf, A. Ricker, J.B. Matthews, N. Tchao, P. Sayre, and P. Bianchine. 2010. Autoantigen-specific regulatory $T$ cells induced in patients with type 1 diabetes mellitus by insulin B-chain immunotherapy. Journal of autoimmunity 34:408-415.

Orban, T., J.M. Sosenko, D. Cuthbertson, J.P. Krischer, J.S. Skyler, R. Jackson, L. Yu, J.P. Palmer, D. Schatz, G. Eisenbarth, and G. Diabetes Prevention Trial-Type 1 Study. 2009. Pancreatic islet autoantibodies as predictors of type 1 diabetes in the Diabetes Prevention Trial-Type 1. Diabetes care 32:2269-2274.

Palmer, J.P., C.M. Asplin, P. Clemons, K. Lyen, O. Tatpati, P.K. Raghu, and T.L. Paquette. 1983. Insulin antibodies in insulin-dependent diabetics before insulin treatment. Science 222:1337-1339.

Panina-Bordignon, P., R. Lang, P.M. van Endert, E. Benazzi, A.M. Felix, R.M. Pastore, G.A. Spinas, and F. Sinigaglia. 1995. Cytotoxic T cells specific 
for glutamic acid decarboxylase in autoimmune diabetes. J Exp Med 181:1923-1927.

Paronen, J., P. Klemetti, J.M. Kantele, E. Savilahti, J. Perheentupa, H.K. Akerblom, and O. Vaarala. 1997. Glutamate decarboxylase-reactive peripheral blood lymphocytes from patients with IDDM express gutspecific homing receptor alpha4beta7-integrin. Diabetes 46:583-588.

Plesner, A., A. Worsaae, T. Dyrberg, C. Gotfredsen, B.K. Michelsen, and J.S. Petersen. 1998. Immunization of diabetes-prone or non-diabetes-prone mice with GAD65 does not induce diabetes or islet cell pathology. J Autoimmun 11:335-341.

Poirot, L., C. Benoist, and D. Mathis. 2004. Natural killer cells distinguish innocuous and destructive forms of pancreatic islet autoimmunity. Proceedings of the National Academy of Sciences of the United States of America 101:8102-8107.

Pozzilli, P., D. Pitocco, N. Visalli, M.G. Cavallo, R. Buzzetti, A. Crino, S. Spera, C. Suraci, G. Multari, M. Cervoni, M.L. Manca Bitti, M.C. Matteoli, G. Marietti, F. Ferrazzoli, M.R. Cassone Faldetta, C. Giordano, M. Sbriglia, E. Sarugeri, and G. Ghirlanda. 2000. No effect of oral insulin on residual beta-cell function in recent-onset type I diabetes (the IMDIAB VII). IMDIAB Group. Diabetologia 43:1000-1004.

Raine, T., P. Zaccone, P. Mastroeni, and A. Cooke. 2006. Salmonella typhimurium infection in nonobese diabetic mice generates immunomodulatory dendritic cells able to prevent type 1 diabetes. Journal of immunology 177:2224-2233.

Ramiya, V.K., X.Z. Shang, C.H. Wasserfall, and N.K. Maclaren. 1997. Effect of oral and intravenous insulin and glutamic acid decarboxylase in NOD mice. Autoimmunity 26:139-151.

Rangel-Moreno, J., J.E. Moyron-Quiroz, D.M. Carragher, K. Kusser, L. Hartson, A. Moquin, and T.D. Randall. 2009. Omental milky spots develop in the absence of lymphoid tissue-inducer cells and support $B$ and $T$ cell responses to peritoneal antigens. Immunity 30:731-743.

Ravanan, R., S.F. Wong, N.G. Morgan, P.W. Mathieson, and R.M. Smith. 2007. Inhalation of glutamic acid decarboxylase 65-derived peptides can protect against recurrent autoimmune but not alloimmune responses in the nonobese diabetic mouse. Clin Exp Immunol 148:368-372.

Roep, B.O., and M. Peakman. 2012. Antigen targets of type 1 diabetes autoimmunity. Cold Spring Harbor perspectives in medicine 2:a007781. 
Rubtsov, Y.P., R.E. Niec, S. Josefowicz, L. Li, J. Darce, D. Mathis, C. Benoist, and A.Y. Rudensky. 2010. Stability of the regulatory T cell lineage in vivo. Science 329:1667-1671.

Rudy, G., N. Stone, L.C. Harrison, P.G. Colman, P. McNair, V. Brusic, M.B. French, M.C. Honeyman, B. Tait, and A.M. Lew. 1995. Similar peptides from two beta cell autoantigens, proinsulin and glutamic acid decarboxylase, stimulate T cells of individuals at risk for insulin-dependent diabetes. Mol Med 1:625-633.

Sai, P., C. Damage, A.S. Rivereau, A. Hoeltzel, and E. Gouin. 1996. Prophylactic oral administration of metabolically active insulin entrapped in isobutylcyanoacrylate nanocapsules reduces the incidence of diabetes in nonobese diabetic mice. J Autoimmun 9:713-722.

Sapone, A., L. de Magistris, M. Pietzak, M.G. Clemente, A. Tripathi, F. Cucca, R. Lampis, D. Kryszak, M. Carteni, M. Generoso, D. lafusco, F. Prisco, F. Laghi, G. Riegler, R. Carratu, D. Counts, and A. Fasano. 2006. Zonulin upregulation is associated with increased gut permeability in subjects with type 1 diabetes and their relatives. Diabetes 55:1443-1449.

Skyler, J.S., C.J. Greenbaum, J.M. Lachin, E. Leschek, L. Rafkin-Mervis, P. Savage, L. Spain, and G. Type 1 Diabetes TrialNet Study. 2008. Type 1 Diabetes TrialNet--an international collaborative clinical trials network. Annals of the New York Academy of Sciences 1150:14-24.

Skyler, J.S., J.P. Krischer, J. Wolfsdorf, C. Cowie, J.P. Palmer, C. Greenbaum, D. Cuthbertson, L.E. Rafkin-Mervis, H.P. Chase, and E. Leschek. 2005. Effects of oral insulin in relatives of patients with type 1 diabetes: The Diabetes Prevention Trial--Type 1. Diabetes care 28:1068-1076.

Sorenson, R.L., D.G. Garry, and T.C. Brelje. 1991. Structural and functional considerations of GABA in islets of Langerhans. Beta-cells and nerves. Diabetes 40:1365-1374.

Steck, A.K., K. Johnson, K.J. Barriga, D. Miao, L. Yu, J.C. Hutton, G.S. Eisenbarth, and M.J. Rewers. 2011. Age of islet autoantibody appearance and mean levels of insulin, but not GAD or IA-2 autoantibodies, predict age of diagnosis of type 1 diabetes: diabetes autoimmunity study in the young. Diabetes care 34:1397-1399.

Steck, A.K., and M.J. Rewers. 2011. Genetics of type 1 diabetes. Clinical chemistry 57:176-185.

Suri, A., J.J. Walters, H.W. Rohrs, M.L. Gross, and E.R. Unanue. 2008. First signature of islet beta-cell-derived naturally processed peptides selected 
by diabetogenic class II MHC molecules. Journal of immunology 180:3849-3856.

Tang, Q., J.Y. Adams, C. Penaranda, K. Melli, E. Piaggio, E. Sgouroudis, C.A. Piccirillo, B.L. Salomon, and J.A. Bluestone. 2008. Central role of defective interleukin-2 production in the triggering of islet autoimmune destruction. Immunity 28:687-697.

Thebault-Baumont, K., D. Dubois-Laforgue, P. Krief, J.P. Briand, P. Halbout, K. Vallon-Geoffroy, J. Morin, V. Laloux, A. Lehuen, J.C. Carel, J. Jami, S. Muller, and C. Boitard. 2003. Acceleration of type 1 diabetes mellitus in proinsulin 2-deficient NOD mice. The Journal of clinical investigation 111:851-857.

Tian, J., M.A. Atkinson, M. Clare-Salzler, A. Herschenfeld, T. Forsthuber, P.V. Lehmann, and D.L. Kaufman. 1996. Nasal administration of glutamate decarboxylase (GAD65) peptides induces Th2 responses and prevents murine insulin-dependent diabetes. J Exp Med 183:1561-1567.

Tisch, R., B. Wang, and D.V. Serreze. 1999. Induction of glutamic acid decarboxylase 65-specific Th2 cells and suppression of autoimmune diabetes at late stages of disease is epitope dependent. J Immunol 163:1178-1187.

Tisch, R., X.D. Yang, S.M. Singer, R.S. Liblau, L. Fugger, and H.O. McDevitt. 1993. Immune response to glutamic acid decarboxylase correlates with insulitis in non-obese diabetic mice. Nature 366:72-75.

Uchizono, Y., C. Alarcon, B.L. Wicksteed, B.J. Marsh, and C.J. Rhodes. 2007. The balance between proinsulin biosynthesis and insulin secretion: where can imbalance lead? Diabetes, obesity \& metabolism 9 Suppl 2:56-66.

Uibo, R., and A. Lernmark. 2008. GAD65 autoimmunity-clinical studies. Advances in immunology 100:39-78.

Vaarala, O. 2000. The role of the gut in beta-cell autoimmunity and type 1 diabetes: a hypothesis. Pediatric diabetes 1:217-225.

Vafiadis, P., S.T. Bennett, J.A. Todd, J. Nadeau, R. Grabs, C.G. Goodyer, S. Wickramasinghe, E. Colle, and C. Polychronakos. 1997. Insulin expression in human thymus is modulated by INS VNTR alleles at the IDDM2 locus. Nature genetics 15:289-292.

Vossenaar, E.R., S. Nijenhuis, M.M. Helsen, A. van der Heijden, T. Senshu, W.B. van den Berg, W.J. van Venrooij, and L.A. Joosten. 2003. Citrullination of 
synovial proteins in murine models of rheumatoid arthritis. Arthritis and rheumatism 48:2489-2500.

Wen, L., R.E. Ley, P.Y. Volchkov, P.B. Stranges, L. Avanesyan, A.C. Stonebraker, C. Hu, F.S. Wong, G.L. Szot, J.A. Bluestone, J.I. Gordon, and A.V. Chervonsky. 2008. Innate immunity and intestinal microbiota in the development of Type 1 diabetes. Nature 455:1109-1113.

Wicksteed, B., Y. Uchizono, C. Alarcon, J.F. McCuaig, A. Shalev, and C.J. Rhodes. 2007. A cis-element in the $5^{\prime}$ untranslated region of the preproinsulin mRNA (pplGE) is required for glucose regulation of proinsulin translation. Cell metabolism 5:221-227.

Wu, H.J., Ivanov, II, J. Darce, K. Hattori, T. Shima, Y. Umesaki, D.R. Littman, C. Benoist, and D. Mathis. 2010. Gut-residing segmented filamentous bacteria drive autoimmune arthritis via T helper 17 cells. Immunity 32:815827.

Yamamoto, T., E. Yamato, F. Tashiro, T. Sato, S. Noso, H. Ikegami, S. Tamura, Y. Yanagawa, and J.I. Miyazaki. 2004. Development of autoimmune diabetes in glutamic acid decarboxylase 65 (GAD65) knockout NOD mice. Diabetologia 47:221-224.

Yamanouchi, J., D. Rainbow, P. Serra, S. Howlett, K. Hunter, V.E. Garner, A. Gonzalez-Munoz, J. Clark, R. Veijola, R. Cubbon, S.L. Chen, R. Rosa, A.M. Cumiskey, D.V. Serreze, S. Gregory, J. Rogers, P.A. Lyons, B. Healy, L.J. Smink, J.A. Todd, L.B. Peterson, L.S. Wicker, and P. Santamaria. 2007. Interleukin-2 gene variation impairs regulatory $T$ cell function and causes autoimmunity. Nature genetics 39:329-337.

Yoon, J.W., C.S. Yoon, H.W. Lim, Q.Q. Huang, Y. Kang, K.H. Pyun, K. Hirasawa, R.S. Sherwin, and H.S. Jun. 1999. Control of autoimmune diabetes in NOD mice by GAD expression or suppression in beta cells. Science 284:1183-1187.

Yu, L., D.T. Robles, N. Abiru, P. Kaur, M. Rewers, K. Kelemen, and G.S. Eisenbarth. 2000. Early expression of antiinsulin autoantibodies of humans and the NOD mouse: evidence for early determination of subsequent diabetes. Proc Natl Acad Sci U S A 97:1701-1706.

Zaccone, P., Z. Fehervari, F.M. Jones, S. Sidobre, M. Kronenberg, D.W. Dunne, and A. Cooke. 2003. Schistosoma mansoni antigens modulate the activity of the innate immune response and prevent onset of type 1 diabetes. European journal of immunology 33:1439-1449. 
Zhang, Z.J., L. Davidson, G. Eisenbarth, and H.L. Weiner. 1991. Suppression of diabetes in nonobese diabetic mice by oral administration of porcine insulin. Proc Natl Acad Sci U S A 88:10252-10256.

Zhou, X., S.L. Bailey-Bucktrout, L.T. Jeker, C. Penaranda, M. Martinez-Llordella, M. Ashby, M. Nakayama, W. Rosenthal, and J.A. Bluestone. 2009. Instability of the transcription factor Foxp3 leads to the generation of pathogenic memory T cells in vivo. Nature immunology 10:1000-1007. 


\section{CHAPTER II}

\section{MECHANISMS UNDERLYING ANTIGEN-SPECIFIC \\ TOLERANCE OF STABLE AND CONVERTIBLE TH17 \\ CELLS DURING SUPPRESSION OF AUTOIMMUNE \\ DIABETES}

(Diabetes, 2012, 61(8), 2054-2065) 


\section{ABSTRACT}

Autoimmune or type 1 diabetes (T1D) involves both Th1 and Th17 pathogenic cells. While the mechanisms underlying the control of Th1 cells are relatively well-defined, those operating modulation of Th17 cells remain largely unknown. Moreover, given that Th17 cells are plastic and can drive disease as stable or convertible T cells, effective approaches to counter T1D would have to alter Th17 function under both circumstances. Herein, diabetogenic BDC2.5 Th17 cells were transferred into NOD mice under convertible or stable conditions and their fate was evaluated upon induction of tolerance and disease suppression. The findings show that upon induction of antigen-specific tolerance, convertible (Th17 to Th1) cells display down-regulation of the chemokine receptor CXCR3 that was associated with diminished T-bet expression, retention of the cells in the spleen and inhibition of trafficking to the pancreas. In contrast, stable Th17 cells downregulated ROR $\gamma$ t but increased FasL expression and died by apoptosis under the same antigen-specific tolerance. Thus, the final signature transcription factor shapes the mechanism of tolerance in plastic Th17 cells. These findings suggest that effective strategies against T1D will require regimens that could drive both mechanisms of tolerance to overcome the disease. 


\section{INTRODUCTION}

Type 1 diabetes (T1D) is a chronic autoimmune disorder characterized by T cellmediated destruction of pancreatic insulin-producing $\beta$ cells. Studies of the nonobese diabetic (NOD) mouse model have revealed that Th1 cells are the key

mediators of T1D (Katz et al., 1995; Wang et al., 1997). NOD mice lacking several Th1-associated regulators, including STAT4 (Yang et al., 2004) and Tbet (Esensten et al., 2009), were prevented from the spontaneous disease onset; however, genetic deletion of IFNy (Hultgren et al., 1996), IFNy receptor (Serreze et al., 2000) or IL-12 (Trembleau et al., 1999) had little impact on disease development in NOD mice. These discrepancies indicate a potential role of other effector CD4 T cell subsets during the development of T1D.

More recently, Th17 cells have been demonstrated to be involved in T1D pathogenesis. Elevated IL-17 expression was detected in diabetic NOD mice (Martin-Orozco et al., 2009), and IL-17 neutralization inhibited disease progression from the effector phase (Emamaullee et al., 2009). A previous study from our laboratory has demonstrated that treatment of hyperglycemic mice with a chimeric agent consisting of immunoglobulin (Ig) and GAD65 peptide 206-220 restored normoglycemia through inhibition of IL-17 response in spleen and pancreas (Jain et al., 2008). In human patients, monocytes isolated from TID individuals secreted IL-6 and IL-1, which induced and expanded Th17 cells (Bradshaw et al., 2009). Enhanced IL-17, RORC2 and IL-22 expression upon monocyte activation was associated with recently diagnosed T1D in children (Honkanen et al., 2010). These findings suggest that Th17 cells are mediators 
and potential therapeutic targets in T1D. However, mechanisms underlying tolerance of diabetogenic Th17 cells remain largely unknown.

Differentiation of naive CD4 T cells to the Th17 lineage is programmed by IL-6, TGF- $\beta$ and IL-1 $\beta$ (Bettelli et al., 2006; Mangan et al., 2006; Sutton et al., 2006; Veldhoen et al., 2006), and IL-23 is required for maintenance and expansion of differentiated Th17 cells (Ahern et al., 2010; McGeachy et al., 2009). However, instructed by different cytokine milieus, Th17 development can be directed to other effector programs (Zhou et al., 2009). In particular, increased concentrations of IL-12 and TGF- $\beta$ can shift Th17 differentiation to either Th1 or Treg pathway, respectively, giving rise to the notion of "Th17 plasticity" (Lee et al., 2009; Zhou et al., 2008). In autoimmune settings, plastic Th17 cells are able to switch their pathogenic phenotypes in response to variable environmental cues, resulting in robust autoimmune responses. Specifically, highly differentiated Th17 cells need to convert into a Th1-like profile before efficiently inducing T1D in lymphopenic environments (Bending et al., 2009; Martin-Orozco et al., 2009). On the other hand, polarized Th17 cells stayed stable when transferred into WT hosts (Nurieva et al., 2009), and may drive T1D development through recruiting macrophages to the islets (Martin-Orozco et al., 2009). These findings indicate that Th17 cells exert differential pathogenic functions due to their plasticity shaped by various environmental factors. Therefore, comprehensive understanding of Th17 tolerance would require analyses based on both cell converting and non-converting settings. 
In the present study, we attempted to explore the mechanisms underlying tolerance of plastic Th17 cells using the well-established adoptive transfer model of BDC2.5 T cells into NOD.scid or NOD recipients. Furthermore, we devised an effective tolerogenic Immunoglobulin (Ig)-based treatment by expressing the library defined BDC2.5-reactive p79 peptide (Judkowski et al., 2001; You et al., 2003) on the Ig backbone. The resulting Ig-p79 was then used in the transfer model of T1D to investigate tolerance of Th17 cells. The results show that Th17 cells transferred into NOD.scid mice converted into Th1 cells and the treatment with Ig-p79 suppressed diabetes by interfering with the expression of the chemokine receptor CXCR3 on the converted Th1 cells, leading to retention of these cells in the spleen and impaired trafficking to the target pancreas. In contrast, when the Th17 cells were transferred into NOD mice, they were unable to convert to Th1 cells and underwent apoptosis upon treatment with Ig-p79. Finally, the different fates of Th1 and Th17 cells were tied to their signature transcription factors as down-regulation of T-bet led to diminished expression of CXCR3 and modulation of ROR $\gamma$ t led to increased FasL expression. These previously unrecognized tolerogenic mechanisms should contribute to the development of effective therapeutic strategies against diabetes. 


\section{RESEARCH DESIGN AND METHODS}

\section{Mice}

NOD $\left(\mathrm{H}-2^{\mathrm{g}}\right)$, NOD.scid, NOD.BDC2.5, BALB/c.IL-12a ${ }^{\mathrm{tm} 1 \mathrm{Jm}}\left(\mathrm{IL}-12 \mathrm{p} 35^{-/-}\right)$mice were purchased from The Jackson Laboratory (Bar Harbor, ME). NOD.FoxP3 ${ }^{\text {GFP.DTR }}$ mice were generated by breeding C57BL/6.FoxP3. ${ }^{\text {GFP.DTR }}$ mice onto the NOD background for 7 backcross generations. The NOD.FOXP3 ${ }^{\text {GFP.DTR }}$ mice were then bred with NOD.BDC2.5 mice to generate NOD.BDC2.5.FoxP3 ${ }^{\text {GFP.DTR }}$ mice. NOD.scid.IL-12p35 $5^{-/-}$mice were generated by breeding BALB/c.IL-12p35 $5^{-1-}$ mice with NOD.scid mice for 7 backcross generations. All mice were used according to the guidelines of the University of Missouri Animal Care and Use Committee.

\section{Peptides and Ig chimeras}

All peptides used in this study were purchased from Metabion and purified by HPLC to $>95 \%$ purity. p79 peptide corresponds to the library defined mimotope (AVRPLWVRME) reactive with BDC2.5 diabetogenic T cells (Judkowski et al., 2001; You et al., 2003). Hen egg lysozyme (HEL) peptide corresponds to aa residues 11-25 (AMKRHGLDNYRGYSL) of HEL. Ig-p79 and Ig-HEL express p79 and HEL peptide, respectively. The genetic engineering of p79 peptide into the heavy chain of the 91A3 anti-arsonate antibody and the production of Ig-p79 was accomplished according to methods used to generate Ig-HEL (Gregg et al., 2004). 


\section{T cell polarization}

Splenic cells $\left(2 \times 10^{6} / \mathrm{ml}\right)$ from 4-6-wk naïve NOD.BDC2.5.FoxP3 ${ }^{\text {GFP.DTR }}$ mice were depleted of red blood cells and stimulated with p79 peptide $(0.5 \mu \mathrm{M})$ under Th1 or Th17 conditions for 4 days. For polarization into Th1 cells, the stimulation was carried out in the presence of $\mathrm{rlL}-12(10 \mathrm{ng} / \mathrm{ml}$, peprotech) and anti-IL-4 $(10 \mu \mathrm{g} / \mathrm{ml}, 11 \mathrm{~B} 11)$. For Th17 polarizaton, the culture was supplemented with rTGF- $\beta$ (3ng/ml, peprotech), rlL-6 (20ng/ml, peprotech), anti-IFNy $(10 \mu \mathrm{g} / \mathrm{ml}, \mathrm{R} 4-$

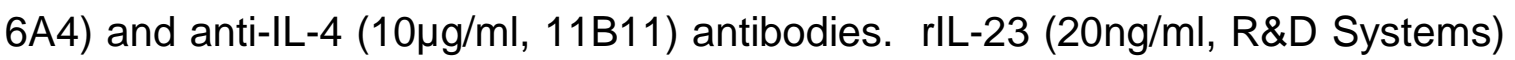
was added to the culture for the last 2 days.

\section{Retroviral transduction}

The MSCV-CXCR3-IRES-Thy1.1 and empty MSCV-IRES-Thy1.1 vector used to over-express CXCR3 in polarized Th17 cells were previously described (Hu et al., 2011). Briefly, 293FT cells (Invitrogen) were transfected with either MSCVCXCR3-IRES-Thy1.1 or MSCV-IRES-Thy1.1 vector along with the retroviral packaging vector $(\mathrm{p} \psi \mathrm{ECO})$ by calcium chloride. The culture supernatant containing the retroviruses was used to transduce Thy1.2 BDC2.5 T cells during polarization to Th17 cells. Briefly, the naïve T cells were cultured under polarizing conditions and the viral supernatant was added $24 \mathrm{~h}$ later. The culture was then spun down (2500rpm for $1 \mathrm{~h}$ at $23^{\circ} \mathrm{C}$ ), the supernatant was discarded and the pelleted infected cells were resuspended in fresh polarizing media and the culture was continued for 3 days. The $\mathrm{CD}^{+} \mathrm{T}$ cells were then isolated and used for transfer experiments. 


\section{Purification and adoptive transfer of polarized Th1 and Th17 cells}

$\mathrm{CD}^{+} \mathrm{T}$ cells were isolated from the culture by negative selection using CD4 $\mathrm{T}$ cell isolation kit II from Miltenyi Biotec. The CD4 ${ }^{+}$T cells $\left(2 \times 10^{6} / \mathrm{ml}\right)$ were then stimulated with PMA $(50 \mathrm{ng} / \mathrm{ml})$ and ionomycin $(500 \mathrm{ng} / \mathrm{ml})$ for $2 \mathrm{~h}$ and the cells were labeled using the Mouse IFNy (APC) and IL-17 (PE) detection kit from Miltenyi Biotec. Subsequently, the enriched Th17 (IL-17 ${ }^{+} \mathrm{IFNy}{ }^{-} \mathrm{FoxP} 3^{-}$) and Th1 $\left(\mathrm{IFNy}{ }^{+} \mathrm{IL}-17^{-} \mathrm{FoxP}^{-}\right)$cells were sorted to at least $98 \%$ purity using a Beckman Coulter MoFlo XDP sorter.

For adoptive transfer, $3 \times 10^{6}$ purified cells were transferred i.v. into NOD.scid mice, and $1 \times 10^{7}$ cells were transferred i.v. into NOD or NOD.FoxP3 ${ }^{\text {GFP.DTR }}$ mice.

\section{Treatment with Ig-p79 chimera and neutralizing anti-cytokine antibodies}

Ig-p79 and the control Ig-HEL were injected into mice (300 $\mu \mathrm{g} /$ mouse) i.p. a few hours after transfer of T cells. For in vivo neutralization of IFNy or IL-17, the mice were given anti-IFNy (R4-6A4), anti-IL-17(TC11-18H10), and isotype Rat IgG1 control (300 $\mu$ g per injection) i.p. on day 0, 2, 4 and 6 after cell transfer.

\section{Depletion of Tregs}

Diphtheria toxin (Sigma) was given to NOD.FoxP3 ${ }^{\text {GFP.DTR }}$ mice i.p. (300 ng/mouse/injection) on days $-2,-1,2,5,8,11$ and 14 after cell transfer. 


\section{Antibodies}

Anti-CD4 (RM4-5), anti-VB4 (KT4), anti-IFNy (XMG1.2) and anti-IL-17 (TC1118H10) were purchased from BD Pharmingen. Anti-T-bet (ebio4B10) and antiRORyt (AFKJS-9) were purchased from eBioscience. Anti-CXCR3 (CXCR3-173), anti-CCR6 (29-2L17), and anti-FASL (MFL3) were purchased from Biolegend. 7amino-actinomycin D (7-AAD) was purchased from EMD Biosciences.

\section{Intracellular staining}

For detection of intracellular IFNy and IL-17 in $\mathrm{CD}^{+}{ }^{\mathrm{T}}$ cells from NOD.scid mice, the cells were stimulated with PMA $(50 \mathrm{ng} / \mathrm{ml})$ and ionomycin $(500 \mathrm{ng} / \mathrm{ml})$ for $2 \mathrm{~h}$ in presence of Brefeldin A $(10 \mu \mathrm{g} / \mathrm{ml})$. For detection of intracellular IFN $\gamma$ and IL-17 in T cells from NOD or NOD.FoxP3 ${ }^{\text {GFP.DTR }}$ mice, total splenic cells were stimulated with p79 mimotope $(0.5 \mu \mathrm{M})$ for $16 \mathrm{~h}$ with addition of Brefeldin A $(10 \mu \mathrm{g} / \mathrm{ml})$ for the last $2 \mathrm{~h}$. For flow cytometry analyses, the cells were then stained for surface markers, fixed in $2 \%$ formaldehyde, permeabilized with $0.2 \%$ saponin and stained for intracellular cytokines.

For nuclear detection of T-bet and RORyt, the cells were stained for surface markers, treated with the Fix/Perm buffer (eBioscience) and then stained with anti-T-bet and anti-ROR $\gamma \mathrm{t}$ according to the manufacturer's instructions.

Flow cytometry analyses were read using a Beckman Coulter CyAn ADP and data were analyzed using Summit V4.3 (Dako). 


\section{Isolation of pancreatic cells}

Pancreatic islets and infiltrating cells were purified as described (Faveeuw et al., 1995). Briefly, the pancreata were digested with collagenase Type IV (Invitrogen) and islets were separated on a ficoll gradient (GE Healthcare). The morphology of purified islets was confirmed by light microscopy, and the infiltrating cells were isolated by mechanical disruption.

\section{Histology}

Pancreata were frozen in OCT compound at $-80^{\circ} \mathrm{C}$. Cryosections of $8 \mu \mathrm{m}$ thickness were cut $200 \mu \mathrm{m}$ apart to prevent double counting of the same islet. At least three non-serial sections per pancreas were stained with hematoxylin and eosin and analyzed by light microscopy. Insulitis scoring was performed according to the following criteria: Intra-insulitis, severe infiltration within the islet; peri-insulitis, infiltration is restricted to the periphery of islets; and no insulitis, absence of cell infiltration.

\section{Quantitative PCR analysis}

The total RNA of pancreatic islets was extracted using the TRI RNA isolation reagent (Sigma). Quantitative PCR was performed using the Power SYBR Green kit and the StepOnePlus instrument (all from Applied Biosystems). The primers are as follows: cc/9, forward, 5'-CGAGGCACGATCCACTACAAAT-3'; reverse, 5'-TCTAGGCAGGTTTGATCTCCGT-3'. cc/10, forward, 5'-CATCAGCACCA 
TGAACCCAAGT-3'; reverse, 5'-TTCCCTATGGCCCTCATTCTCA-3'. ccl11, forward, 5'-AATTTACCCGAGTAACGGCTGC-3'; reverse, 5'ATTATGAGGCGAGC

TTGCTTGG-3'. ccl20, forward, 5'-CTGCTCTTCCTTGCTTTGGCAT-3'; reverse, 5'-CATCGGCCATCTGTCTTGTGA-3'. Actb, forward, 5'TACAATGAGCTGCGTGTGG

C-3'; reverse, 5'-AGCCTGGATGGCTACGTACA-3'. Gene expression was calculated based on ${ }^{\Delta \Delta} \mathrm{CT}$ upon normalization to Actb gene expression.

\section{Statistics}

The $\mathrm{p}$ values were calculated using the two-tailed Student $\mathrm{t}$ test. 


\section{RESULTS}

Environmental IL-12 is essential for Th17 cells to convert into Th1 cells and efficiently induce T1D in NOD.scid mice.

To ensure the purity of the transferred Th1 or Th17 cells, we selectively enriched and sorted the $\mathrm{IFNy}{ }^{+} \mathrm{IL}-17^{-}$or the $\mathrm{IL}-17^{+} \mathrm{IFNy}{ }^{-}$fraction from Th1 or Th17 polarizing cultures, respectively. The purities obtained were routinely higher than 98\% (Fig. 1).

Th1

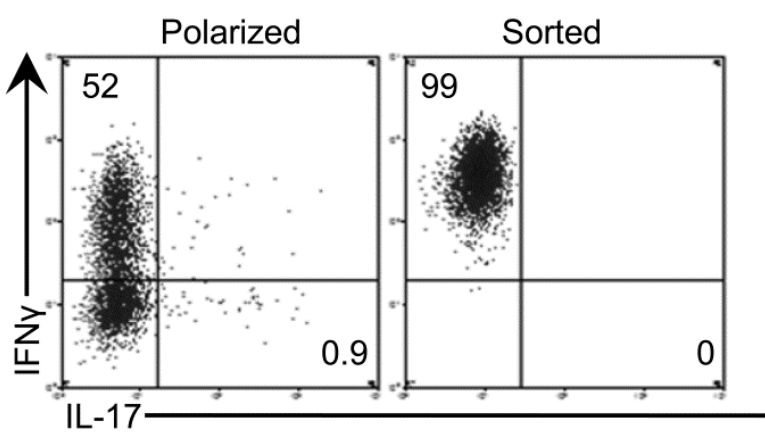

Th17

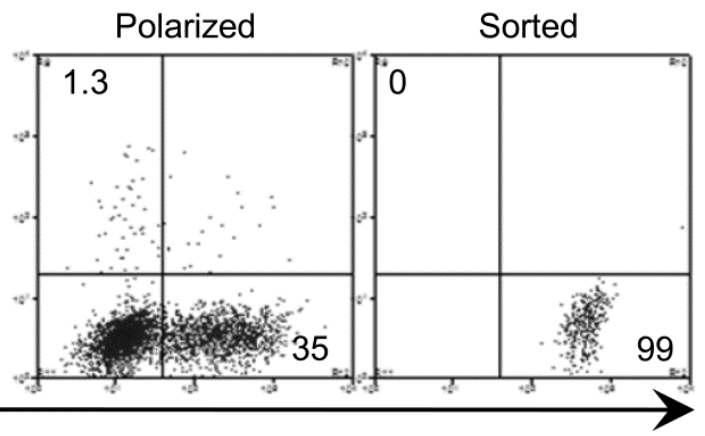

Figure 1. Sorted Th1 and Th17 cells display high degree of purity. Splenic cells from NOD.BDC2.5.FoxP3 ${ }^{\text {GFP.DTR }}$ mice were cultured under Th1 and Th17 polarizing conditions and the $\mathrm{CD} 4^{+} \mathrm{T}$ cells were isolated by negative selection. The purified T cells were then stimulated with PMA/ionomycin for $2 \mathrm{~h}$, and IFNY(Th1) and IL-17- (Th17) producing T cells were labeled using the Mouse IFN $\gamma$ and IL-17 detection kit. The culture was depleted of GFP ${ }^{+}$(Tregs) cells and the Th1 and Th17 cells were sorted using the MoFlo XDP sorter. The panels show polarized Th1 and Th17 cells before and after sorting. 
These highly purified Th1 or Th17 cells were then transferred into NOD.scid recipients, and the mice that received Th17 cells developed diabetes on day 8 or 9 post transfer, while transfer of Th1 cells induced diabetes on day 4 or 5 (Fig. 2A). Despite the thorough depletion of $\mathrm{IFNy}^{+}$contaminants from Th17 cells before transfer (Fig. 1, right panels), a sizable portion of IFNy-producing cells (7.1\%) was readily detectable in pancreatic lymph nodes (PLN) on day 3 post transfer, whereas $23 \%$ of the transferred Th17 cells still maintained the IL-17 production (Fig. 2B, left panel). However, the IFNy-producing cells outnumbered the IL-17-producers by day 7 post transfer (Fig. 2B, right panel), suggesting that Th17 cells have actively converted into a Th1 profile before disease induction. Furthermore, in vivo neutralization of IFNy completely abrogated Th17-initiated diabetes induction, whereas mice treated with anti-IL-17 still developed normal disease (Fig. 2C), suggesting that conversion into Th1 cells is necessary for Th17 cells to acquire the full competence to effectively induce diabetes.

We next attempted to examine the key factor responsible for the in vivo Th17 to Th1 conversion. Previous studies have demonstrated that Th17 cells express the IL-12 receptor and in vitro exposure to IL-12 substantially upregulated IFNy and T-bet expression in Th17 cells (Bending et al., 2009; Lee et al., 2009). Therefore, we utilized the IL-12(p35) ${ }^{-1-}$.NOD.scid mice as hosts, and analyzed whether the absence of environmental IL-12 would affect the Th17 to Th1 conversion in vivo. Indeed, kinetic cytokine analyses revealed a consistent lower frequency of IFNYproducing but a higher frequency of IL-17-producing cells in spleen and pancreas in IL-12(p35) $)^{-/-}$mice as compared to the IL-12(p35) ${ }^{+/+}$counterparts (Fig. 2D). The 
ratio of IFNY- to IL-17-producing cells in spleen and pancreas was significantly higher in IL-12(p35) ${ }^{+/+}$mice relative to the IL-12(p35) $)^{-/-}$mice on day 4,8 and 14 post transfer (Fig. 2E). Furthermore, only $20 \%$ of the IL-12(p35) ${ }^{-1-}$.NOD.scid mice developed diabetes following Th17 transfer, whereas all the IL-12(p35) ${ }^{+/+}$ littermates developed robust disease (Fig. 2F, left panel). On the other hand, transfer of Th1 cells induced a similar kinetics of disease development in both IL12(p35) $)^{-/-}$and IL-12(p35) ${ }^{+/+}$recipients (Fig. 2F, right panel). Collectively, these results demonstrate that IL-12 in the lymphopenic environment is essential for Th17 cells to convert into Th1 cells and induce potent diabetes. 
A

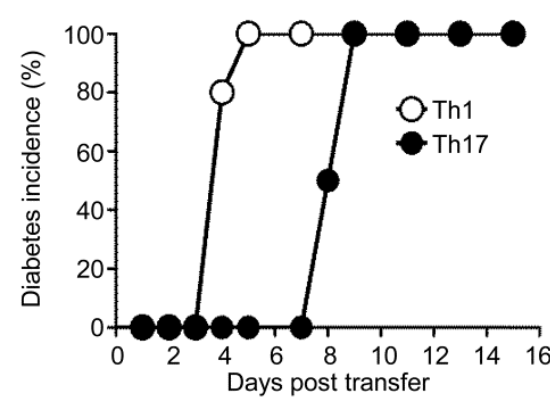

C

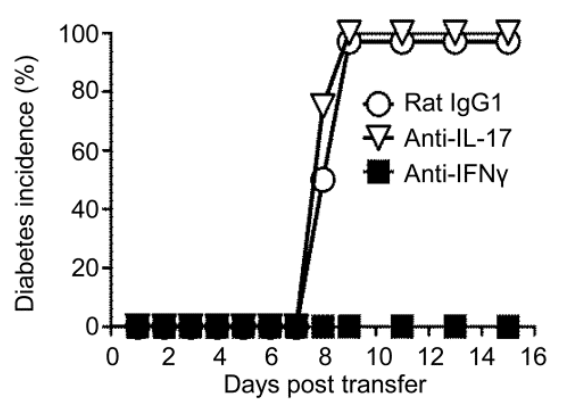

E

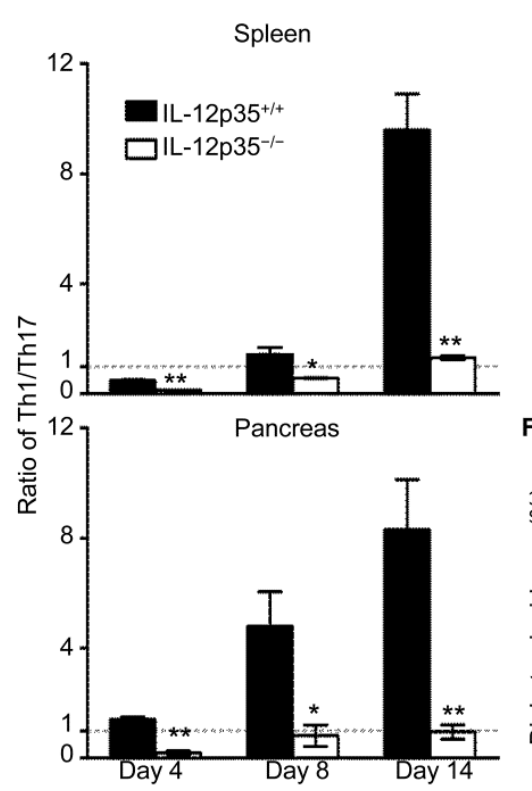

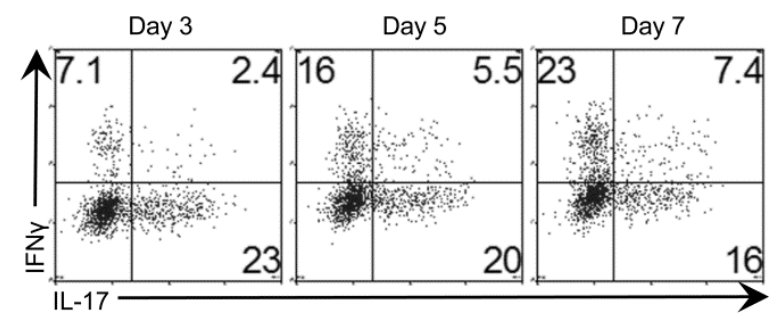

D

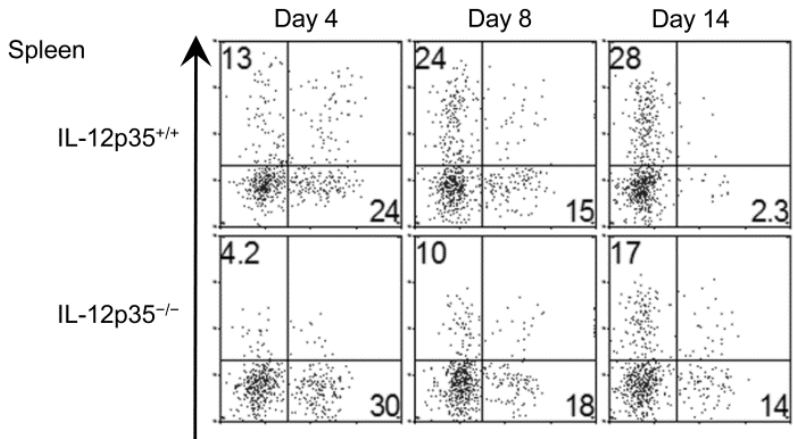

Pancreas

IL-12p35 $1 /+$

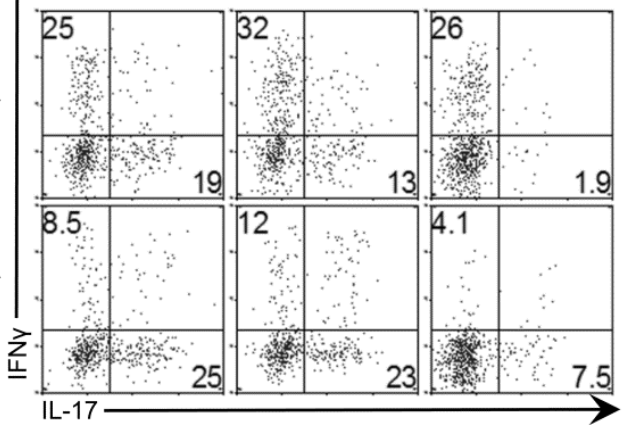

IL-12p35-/

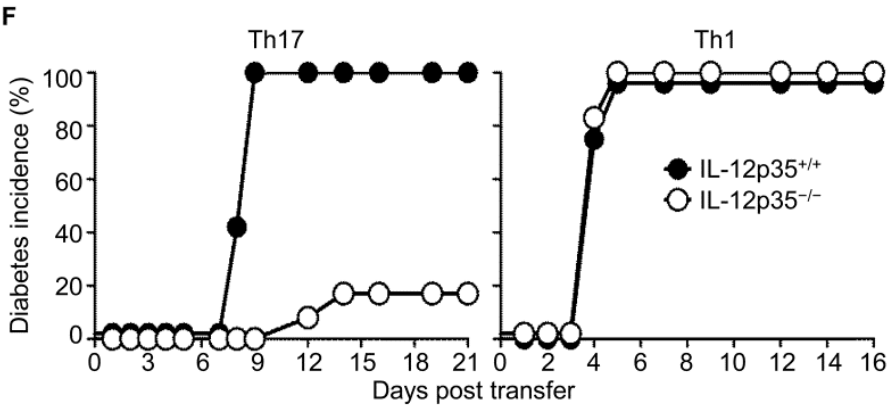

Figure 2: Th17 cells undergo cell conversion to sustain development of T1D in NOD.scid mice. (A) BDC2.5 T cells were polarized into Th1 or Th17 cells, transferred into NOD.scid mice and the hosts ( $n=15$ and 16 per group, respectively) were monitored for incidence of diabetes. (B) Kinetics of Th17 to Th1 conversion as measured by intracellular staining of IFNy and IL-17 in PLN 
$\mathrm{CD}^{+} \mathrm{V} \beta 4^{+} \mathrm{T}$ cells on day 3,5 and 7 following cell transfer. Numbers indicate the percentage of cells in each quadrant. (C) Neutralization of cytokines in vivo by treatment of Th17-recipient NOD.scid mice with anti-IL-17 $(n=8)$, anti-IFNY $(n=$ 6), or Rat IgG1 isotype control $(n=8)$. (D-F) Polarized BDC2.5 Th17 or Th1 cells were transferred into IL-12(p35) $)^{-/-}$or IL-12(p35) ${ }^{+/+}$NOD.scid mice and the hosts were monitored for blood glucose levels. (D) shows kinetics of cell conversion measured by intracellular cytokine staining of splenic and pancreatic $C D 4^{+} \vee \beta 4^{+}$ T cells on day 4,8 , and 14 following cell transfer. Numbers indicate the percentage of cells in each quadrant. (E) shows the ratio of Th1 to Th17 (\% IFNy-producing cells over \% IL-17-producing cells) compiled from 3 independent experiments. Each bar represents mean \pm SEM of 6 mice. (F) shows incidence of diabetes $(n=12) .{ }^{* \star} P<0.01,{ }^{*} P<0.05$. The experiments were performed twice (C) or three times (A, B, D, F) with consistent results.

\section{Tolerance of the converted Th1 cells accounts for suppression of T1D induced by Th17 cell transfer.}

To explore the mechanisms underlying the tolerance of Th17 cells in the converting environment, we started by injecting tolerogens to NOD.scid mice along with Th17 transfer. To magnify tolerance, the 1140-79 mimotope (p79), which displayed a high affinity to BDC2.5 T cells (Judkowski et al., 2001), was genetically incorporated into an Ig molecule. The resulting Ig-p79 was used to test against T1D. Similarly, the nondiabetogenic $1-A^{g 7}$-restricted hen egg lysozyme (HEL) 11-25 sequence was also incorporated into an $\mathrm{lg}$, and the 
resulting Ig-HEL was used as a control treatment. As shown in Fig. 3A, 100\% of the mice treated by Ig-p79 were protected against T1D following Th17 transfer, whereas mice treated by Ig-HEL and soluble p79 developed a rapid onset of T1D. Therefore, the protection mediated by Ig-p79 could be due to disturbed Th17 to Th1 conversion and/or inactivation of the converted Th1 cells. Indeed, IFNy-producing cells can be detected in the spleen and pancreas on both day 4 and 8 following Ig-p79 treatment, indicating a sustained level of Th17 to Th1 conversion in Ig-p79-treated mice (Fig. 3B). Thus, it is unlikely that Ig-p79 suppressed the disease through inhibition of the conversion.

Because the disease is likely driven by the converted Th1 cells (Fig. 2C), we sought to determine the presence of these cells in the site of inflammation (pancreas) to correlate tolerance with the suppression of the disease. Indeed, the IFNy ${ }^{+} \mathrm{IL}-17^{-}$(converted Th1) cells displayed a strikingly lower frequency (Fig. 3B, right panel) and absolute number (Fig. 3C, right panel) in the pancreas on both day 4 and 8 during treatment with Ig-p79 relative to Ig-HEL. In contrast, these cells accumulated more efficiently in the spleen by both criteria in mice given Igp79 relative to Ig-HEL (Fig. 3B and C, left panels). These results indicate that the converted Th1 cells may have impaired abilities to migrate into pancreas and are therefore retained in the spleen. It should be noted that the number of the IFNy ${ }^{-}$IL-17 $7^{+}$(unconverted Th17) cells remained minimal in the pancreas on both day 4 and 8 (Fig. 3C, right panel), indicating an inability of these cells to migrate into pancreas. Furthermore, the number of the unconverted Th17 cells was consistently comparable between Ig-p79 and Ig-HEL groups (Fig. 3C), 
suggesting that tolerance induction did not involve these cells. Overall, these results suggest that although disease development occurs through conversion from Th17 to Th1 cells, its suppression is mediated by interference with trafficking of the converted Th1 cells.

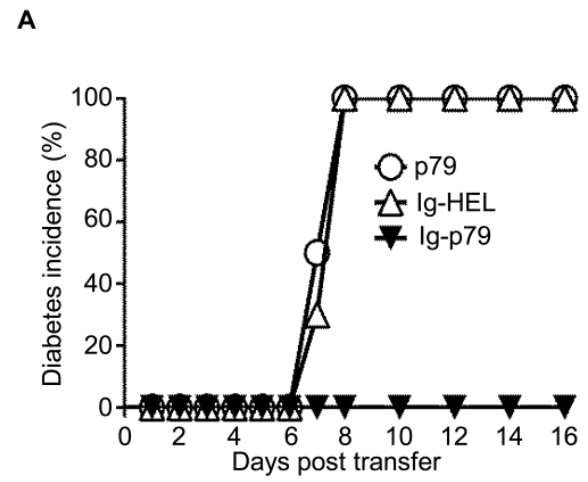

B
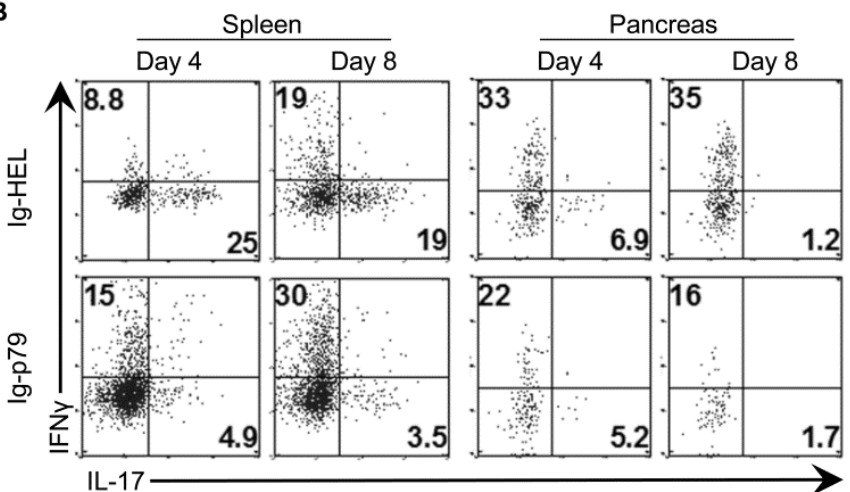

C

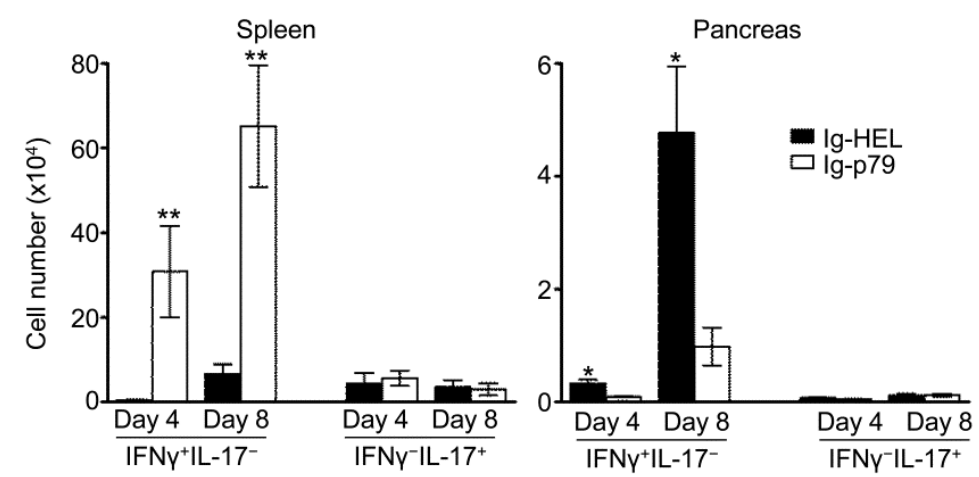

Figure 3. Treatment with Ig-p79 retained the Th17-derived Th1 cells in the spleen and impaired their trafficking into pancreas. (A) NOD.scid mice recipient of Th17 polarized BDC2.5 cells were treated with p79 peptide $(n=8)$, Ig-p79 ( $n=14)$, or the control Ig-HEL $(n=16)$ and then monitored for blood glucose levels for a period of 16 days. (B-C) $\mathrm{CD}^{+} \mathrm{T}$ cells were isolated from the spleen and pancreatic islets of Ig-HEL and Ig-p79-treated mice ( $n=6$ per group) on day 4 and 8 post Th17 cell transfer, stimulated in vitro with PMA/ionomycin for 
$2 \mathrm{~h}$ in the presence of Brefeldin A, and intracellular IFNy and IL-17 were measured in $C D 4^{+} \vee B 4^{+} T$ cells. (B) shows a representative dot plot cytokine measurement with the numbers in each quadrant indicating the percentage of cytokine positive cells. (C) shows the absolute number of IFNy ${ }^{+} \mathrm{IL}-17^{-}$or IFNy ${ }^{-} \mathrm{IL}-$ $17^{+}$cells in spleen (left panel) and pancreas (right panel). Each bar represents mean \pm SEM of 12 mice from 4 experiments. ${ }^{*} P<0.01 * P<0.05$.

Treatment with Ig-p79 interferes with CXCR3 expression on converted Th1 cells.

To test the hypothesis that Ig-p79 may dampen the trafficking ability of the converted Th1 cells and cause ineffective infiltration of these cells into pancreas, we attempted to investigate whether Ig-p79 affected the expression of chemokine receptors on the converted Th1 cells. In line with previous findings (Singh et al., 2008; Syrbe et al., 1999), polarized Th17 BDC2.5 cells expressed high levels of CCR6 (87\%), the signature Th17-associated chemokine receptor, and low levels of CXCR3 (26\%), which is usually highly expressed on Th1 cells (65\%) (Fig. 4A). Interestingly, the $\mathrm{CXCR}^{\mathrm{lo}} \mathrm{CCR} 6^{\text {hi }}$ Th17 cells upregulated CXCR3 (82\%) and downregulated CCR6 (12\%) expression upon converting into IFNY ${ }^{+} \mathrm{IL}-17^{-}$Th1 cells in Ig-HEL treated mice, whereas cells that were IFNY-IL-17 ${ }^{+}$still maintained high CCR6 (89\%) and low CXCR3 (33\%) expression (Fig. 4B, upper panels). Thus, the Th17 to Th1 conversion is accompanied by the acquisition of the CXCR3 expression on the converted Th1 cells, which could be important for directing these cells into pancreas and induce $\beta$ cell damage. On the other hand, 
when treated by Ig-p79, only $42 \%$ of the converted Th1 cells expressed CXCR3 (Fig. 4B, lower panels), indicating that the majority of these cells would be limited for migration into the site of inflammation. In addition, quantification of CXCR3 MFI demonstrated that Ig-p79 treatment significantly downregulated CXCR3 expression on converted Th1 cells in spleen and PLN (Fig. 4C). These results indicate that the CXCR3 interference took place in spleen and PLN when the transferred cells encounter Ig-p79, resulting in limited pancreatic infiltration of these cells. We also examined another Th1-associated chemokine receptor CCR5, which consistently remained at the background level on the converted Th1 cells regardless of treatment with Ig-p79 or Ig-HEL (data not shown). Furthermore, only $43 \%$ of the converted Th1 cells treated by Ig-p79 expressed Tbet as compared to $85 \%$ of the cells treated by Ig-HEL (Fig. 4D). Given that CXCR3 transcription is controlled by binding of t-bet to the CXCR3 promoter region, (Beima et al., 2006; Koch et al., 2009), it is likely that Ig-p79 interfered with CXCR3 expression through inhibition of the upstream T-bet expression. Considering the migration of CXCR3-bearing $\mathrm{T}$ cells to the site of inflammation is directed by the chemotaxis towards the CXCR3 chemokine ligands, including CCL9, CCL10 and CCL11, we next examined if Ig-p79 would affect CXCR3 ligands expression in the pancreatic islets. We first confirmed the enhanced CXCR3 ligands expression in pancreatic islets induced by Th17 cell transfer, which could be essential for recruiting CXCR3-expressing T cells. Specifically, a 35-50-fold upregulation of CCL9 and CCL10 gene expression was detected on day 8 by Th17 transfer as compared to the no transfer group (Fig. 4E). The high 
level of $c c / 9$ and $c c / 10$ expression was also maintained in the pancreas of mice given either Ig-HEL or Ig-p79 (Fig. 4E). Thus, pronounced expression of CXCR3 ligands was established in the pancreatic islets of the lg-p79-treated mice, suggesting that downregulation of CXCR3 rather than insufficient stimuli is the major contributor to the impaired trafficking of the converted Th1 cells. Notably, the CCR6 ligand CCL20, which displayed robust chemotaxis for $\mathrm{CCR}^{+} \mathrm{Th} 17$ cells (Reboldi et al., 2009), remained at a basal level in all the experimental groups (Fig. 4E). Thus, despite the fact that the unconverted Th17 cells highly expressed CCR6 (Fig. 4B), the lack of CCL20 may account for the rare presence of these cells in pancreas (Fig. 3C). 
A

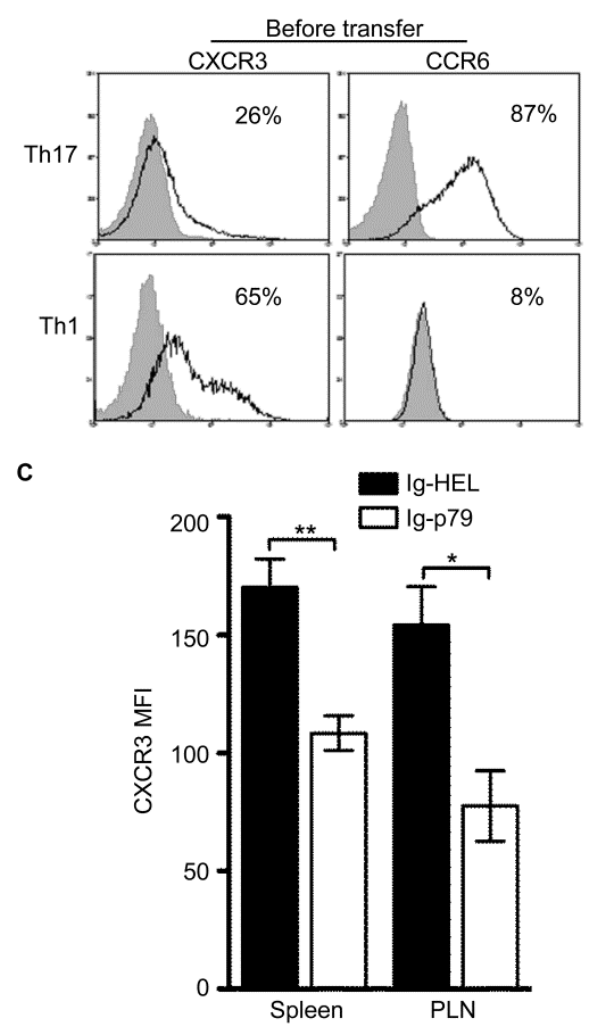

D

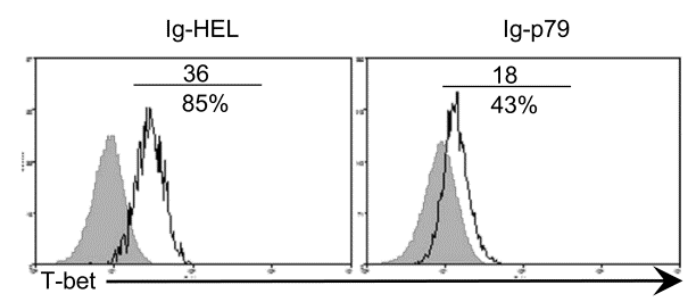

B

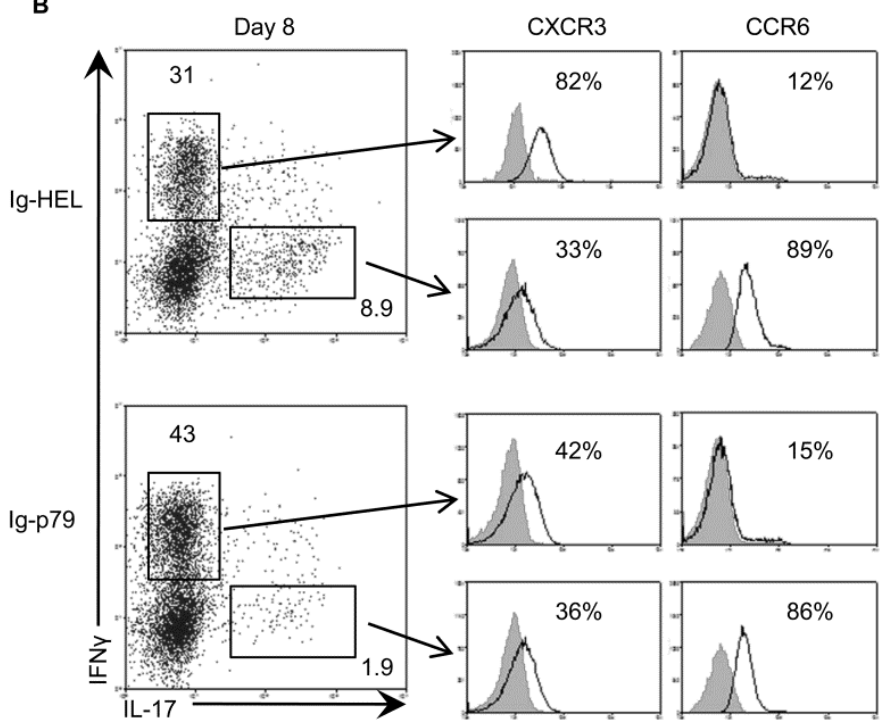

E

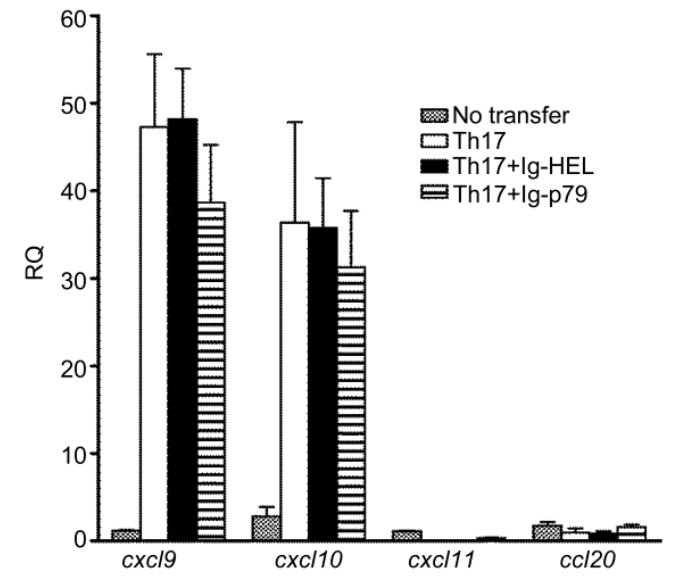

Figure 4: Treatment with Ig-p79 interferes with CXCR3 expression on converted Th1 cells. (A) shows expression of CXCR3 and CCR6 on polarized Th1 and Th17 cells. The results are representative of 4 independent experiments. (B-C) NOD.scid mice were transferred with Th17 polarized BDC2.5 cells and treated with Ig-HEL or Ig-p79 (3-6 mice per group). The mice were sacrificed on day 8 after treatment and their splenic and PLN CD4 ${ }^{+} \mathrm{T}$ cells were isolated. The $\mathrm{T}$ cells were then stimulated with PMA/ionomycin for $2 \mathrm{~h}$ in the 
presence of Brefeldin A and stained for surface CXCR3 and CCR6 and for intracellular IFNy and IL-17. (B) shows a representative experiment of splenic $\mathrm{CD} 4^{+} \mathrm{V} \beta 4^{+} \mathrm{IFNY}{ }^{+} \mathrm{IL}-17^{-}$(converted Th1) and IFNY'IL-17 ${ }^{+}$(unconverted Th17) cells (left panels) and expression of CXCR3 and CCR6 by each population (right panels). (C) shows MFI of CXCR3 expression on splenic and PLN $\mathrm{CD}^{+} \mathrm{V} \beta 4^{+} \mathrm{IFNy}{ }^{+} \mathrm{IL}-17^{-}$cells on day 8 after treatment with Ig-p79 or Ig-HEL. Each bar represents the mean \pm SEM of 10 mice from 3 independent experiments. (D) shows $\mathrm{T}$-bet expression by splenic $\mathrm{CD} 4^{+} \mathrm{V} \beta 4^{+} \mathrm{IFNY}{ }^{+} \mathrm{IL}-17^{-}$cells on day 8 after Igp79 or Ig-HEL treatment. The results are representative of 3 independent experiments. (E) Quantitative PCR analysis of $c x c / 9, c x c / 10, c x c / 11$ and $c x c / 20$ chemokine expression in pancreatic islets on day 8 following lg-p79 or lg-HEL treatment. Each bar represents the mean \pm SEM of 7 mice from 2 independent experiments. The numbers in histograms $(A, B, D)$ represent the percentage of cells that are positive for expression for the indicated markers. ${ }^{*} \mathrm{P}<0.01$. ${ }^{*} \mathrm{P}<$ 0.05 .

In parallel, we analyzed in vivo proliferation and survival of the converted Th1 cells, which could also contribute to the rare presence of these cells in pancreas of the Ig-p79-treated mice. However, the purified IFNy ${ }^{+} \mathrm{IL}_{-1}-17^{-}$cells from Ig-HEL or Ig-p79-treated mice displayed similar levels of CFSE dilution and 7-AAD incorporation (Fig. 5), suggesting that Ig-p79 treatment did not affect the proliferation and apoptosis rate of the converted Th1 cells in vivo. Therefore, these results further confirm that the minimal presence of converted Th1 cells in 
the pancreas of the Ig-p79-treated mice is mainly due to their impaired trafficking abilities.

A

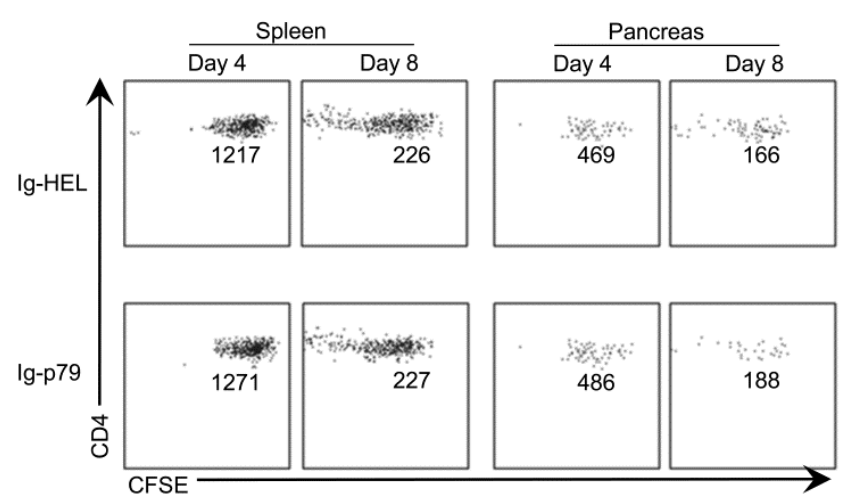

B

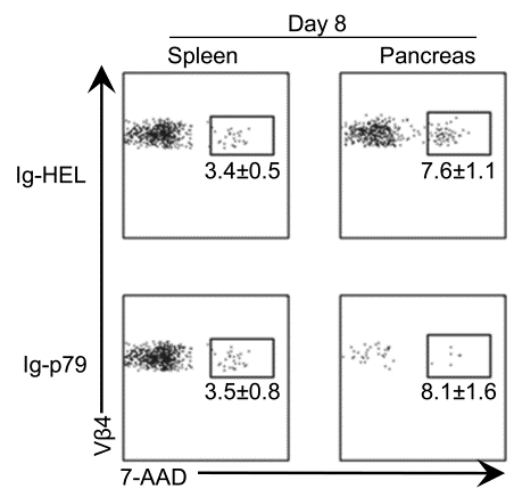

Figure 5. Converted Th1 cells display equivalent proliferative and survival attributes in the spleen and pancreas of Ig-p79-versus Ig-HEL- treated NOD.scid mice. NOD.scid mice were transferred with CFSE-labeled Th17 cells, and the hosts were treated with Ig-p79 or the control Ig-HEL. The converted Th1 cells were then sorted from the spleens and pancreata and analyzed for CFSE dilution (A) and incorporation of 7-AAD (B) as a measure of proliferation and survival, respectively. The numbers represent MFI $(A)$ and mean \pm SEM percent of $7-\mathrm{AAD}^{+}$cells $(\mathrm{B})$. The results are representative of 3 independent experiments.

Downregulation of CXCR3 expression on regular Th1 cells after treatment with Ig-p79.

Next we asked if the tolerance of converted Th1 cells can also be applied to polarized genuine Th1 cells. To this end, polarized Th1 cells were transferred into NOD.scid mice, and disease development in the recipients was monitored 
during treatment with Ig-p79 or Ig-HEL. As shown in Fig. 6A, the Th1-mediated diabetes was prevented by Ig-p79, but not Ig-HEL or p79 peptide. Compared with the Ig-HEL-treated controls, IFNy ${ }^{+}$cells were present at a lower frequency in pancreas when treated with Ig-p79, while these cells had a higher frequency in the spleen (Fig. 6B). Correspondingly, the absolute cell number of the IFNy ${ }^{+} C D 4^{+} V \beta 4^{+}$cells in pancreas was significantly lower in Ig-p79-treated mice on day 5 as compared to the Ig-HEL-treated controls (Fig. 6C, right panel). However, these cells were present at a significantly higher number in the spleen (Fig. 6C, right panel). Thus, it is likely that Ig-p79 impaired the trafficking ability of the transferred Th1 cells and limited their migration to the pancreas. Indeed, the splenic Th1 cells from Ig-p79-treated mice had a significantly lower level of CXCR3 and T-bet expression than the Ig-HEL-treated controls (Fig. 6D and E). Furthermore, all the three CXCR3 chemokine ligands (CCL9, CCL10 and CCL11) were highly upregualted (10 to 75 folds) in the pancreatic islets after transfer of Th1 cells, and this upregulation was maintained during treatment with either Ig-p79 or Ig-HEL (Fig. 6F). These results suggest that the diminished CXCR3 expression on the Ig-p79-tolerized Th1 cells resulted in abrogated trafficking and pancreatic infiltration. Thus, both the converted and regular Th1 cells use a similar mechanism upon tolerance. 

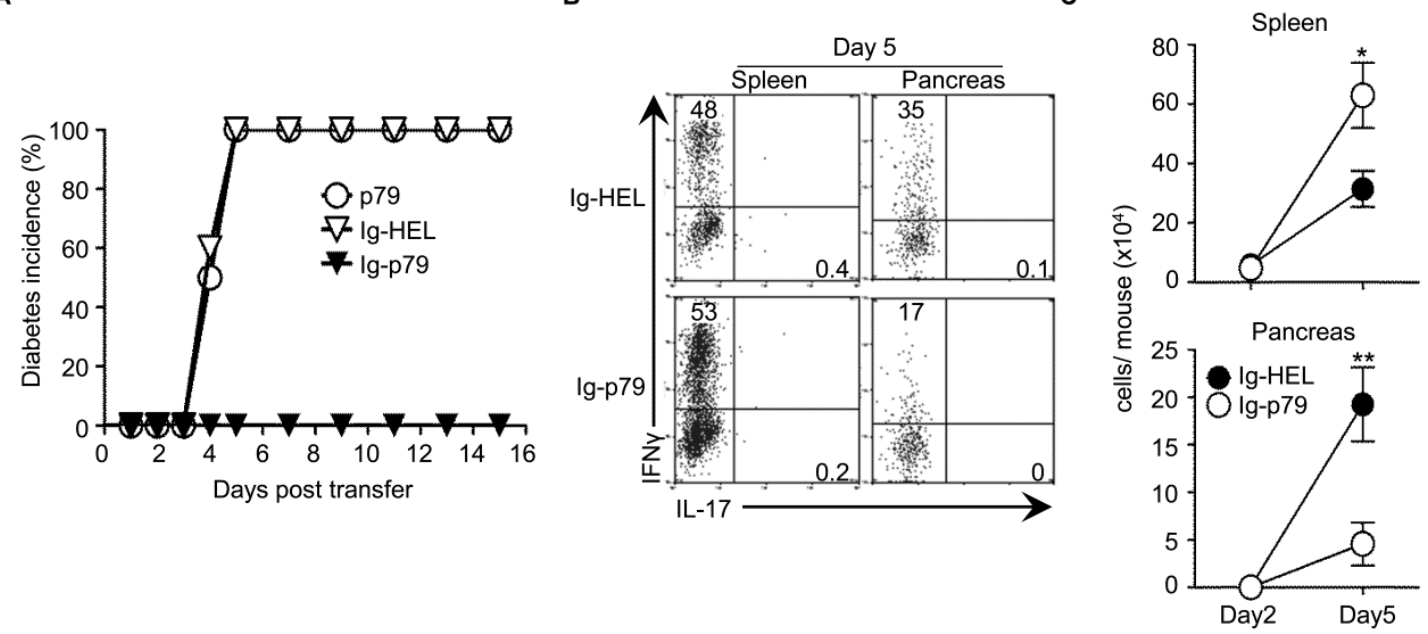

D

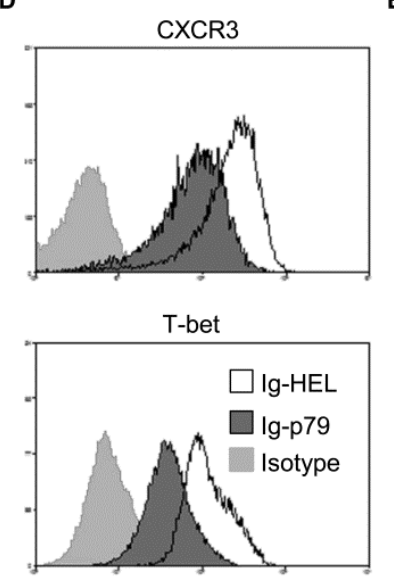

E

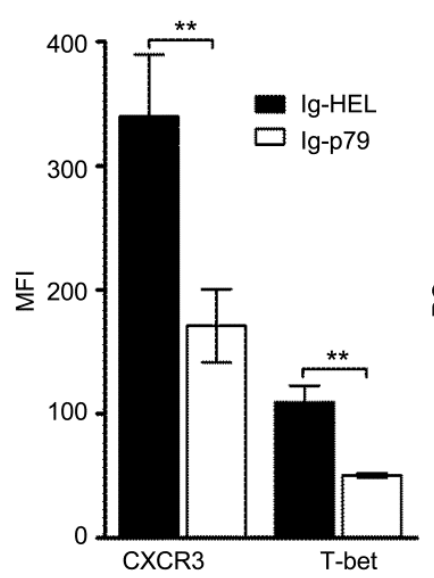

$\mathbf{F}$

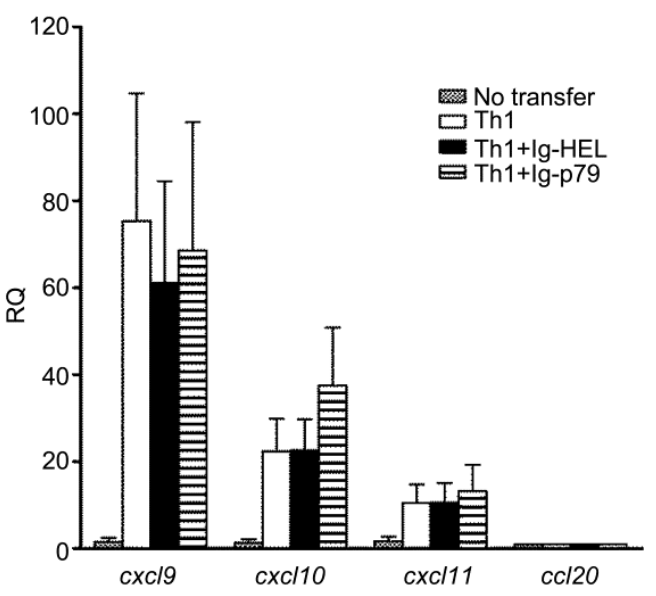

Figure 6. Polarized, like converted Th1 cells, down-regulate CXCR3 upon treatment of the NOD.scid host with Ig-p79. (A) Polarized Th1 cells were transferred into NOD.scid mice and the hosts were treated with p79 peptide ( $\mathrm{n}=$ 8), Ig-HEL ( $n=12)$, or Ig-p79 $(n=16)$ and monitored for blood glucose levels. The graph shows diabetes incidence during a 16-day monitoring period. (B) shows intracellular IFN $\gamma$ and IL-17 production by splenic and pancreatic $\mathrm{CD}^{+} \mathrm{V} \beta 4^{+} \mathrm{T}$ cells harvested on day 5 after Th1 transfer. The results are representative of 3 independent experiments. The numbers indicate the percentage of cells in each quadrant. (C) shows the absolute number of 
IFN $\gamma^{+} \mathrm{CD} 4^{+} \mathrm{V} \beta 4^{+} \mathrm{T}$ cells in the spleen and pancreas on day 2 and 5 after Th1 transfer. Each point represents the mean \pm SEM of 10 mice from 3 independent experiments. (D) shows CXCR3 and T-bet expression on splenic IFN $\gamma^{+} \mathrm{CD} 4^{+} \mathrm{V} \beta 4^{+}$ T cells on day 5 after Th1 transfer. The results are representative of 4 independent experiments. (E) shows MFI of CXCR3 and T-bet on Th1 cells described in (D). Each bar represents the mean \pm SEM of 12 mice. (F) Quantitative PCR analysis of $c x c / 9, c x c / 10, c x c / 11$ and $c x c / 20$ chemokine expression in pancreatic islets on day 5 after Th1 transfer. Each bar represents mean \pm SEM of 6 mice from 2 independent experiments. ${ }^{*} \mathrm{P}<0.01 .{ }^{*} \mathrm{P}<0.05$.

\section{Overexpression of CXCR3 on Th17 cells nullifies tolerance.}

Tolerance of converted and polarized Th1 cells likely operates at the level of chemokine receptor expression and its consequent effect on trafficking. In fact, when CXCR3 was over-expressed in the polarized Th17 cells, Ig-p79 was no longer able to suppress the disease despite conversion of the cells into Th1 cells (Fig. 7). Indeed, when polarized Thy1.2 BDC2.5 Th17 cells were infected with the mouse stem cell virus (MSCV) carrying CXCR3-IRES-Thy1.1 (Hu et al., 2011), 93\% of the cells that were transduced (expressing Thy1.1) had CXCR3 expression (Fig. 7A). Furthermore, when the CXCR3-transduced Th17 cells were transferred into NOD.scid mice, the hosts developed a slightly faster onset of diabetes relative to the control mice recipient of empty vector-transduced cells (Fig. 7B). The cells did convert into Th1 cells whether transduced with CXCR3 or empty vector as $31 \%$ and $28 \%$ of the cells produced IFN $\gamma$, respectively (Fig. $7 \mathrm{C}$ ). 
Interestingly, while the mice recipient of Th17 cells transduced with empty vector did not develop T1D when treated with Ig-p79, those recipient of CXCR3transduced Th17 cells did (Fig. 7D). Treatment with Ig-HEL did not protect against the disease whether the cells were transduced with CXCR3 or empty vector. These observations indicate that over-expression of CXCR3 nullifies Igp79-induced tolerance. Overall, down-regulation of CXCR3 is essential for tolerance of Th1 cells and suppression of T1D.

A

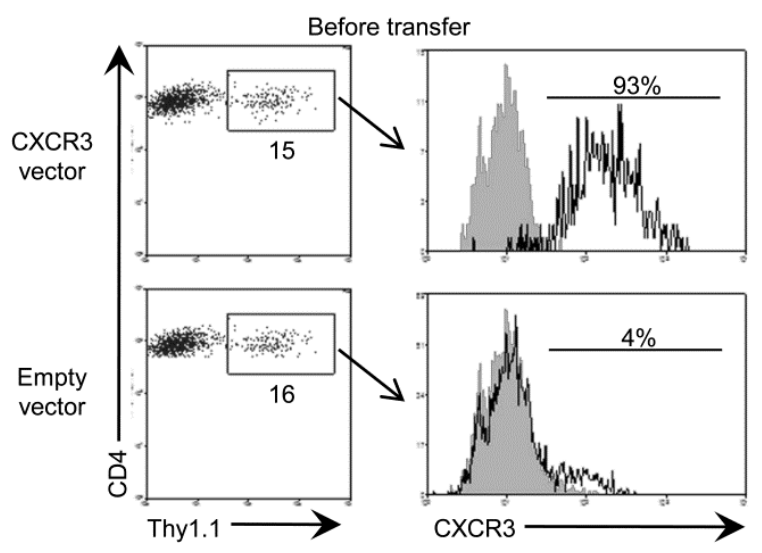

B

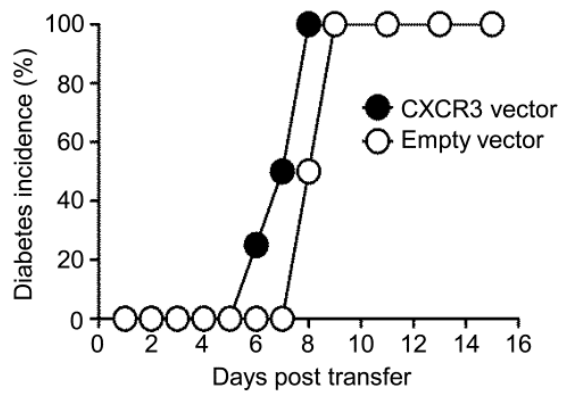

C

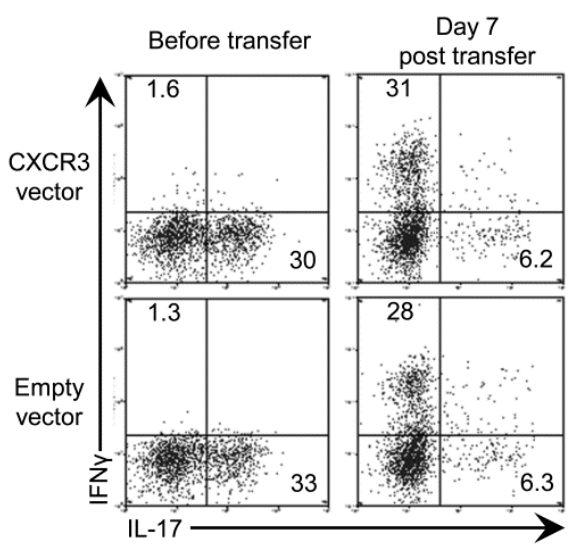

D

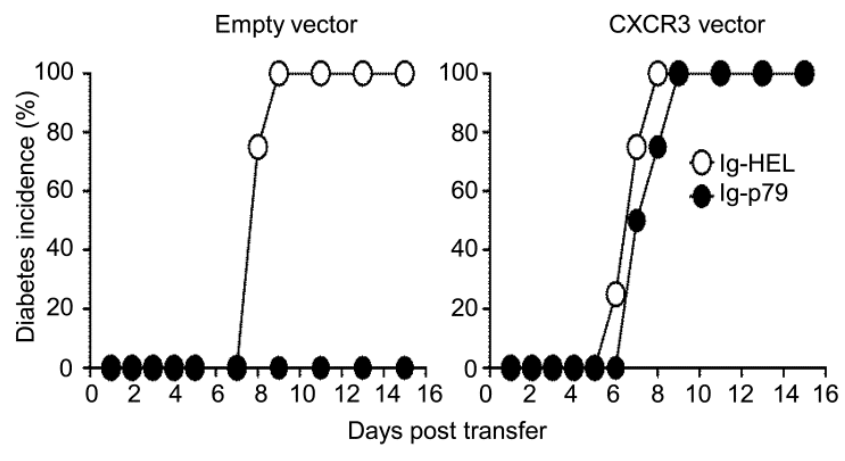


Figure 7. Over-expression of CXCR3 in plastic Th17 cells confers resistance to converted Th1 cells against Ig-p79-induced tolerance. (A-C) Polarized Th17 BDC2.5 T cells (Thy 1.2) were transduced ex vivo with MSCVCXCR3-IRES-Thy1.1 or empty MSCV-IRES-Thy1.1 vector and transferred into NOD.scid mice. The hosts were then monitored for blood glucose levels and the transferred Th17 cells were analyzed for Th17 to Th1 conversion. (A) shows the expression of Thy1.1 by $\mathrm{CD} 4^{+} \mathrm{V} \beta 4^{+}$polarized Th17 cells (left panels). The right panels show the expression of CXCR3 by Thy $1.1^{+} \mathrm{CD} 4^{+} \mathrm{V} \beta 4^{+}$polarized Th17 cells. (B) shows diabetes incidence of mice recipient of Th17 cells described in (A) ( $\mathrm{n}=4$ per group). (C) shows production of IFNY and IL-17 by CXCR3transduced $C D 4^{+} \vee \beta 4^{+}$Thy $1.1^{+}$cells before and 7 days after transfer. The results in (A-C) are representative of 3 independent experiments. (D) NOD.scid mice recipient of CXCR3- or empty vector-transduced Th17 cells were treated with IgHEL or Ig-p79 ( $n=4$ per group) and monitored for diabetes. Data depicts diabetes incidence. The experiment was performed twice with consistent results.

Th17 cells are unable to undergo Th1 conversion upon transfer into NOD mice and require depletion of Tregs to transfer diabetes to the host.

The fact that Th17 cells need to convert into Th1 cells to induce T1D in the lymphopenic environment puts into question that whether Th17 cells can be pathogenic in a non-converting environment. Because Th17 cells maintained their stability in normal but not lymphopenic B6 mice (Nurieva et al., 2009), we first tested the stability of BDC2.5 Th17 cells in normal NOD recipients. To 
distinguish from the endogenous $\mathrm{CD} 4^{+} \mathrm{V} \beta 4^{+} \mathrm{T}$ cells, Th17 cells were labeled with CFSE and transferred into 4-wk female NOD mice. The choice of CFSE labeling is based on the observation that Th17 cells did not undergo significant proliferation in NOD mice over a kinetic 7-day monitoring period (data not shown), therefore the CFSE labeling was maintained stable to mark the distinct population of the transferred Th17 cells (Fig. 8A). As expected, the transferred Th17 cells (CD4 ${ }^{+} \vee \beta 4^{+} \mathrm{CFSE}^{+}$) mainly produced IL-17 (Fig. 8A), indicating that in vitro generated BDC2.5 Th17 cells stayed stable in normal NOD hosts. We next examined the islet inflammation by histology, and found that Th17 transfer induced remarkable lymphocyte infiltration in the islets (Fig. 8B). However, the stable Th17 cells did not induce hyperglycemia during a 21-day monitoring period, while transfer of Th1 cells rapidly induced elevated blood glucose levels in the host NOD mice (Fig. 8C), suggesting an inability of Th17 cells to induce clinical diabetes in a normal environment.

Because regulatory $T$ cells (Tregs) have been shown to be able to suppress Th17 cells (Chaudhry et al., 2009; Chaudhry et al., 2011; Huber et al., 2011), we wondered if depletion of Tregs in the NOD hosts would accelerate the transition of insulitis to clinical diabetes following Th17 cell transfer. To test this premise, we utilized NOD.FoxP3 ${ }^{\text {GFP.DTR }}$ mice as hosts, and injected diphtheria toxin (DT) before and after Th17 transfer to conditionally deplete FoxP3 ${ }^{+}$Tregs. As shown in Fig. 8D, induction of clinical diabetes was not observed in mice given DT or Th17 cells alone, whereas as high as $75 \%$ of the mice recipient of both Th17 cells and DT injections developed clinical diabetes (peaked at day 11 post 
transfer). Thus, stable Th17 cells trigger pancreatic inflammation without clinical diabetes in the NOD mouse but depletion of Tregs sustains transition to overt diabetes.

A

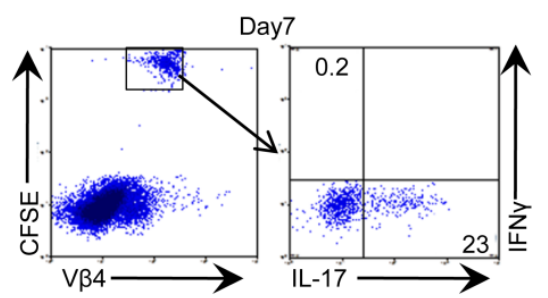

C

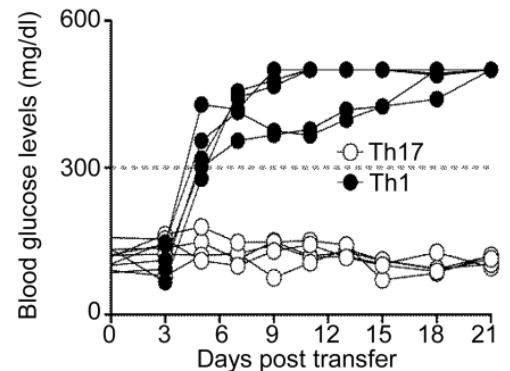

D

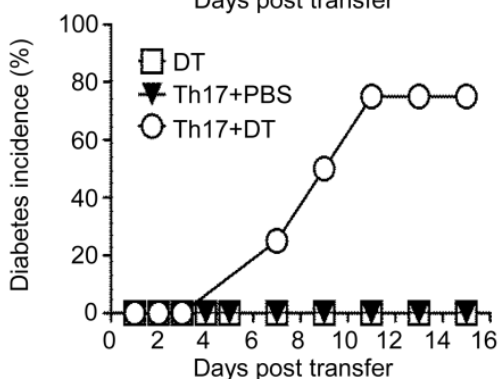

$\mathbf{F}$

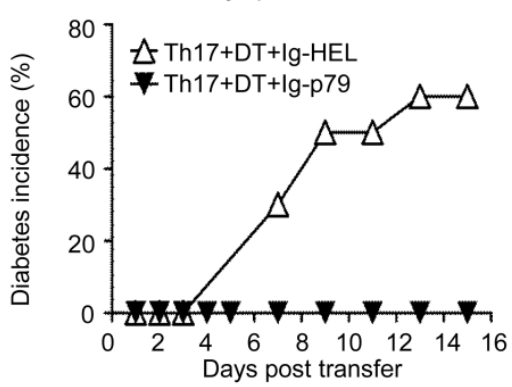

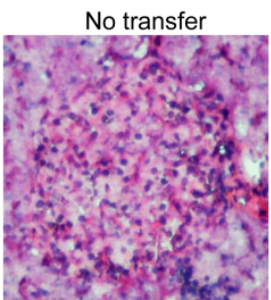

Th1 transfer

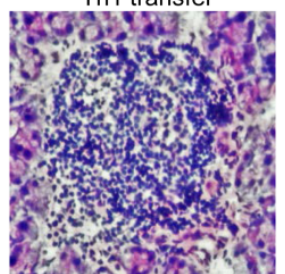

Th17 transfer

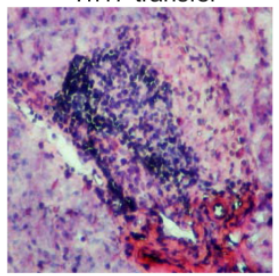

E

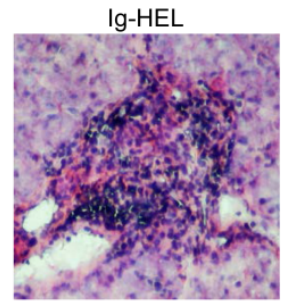

lg-p79
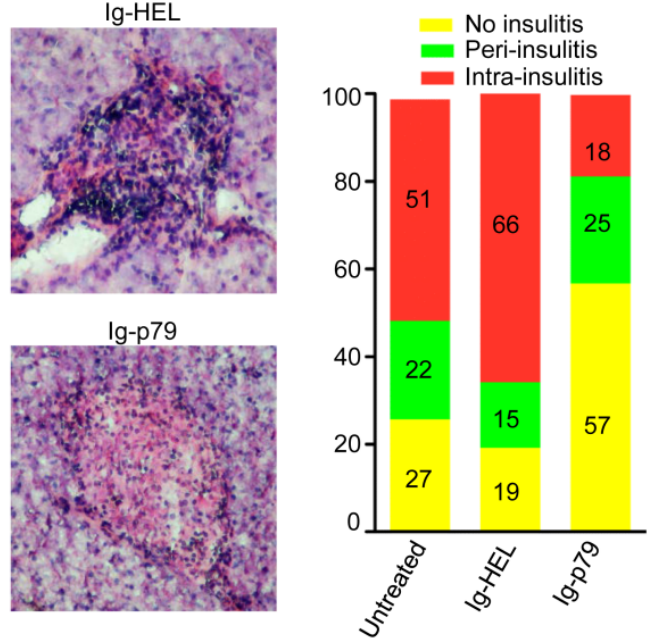

G

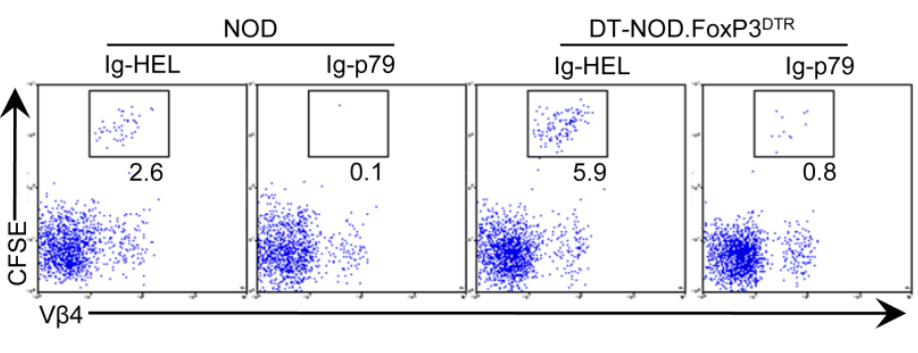

Figure 8. Ig-p79 ameliorates islet histopathology and clinical diabetes caused by transfer of Th17 cells into NOD mice. (A) CFSE-labeled Th17 cells were transferred into 4-wk-old female NOD mice and 7 days later, the splenic cells were stimulated with p79 peptide for $16 \mathrm{~h}$. The cells were stained with anti- 
V 34 and anti-CD4 antibodies and then stained for intracellular IFNY and IL-17 cytokines. The plot shows IFN $\gamma$ and IL-17 production by $\mathrm{CD}^{+}{ }^{+} \mathrm{CFSE}^{+} \mathrm{V} \beta 4^{+} \mathrm{T}$ cells. The results are representative of 3 independent experiments. (B) shows H\&E staining (100X magnification) of non-serial pancreatic sections (200 $\mu \mathrm{m}$ apart) from NOD mice that did not receive T cell transfer (No transfer, $n=3$ ) or mice recipient of either Th1 or Th17 polarized cells ( $n=6$ per group). (C) shows blood glucose levels $(\mathrm{mg} / \mathrm{dl})$ of individual NOD mice recipient of either Th1 or Th17 polarized cells ( $n=5$ per group). (D) shows incidence of diabetes in NOD.FoxP3 ${ }^{\text {GFP.DTR }}$ mice recipient of Th17 cells ( $n=8$ per group) that were treated with DT (Th17 + DT) or PBS (Th17 + PBS). A group treated with DT without transfer of Th17 cells (DT, $n=3$ ) was included for control purposes. (E) shows representative H\&E staining and islet infiltration severity scores (bar graph) of NOD mice recipient of Th17 cells and treated with Ig-p79 or Ig-HEL ( $\mathrm{n}=$ 6 per group). The scoring system is described in Materials and Methods. The percentages represent the number of islets with a specific score over the total number of islets (30-40 per pancreas). ( $F$ ) shows incidence of diabetes in Tregdepleted (by DT) NOD.FoxP3 ${ }^{\text {GFP.DTR }}$ mice recipient of Th17 cells and treated with Ig-p79 or Ig-HEL ( $n=10$ per group). (G) shows the frequency of $\mathrm{CFSE}^{+} \mathrm{CD} 4^{+} \mathrm{V} \beta 4^{+} \mathrm{T}$ cells recovered from pancreatic islets of NOD or Tregdepleted NOD.FoxP3 ${ }^{\text {GFP.DTR }}$ mice recipient of Th17 transfer and treated with Igp79 or Ig-HEL. All pancreatic histology and flow cytometry analyses (B, E, G) were performed on day 7 post $T$ cell transfer. The results in each panel are representative of 2 or 3 independent experiments. 
Treatment with Ig-p79 suppresses both islet pathology and clinical diabetes induced by stable Th17 cells.

To determine whether the non-convertible Th17 cells can be tolerized by Ig-p79, the NOD mice recipient of Th17 cells (without depletion of Tregs) were given Igp79 and assessed for pancreatic inflammation. The findings indicate that cell infiltration was significantly reduced in Ig-p79- relative to Ig-HEL-treated mice (Fig. 8E). In fact, the majority (57\%) of the islets in Ig-p79-treated mice had minimal infiltration (No insulitis). $25 \%$ of the remaining islets had peri-insulitis and only $18 \%$ had intra-insulitis. In contrast, in untreated and Ig-HEL-treated mice, most of the islets (51\% and 65\%, respectively) displayed intra-insulitis (Fig. 8E). Furthermore, Ig-p79 but not the control Ig-HEL was able to suppress clinical diabetes when given to DT-treated (Treg depleted) NOD.FoxP3 ${ }^{\text {GFP.DTR }}$ mice recipient of Th17 cells (Fig. 8F). Analysis of Th17 relocation to the pancreas upon treatment with Ig-p79 indicated the presence of a minimal frequency of CFSE-labeled cells relative to Ig-HEL treatment (Fig. 8G). Thus, Ig-p79 is able to suppress both forms of disease.

\section{Apoptosis of stables Th17 cells represents the mechanism of the tolerance induced by treatment with Ig-p79.}

We reasoned that the minimal presence of Th17 cells in the pancreas of Ig-p79treated mice (Fig. 8G) could be due to impaired trafficking and or cell death in other organs. To address this issue, we searched for the Th17 cells in both the spleen and PLN of Treg-depleted (DT-Foxp3 ${ }^{\text {DTR }}$ ) as well as un-depleted mice. 
The results show that very few cells were present in the spleen in Ig-p79-treated relative to untreated or Ig-HEL-treated mice (Fig. 9A). Moreover, by day 2 post treatment the numbers of Th17 cells decreased significantly in the spleen and PLN relative to Ig-HEL treatment in both strains (Fig. 9B). In fact, by day 7 the Th17 cells were barely detectable in either organ. The treatment with Ig-p79 did not induce conversion because there was no Th1 cells in the PLN of either strain and the very few residual cells were IL-17-producing cells like the untreated or IgHEL treated mice (Fig. 9C). Overall, Ig-p79 did not induce conversion but reduced the number of Th17 cells in the spleen and PLN.

Since the number of Th17 cells diminished gradually both in the spleen and PLN and the cells were barely found in the pancreas, it is likely that Ig-p79 drives death of the cells rather than conversion to Th1 or interference with trafficking. Indeed, when the splenic non-convertible Th17 cells were analyzed for incorporation of 7 amino-actinomycin $D(7-A A D)$ on day 2 after transfer to the hosts, there was a significant incorporation of 7-AAD by the Th17 cells in both NOD and DT-NOD.FoxP3 ${ }^{\mathrm{DTR}}$ mice, indicating that the cells are undergoing apoptosis (Fig. 9D). The untreated or Ig-HEL-treated mice had much less incorporation of 7-AAD. Like in the spleen, significant 7-AAD incorporation was also observed in the PLN (Fig. 9E). Incorporation of 7-AAD continued at a similar level on day 7 , indicating that the residual cells are undergoing death at a significant rate. Furthermore, in the Ig-p79-treated mice, the cells displayed an increased level of FasL but decreased expression of ROR $\gamma t$ relative to untreated or Ig-HEL-treated mice (Fig. 9F). Since RORyt functions as a negative regulator 
for FasL (He et al., 1998), it is likely that its down-regulation in Th17 cells led to the up-regulation of FasL, the trigger of a signaling cascade that sustains apoptosis (Fang et al., 2010; Zhang et al., 2008). Collectively, these results indicate that stable Th17 cells undergo apoptosis upon treatment with Ig-p79.

A

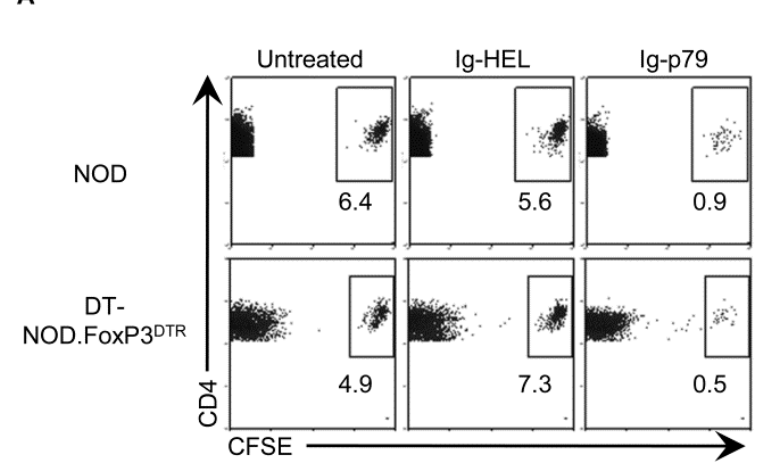

C

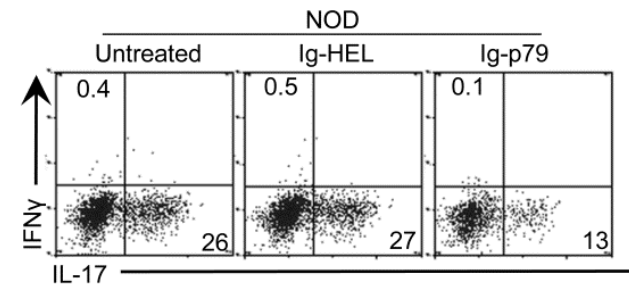

D

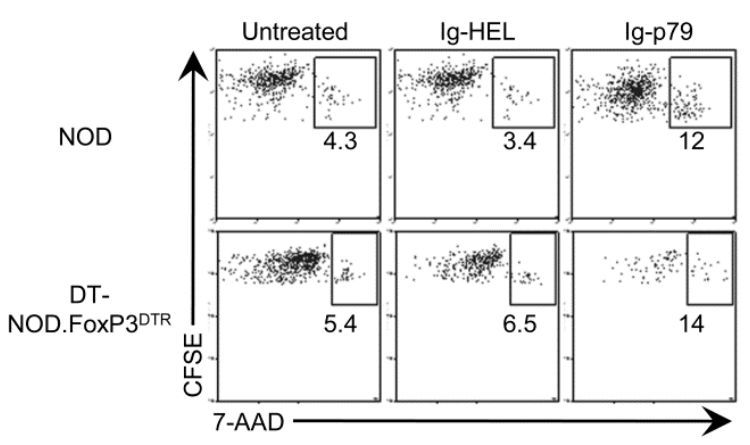

$\mathbf{F}$

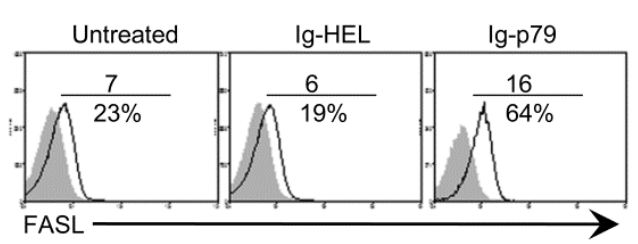

B

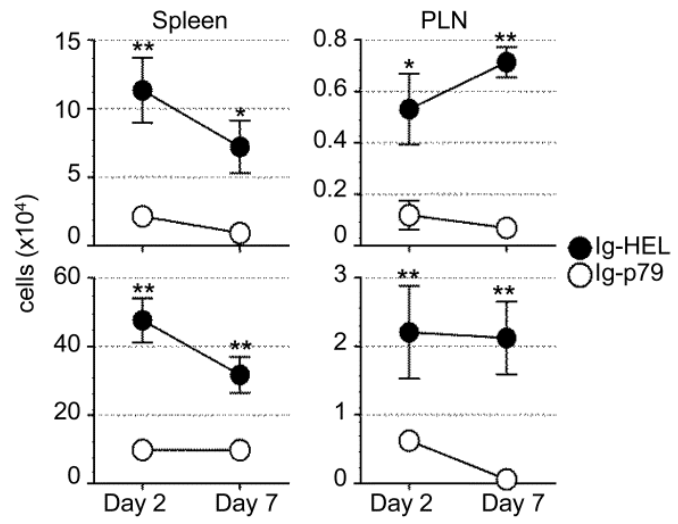

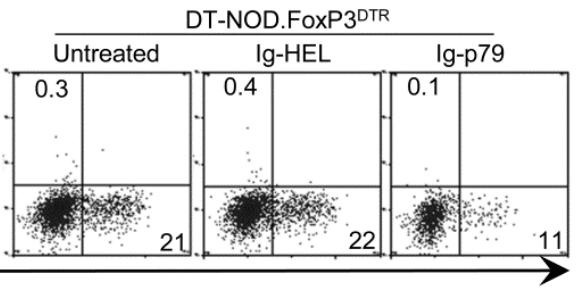

E
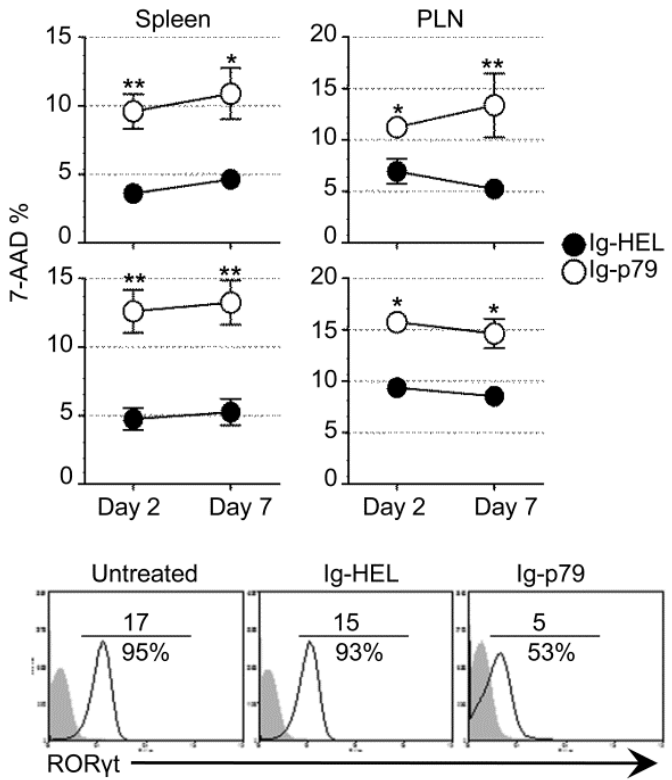
Figure 9. Apoptosis of stable Th17 cells represents the mechanism underlying amelioration of clinical and histopathological diabetes by Igp79. NOD or Treg-depleted NOD.FoxP3GFP.DTR mice recipient of CFSElabeled Th17 cells were treated with Ig-p79 or Ig-HEL and the spleens or PLN were harvested at the indicated time points. (A) shows the frequency of Th17 cells on day 2 after treatment with Ig-p79 or Ig-HEL ( $n=2$ for each time). A group of mice that did not receive any treatment (Untreated) is shown for control purposes. (B) shows the absolute cell number of $\mathrm{CD}^{+} \mathrm{CFSE}^{+}$cells in spleen and PLN on day 2 and 7 post transfer. The numbers represent the mean \pm SEM of 6 mice. ${ }^{* *} \mathrm{P}<0.01 .{ }^{*} \mathrm{P}<0.05$. (C) shows the production of intracellular IFN $\gamma$ and IL-17 by $\mathrm{CD}^{+} \mathrm{V} \beta 4^{+} \mathrm{CFSE}{ }^{+} \mathrm{T}$ cells from the PLN that were harvested on day 7 post transfer and stimulated with p79 peptide. (D) shows 7-AAD binding by splenic cells from the mice described in (A). (E) shows the percentage of 7$\mathrm{AAD}^{+}$cells from spleen and PLN on day 2 and 7 post transfer of CFSE-labeled Th17 cells. The percentages represent the mean \pm SEM of 6 mice. ${ }^{*} \mathrm{P}<0.01$. * $P<0.05$. (F) shows FasL (left panels) and RORyt (right panels) expression by $\mathrm{CD}^{+} \mathrm{V} \beta 4^{+} \mathrm{CFSE}^{+}$cells on day 2 for untreated, Ig-p79- or Ig-HEL- treated mice ( $\mathrm{n}$ $=2$ for each time) post Th17 transfer. The results in each panel are representative of 3 independent experiments.

\section{Ig-p79-induced apoptosis is specific for Th17 but not Th1 cells.}

The fact that Ig-p79 induced Th17 apoptosis in normal NOD hosts led us to further explore if apoptosis can be induced to Th1 cells in the same host. 
Transfer of Th1 cells induced rapid onset of clinical diabetes in 4-wk female NOD mice with Ig-HEL treatment, while Ig-p79 treatment completely suppressed the Th1-mediated diabetes (Fig. 10A). The Ig-p79-treated Th1 cells were present at a much higher frequency (2.4\%) in spleen than the Ig-HEL-treated controls $(0.25 \%)$ on day 2 after transfer, indicating that these cells preferentially accumulated in the spleen (Fig. 10B). Furthermore, the Ig-p79-treated Th1 cells displayed a low level of 7-AAD incorporation (5.6 $\pm 0.7 \%)$ which was comparable to the Ig-HEL-treated controls (5.8 $\pm 1.2 \%$ ) (Fig. 10C), suggesting that Ig-p79 did not increase the apoptotic level of the Th1 cells. Moreover, $63 \pm 4.2 \%$ of the Igp79-treated Th1 cells had lower CXCR3 expression than the Ig-HEL-treated controls (Fig. 10D), indicating the dampened trafficking ability of these Th1 cells. Thus, unlike Th17 cells, Ig-p79 did not induce significant apoptosis to Th1 cells, and the Ig-p79-mediated CXCR3 downregualtion on Th1 cells is consistent between normal and lymphopenic environment. 
A

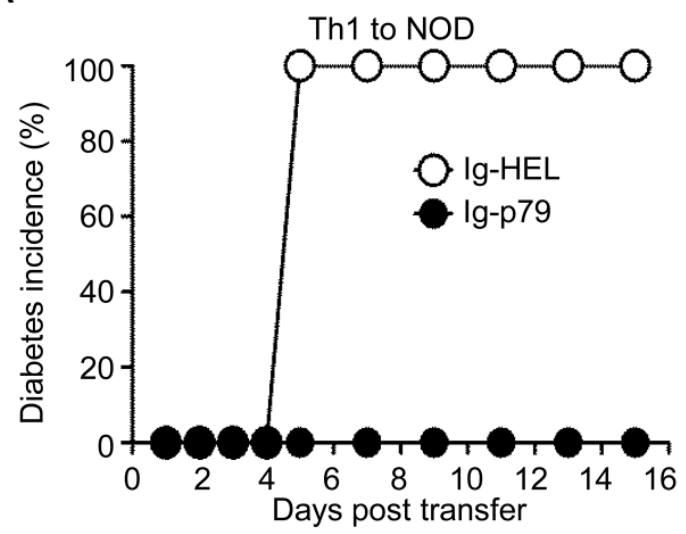

C

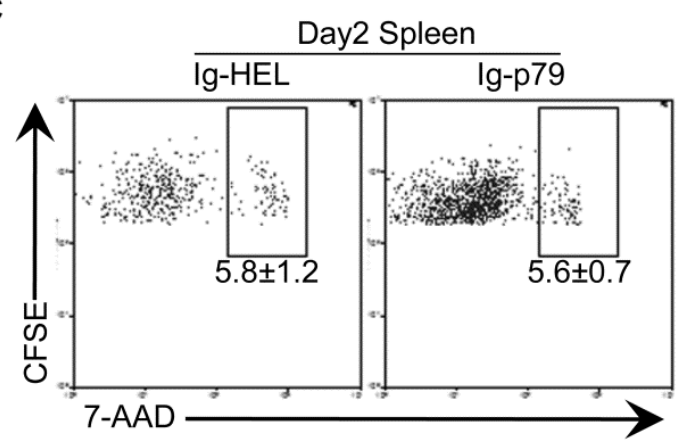

B

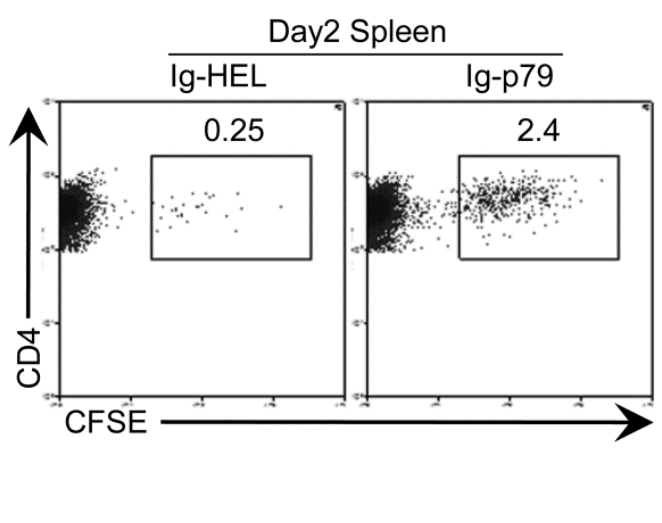

D

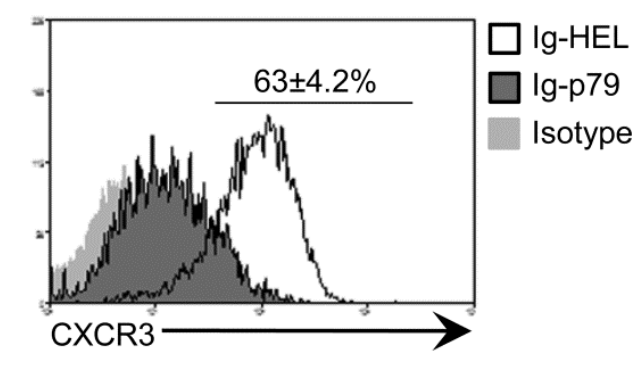

Figure 10. Polarized Th1 cells transferred into NOD mice down-regulate CXCR3 expression upon treatment with Ig-p79. CFSE-labeled polarized Th1 cells were transferred into NOD mice and 24h later the hosts were given Ig-p79 or the control Ig-HEL. (A) shows incidence of diabetes in both groups of mice ( $\mathrm{n}$ $=6$ per group). (B-D) The frequency of splenic $\mathrm{CD}^{+} \mathrm{CFSE}^{+}$cells (B), their apoptosis (C) and CXCR3 expression (D) was analyzed on day 2 after T cell transfer. The numbers indicate the mean \pm SEM of 6 mice. Each panel is representative of 3 independent experiments. 


\section{DISCUSSION}

Although T1D has been long viewed as a Th1-driven disease, the discovery of Th17 cells has challenged these studies and provides a new avenue for further exploring the roles of this helper $\mathrm{T}$ cell subset during T1D development. However, due to different experimental models and approaches, controversial results have been obtained, resulting in obscure understandings as to whether Th17 cells are required or involved in T1D pathogenesis. A recent study supported a negative role of the IL-17 cytokine in T1D (Joseph et al., 2012). By generating an IL-17 knockdown (IL-17 KD) NOD mouse model using RNA silencing, it was shown that these IL-17 KD NOD mice had a very similar disease development with the WT counterparts. These results seemed to indicate that Th17 cells are dispensable throughout T1D development. However, because this study only used blood glucose levels as the readout of the disease development without analyzing islet inflammation, it is still possible that IL-17 plays a role in the course of insulitis, but the cytokine alone cannot drive the transition to hyperglycemia. This is supported by the findings that anti-IL-17A and anti-17E (IL-25) neutralizing antibodies were able to curtail islet infiltration and reduce the formation of GAD65 autoantibodies (Emamaullee et al., 2009). In fact, in the present study we provide evidence showing that in vitro polarized BDC2.5 Th17 cells are able to trigger cell infiltration but not overt T1D in young NOD recipients. Furthermore, the transition of insulitis to critical $\beta$-cell damage is tightly checked by the host Tregs in that depletion of Tregs resulted in development of 
hyperglycemia. Therefore, Th17 cells could be more involved in the insulitis stage rather than direct killing of $\beta$ cells.

Furthermore, the disease stage in which IL-17 is targeted is crucial for the effectiveness of the intervention and interpretation of the results. For example, anti-IL-17A antibodies delayed T1D onset in NOD mice only when given at the 10-wk-old of age but not before 5-wk-old or after diabetes onset. Interestingly, treatment with anti-IL-17E antibodies was able to reduce the blood glucose levels in mice with already established hyperglycemia (Emamaullee et al., 2009). Therefore, the function of the IL-17 family should be carefully dissected and analyzed at different disease stages. This would require studies using genetic approaches to induce selective ablation the individual IL-17 cytokines on a temporal basis. In this sense, the Cre-ER system (driven by a T cell specific promoter) in which injection of tamoxifen induces nuclear relocation of the Cre recombinase and the subsequent deletion of the IL-17 DNA fragment flanked by two Loxp sites will be helpful. However, it should be noted that analyzing or targeting the IL-17 cytokines does not necessarily represent the role of the bona fide Th17 cells in vivo especially since Th17 cells are able to produce various inflammatory cytokines including IL-21. In fact, IL-21 receptor-deficient NOD mice did not develop insulitis or diabetes and displayed reduced IL-17 production in the spleen or PLN (Spolski et al., 2008). Thus, experiments with depletion of the bona fide Th17 cells rather than a certain Th17-associated cytokine would be required to address these issues. 
Another difficulty to analyze the genuine in vivo generated Th17 cells is their plasticity. In the present study we observed that in vitro generated BDC2.5 Th17 cells maintained their lineage commitment in NOD hosts, but these results should not repute the possibility that polyclonal Th17 cells may convert into other effector $\mathrm{T}$ cell subsets in vivo. Indeed, in vivo generated Th17 cells are convertible in presence of IFNy and IL-12. (Lexberg et al., 2010). In addition, despite the fact that $\mathrm{IL}-17^{+}$cells can be detected in advanced stages of T1D, their frequency is much lower than the IFNy ${ }^{+}$counterparts (Jain et al., 2008; Martin-Orozco et al., 2009), indicating that Th17 cells may have converted into Th1 cells in pre-diabetic stages. Elaborating these issues requires genetic tracking of the in vivo generated Th17 cells throughout T1D development. In this case, the fate mapping system (IL-17-Cre crossed with Rosa26-Loxp-Stop-YFP) used for monitoring Th17 cells in EAE (Hirota et al., 2011) should be of great value. These studies would provide important clinical implications in that the plasticity of Th17 cells should be considered for design of treatment targeting typical Th17-associated factors, such as neutralization of IL-17 and IL-22 cytokines because these factors may not be the major mediators in a certain disease stage when Th17 cells convert into other effector cell types.

Given that plasticity is an important mechanism that Th17 cells use to exert their pathogenic functions, tolerance of the Th17 cells should be analyzed under both converting and non-converting circumstances. Interestingly, we found that the mechanism or phenotype of tolerance is shaped by the final transcription factors of the effector $T$ cells. This is likely a direct effect of the Ig-p79 treatment through 
engagement with the T cell receptor without costimulatory signaling in both Th1 and Th17 cells, and the downstream "tolerogenic" signaling leads to interruption of T-bet and RORyt, respectively. Further studies are required to dissect the signaling events between TCR/CD28 (i.e. PI3K/AKT/Ras-MAPK) and the JAK/STAT pathways (i.e. STAT4/T-bet or STAT3/ RORyt) upon tolerance induction. This is important in that our tolerogenic model is established with minimal involvement of Tregs. In the converting system, we removed $\mathrm{FoxP}^{+}$ cells before transfer and we did not detect any $\mathrm{FoxP}^{+}$cells during tolerance induction and disease suppression (data not shown). In the non-converting system, Ig-p79 treatment was able to overcome clinical diabetes when the host Tregs are depleted. These results suggest that effective tolerance can be established using intrinsic mechanisms without assistance of Tregs. The implication here would be particularly useful when facing autoimmune situations associated with dysfunction of Tregs, including T1D (Lindley et al., 2005). 


\section{ACKNOWLEDGEMENTS}

We thank Dr. Mohamed Oukka (Seattle Children's Research Institute) for providing the C57BL/6.FoxP3. ${ }^{\text {GFP.DTR }}$ mice and Dr. Mehrhad Matloubian (University of California, San Francisco) for proving the MSCV-CXCR3-IRESThy1.1 and empty MSCV-IRES-Thy1.1 vector. 


\section{REFERENCES}

Ahern, P.P., C. Schiering, S. Buonocore, M.J. McGeachy, D.J. Cua, K.J. Maloy, and F. Powrie. 2010. Interleukin-23 drives intestinal inflammation through direct activity on T cells. Immunity 33:279-288.

Beima, K.M., M.M. Miazgowicz, M.D. Lewis, P.S. Yan, T.H. Huang, and A.S. Weinmann. 2006. T-bet binding to newly identified target gene promoters is cell type-independent but results in variable context-dependent functional effects. J Biol Chem 281:11992-12000.

Bending, D., H. De la Pena, M. Veldhoen, J.M. Phillips, C. Uyttenhove, B. Stockinger, and A. Cooke. 2009. Highly purified Th17 cells from BDC2.5NOD mice convert into Th1-like cells in NOD/SCID recipient mice. J Clin Invest 119:565-572.

Bettelli, E., Y. Carrier, W. Gao, T. Korn, T.B. Strom, M. Oukka, H.L. Weiner, and V.K. Kuchroo. 2006. Reciprocal developmental pathways for the generation of pathogenic effector TH17 and regulatory T cells. Nature 441:235-238.

Bradshaw, E.M., K. Raddassi, W. Elyaman, T. Orban, P.A. Gottlieb, S.C. Kent, and D.A. Hafler. 2009. Monocytes from patients with type 1 diabetes spontaneously secrete proinflammatory cytokines inducing Th17 cells. $J$ Immunol 183:4432-4439.

Chaudhry, A., D. Rudra, P. Treuting, R.M. Samstein, Y. Liang, A. Kas, and A.Y. Rudensky. 2009. CD4+ regulatory T cells control TH17 responses in a Stat3-dependent manner. Science 326:986-991.

Chaudhry, A., R.M. Samstein, P. Treuting, Y. Liang, M.C. Pils, J.M. Heinrich, R.S. Jack, F.T. Wunderlich, J.C. Bruning, W. Muller, and A.Y. Rudensky. 2011. Interleukin-10 signaling in regulatory $T$ cells is required for suppression of th17 cell-mediated inflammation. Immunity 34:566-578.

Emamaullee, J.A., J. Davis, S. Merani, C. Toso, J.F. Elliott, A. Thiesen, and A.M. Shapiro. 2009. Inhibition of Th17 cells regulates autoimmune diabetes in NOD mice. Diabetes 58:1302-1311.

Esensten, J.H., M.R. Lee, L.H. Glimcher, and J.A. Bluestone. 2009. T-betdeficient NOD mice are protected from diabetes due to defects in both $\mathrm{T}$ cell and innate immune system function. $\mathrm{J}$ Immunol 183:75-82.

Fang, Y., S. Yu, J.S. Ellis, T. Sharav, and H. Braley-Mullen. 2010. Comparison of sensitivity of Th1, Th2, and Th17 cells to Fas-mediated apoptosis. J Leukoc Biol 87:1019-1028. 
Faveeuw, C., M.C. Gagnerault, and F. Lepault. 1995. Isolation of leukocytes infiltrating the islets of Langerhans of diabetes-prone mice for flow cytometric analysis. J Immunol Methods 187:163-169.

Gregg, R.K., R. Jain, S.J. Schoenleber, R. Divekar, J.J. Bell, H.H. Lee, P. Yu, and $\mathrm{H}$. Zaghouani. 2004. A sudden decline in active membrane-bound TGF-beta impairs both $T$ regulatory cell function and protection against autoimmune diabetes. J Immunol 173:7308-7316.

He, Y.W., M.L. Deftos, E.W. Ojala, and M.J. Bevan. 1998. RORgamma t, a novel isoform of an orphan receptor, negatively regulates Fas ligand expression and IL-2 production in T cells. Immunity 9:797-806.

Hirota, K., J.H. Duarte, M. Veldhoen, E. Hornsby, Y. Li, D.J. Cua, H. Ahlfors, C. Wilhelm, M. Tolaini, U. Menzel, A. Garefalaki, A.J. Potocnik, and B. Stockinger. 2011. Fate mapping of IL-17-producing T cells in inflammatory responses. Nat Immunol 12:255-263.

Honkanen, J., J.K. Nieminen, R. Gao, K. Luopajarvi, H.M. Salo, J. Ilonen, M. Knip, T. Otonkoski, and O. Vaarala. 2010. IL-17 immunity in human type 1 diabetes. J Immunol 185:1959-1967.

Hu, J.K., T. Kagari, J.M. Clingan, and M. Matloubian. 2011. Expression of chemokine receptor CXCR3 on T cells affects the balance between effector and memory CD8 T-cell generation. Proc Natl Acad Sci U S A 108:E118-127.

Huber, S., N. Gagliani, E. Esplugues, W. O'Connor, Jr., F.J. Huber, A. Chaudhry, M. Kamanaka, Y. Kobayashi, C.J. Booth, A.Y. Rudensky, M.G. Roncarolo, M. Battaglia, and R.A. Flavell. 2011. Th17 Cells Express Interleukin-10 Receptor and Are Controlled by Foxp3(-) and Foxp3(+) Regulatory CD4(+) T Cells in an Interleukin-10-Dependent Manner. Immunity 34:554-565.

Hultgren, B., X. Huang, N. Dybdal, and T.A. Stewart. 1996. Genetic absence of gamma-interferon delays but does not prevent diabetes in NOD mice. Diabetes 45:812-817.

Jain, R., D.M. Tartar, R.K. Gregg, R.D. Divekar, J.J. Bell, H.H. Lee, P. Yu, J.S. Ellis, C.M. Hoeman, C.L. Franklin, and H. Zaghouani. 2008. Innocuous IFNgamma induced by adjuvant-free antigen restores normoglycemia in NOD mice through inhibition of IL-17 production. J Exp Med 205:207-218.

Joseph, J., S. Bittner, F.M. Kaiser, H. Wiendl, and S. Kissler. 2012. IL-17 silencing does not protect nonobese diabetic mice from autoimmune diabetes. J Immunol 188:216-221. 
Judkowski, V., C. Pinilla, K. Schroder, L. Tucker, N. Sarvetnick, and D.B. Wilson. 2001. Identification of MHC class II-restricted peptide ligands, including a glutamic acid decarboxylase 65 sequence, that stimulate diabetogenic T cells from transgenic BDC2.5 nonobese diabetic mice. J Immunol 166:908-917.

Katz, J.D., C. Benoist, and D. Mathis. 1995. T helper cell subsets in insulindependent diabetes. Science 268:1185-1188.

Koch, M.A., G. Tucker-Heard, N.R. Perdue, J.R. Killebrew, K.B. Urdahl, and D.J. Campbell. 2009. The transcription factor T-bet controls regulatory $\mathrm{T}$ cell homeostasis and function during type 1 inflammation. Nat Immunol 10:595-602.

Lee, Y.K., H. Turner, C.L. Maynard, J.R. Oliver, D. Chen, C.O. Elson, and C.T. Weaver. 2009. Late developmental plasticity in the $T$ helper 17 lineage. Immunity 30:92-107.

Lexberg, M.H., A. Taubner, I. Albrecht, I. Lepenies, A. Richter, T. Kamradt, A. Radbruch, and H.D. Chang. 2010. IFN-gamma and IL-12 synergize to convert in vivo generated Th17 into Th1/Th17 cells. Eur J Immunol 40:3017-3027.

Lindley, S., C.M. Dayan, A. Bishop, B.O. Roep, M. Peakman, and T.I. Tree. 2005. Defective suppressor function in CD4(+)CD25(+) T-cells from patients with type 1 diabetes. Diabetes 54:92-99.

Mangan, P.R., L.E. Harrington, D.B. O'Quinn, W.S. Helms, D.C. Bullard, C.O. Elson, R.D. Hatton, S.M. Wahl, T.R. Schoeb, and C.T. Weaver. 2006. Transforming growth factor-beta induces development of the $T(H) 17$ lineage. Nature 441:231-234.

Martin-Orozco, N., Y. Chung, S.H. Chang, Y.H. Wang, and C. Dong. 2009. Th17 cells promote pancreatic inflammation but only induce diabetes efficiently in lymphopenic hosts after conversion into Th1 cells. Eur J Immunol 39:216-224.

McGeachy, M.J., Y. Chen, C.M. Tato, A. Laurence, B. Joyce-Shaikh, W.M. Blumenschein, T.K. McClanahan, J.J. O'Shea, and D.J. Cua. 2009. The interleukin 23 receptor is essential for the terminal differentiation of interleukin 17-producing effector $\mathrm{T}$ helper cells in vivo. Nat Immunol 10:314-324.

Nurieva, R., X.O. Yang, Y. Chung, and C. Dong. 2009. Cutting edge: in vitro generated Th17 cells maintain their cytokine expression program in normal but not lymphopenic hosts. J Immunol 182:2565-2568. 
Reboldi, A., C. Coisne, D. Baumjohann, F. Benvenuto, D. Bottinelli, S. Lira, A. Uccelli, A. Lanzavecchia, B. Engelhardt, and F. Sallusto. 2009. C-C chemokine receptor 6-regulated entry of TH-17 cells into the CNS through the choroid plexus is required for the initiation of EAE. Nat Immunol 10:514-523.

Serreze, D.V., C.M. Post, H.D. Chapman, E.A. Johnson, B. Lu, and P.B. Rothman. 2000. Interferon-gamma receptor signaling is dispensable in the development of autoimmune type 1 diabetes in NOD mice. Diabetes 49:2007-2011.

Singh, S.P., H.H. Zhang, J.F. Foley, M.N. Hedrick, and J.M. Farber. 2008. Human $T$ cells that are able to produce IL-17 express the chemokine receptor CCR6. J Immunol 180:214-221.

Spolski, R., M. Kashyap, C. Robinson, Z. Yu, and W.J. Leonard. 2008. IL-21 signaling is critical for the development of type I diabetes in the NOD mouse. Proc Natl Acad Sci U S A 105:14028-14033.

Sutton, C., C. Brereton, B. Keogh, K.H. Mills, and E.C. Lavelle. 2006. A crucial role for interleukin (IL)-1 in the induction of IL-17-producing $\mathrm{T}$ cells that mediate autoimmune encephalomyelitis. J Exp Med 203:1685-1691.

Syrbe, U., J. Siveke, and A. Hamann. 1999. Th1/Th2 subsets: distinct differences in homing and chemokine receptor expression? Springer Semin Immunopathol 21:263-285.

Trembleau, S., G. Penna, S. Gregori, H.D. Chapman, D.V. Serreze, J. Magram, and L. Adorini. 1999. Pancreas-infiltrating Th1 cells and diabetes develop in IL-12-deficient nonobese diabetic mice. J Immunol 163:2960-2968.

Veldhoen, M., R.J. Hocking, C.J. Atkins, R.M. Locksley, and B. Stockinger. 2006. TGFbeta in the context of an inflammatory cytokine milieu supports de novo differentiation of IL-17-producing T cells. Immunity 24:179-189.

Wang, B., I. Andre, A. Gonzalez, J.D. Katz, M. Aguet, C. Benoist, and D. Mathis. 1997. Interferon-gamma impacts at multiple points during the progression of autoimmune diabetes. Proc Natl Acad Sci U S A 94:13844-13849.

Yang, Z., M. Chen, J.D. Ellett, L.B. Fialkow, J.D. Carter, M. McDuffie, and J.L. Nadler. 2004. Autoimmune diabetes is blocked in Stat4-deficient mice. $J$ Autoimmun 22:191-200.

You, S., C. Chen, W.H. Lee, C.H. Wu, V. Judkowski, C. Pinilla, D.B. Wilson, and C.P. Liu. 2003. Detection and characterization of $T$ cells specific for BDC2.5 T cell-stimulating peptides. J Immunol 170:4011-4020. 
Zhang, Y., G. Xu, L. Zhang, A.I. Roberts, and Y. Shi. 2008. Th17 cells undergo Fas-mediated activation-induced cell death independent of IFN-gamma. $J$ Immunol 181:190-196.

Zhou, L., M.M. Chong, and D.R. Littman. 2009. Plasticity of CD4+ T cell lineage differentiation. Immunity 30:646-655.

Zhou, L., J.E. Lopes, M.M. Chong, Ivanov, II, R. Min, G.D. Victora, Y. Shen, J. Du, Y.P. Rubtsov, A.Y. Rudensky, S.F. Ziegler, and D.R. Littman. 2008. TGF-beta-induced Foxp3 inhibits $\mathrm{T}(\mathrm{H}) 17$ cell differentiation by antagonizing RORgammat function. Nature 453:236-240. 
CHAPTER III

RECOVERY FROM OVERT TYPE 1 DIABETES ENSUES

WHEN IMMUNE TOLERANCE AND $\beta$-CELL FORMATION

ARE COUPLED WITH REGENERATION OF

ENDOTHELIAL CELLS IN THE PANCREATIC ISLETS

(Diabetes, 2013, in press) 


\section{ABSTRACT}

Immune modulation of pancreatic inflammation induces recovery from type 1 diabetes (T1D) but remission was not durable perhaps due to an inability to sustain the formation and function of new pancreatic $\beta$-cells. We have previously shown that Ig-GAD2, carrying glutamic acid decarboxylase (GAD) 206-220 peptide, induced in hyperglycemic mice immune modulation that was able to control pancreatic inflammation, stimulate $\beta$-cell regeneration and prevent T1D progression. Herein, we show that the same Ig-GAD2 regimen given to mice with overt T1D is unable to reverse the course of disease despite eradication of Th1 and Th17 cells from the pancreas. However, the regimen is able to sustain recovery from T1D when Ig-GAD2 was accompanied with transfer of bone marrow (BM) cells from healthy donors. Interestingly, alongside immune modulation there was concomitant formation of new $\beta$ and endothelial cells in the pancreas. The new $\beta$-cells were of host origin while the donor BM cells gave rise to the endothelial cells. Moreover, transfer of purified BM endothelial progenitors instead of whole BM cells sustained both $\beta$ and endothelial cell formation and reversal of diabetes. Thus, overcoming T1D requires both immune modulation and repair of the islet vascular niche to preserve newly formed $\beta$-cells. 


\section{INTRODUCTION}

T1D is a chronic disease in which the insulin-producing $\beta$-cells of the pancreatic islets are destroyed by inflammatory $\mathrm{T}$ lymphocytes of the immune system (Atkinson and Eisenbarth, 2001; Bluestone et al., 2010). Broad-based T-celltargeted therapies, such as anti-CD3 monoclonal antibodies, were able to reverse established T1D in the NOD mouse (Belghith et al., 2003). In humans however, while the regimen preserved C-peptide responses, disease remission is not sustained perhaps due to return of inflammation after termination of the treatment (Herold et al., 2005; Herold et al., 2002). In addition, non-specific targeting of the $T$ cells may compromise the normal function of the immune system against pathogen infections (Chatenoud and Bluestone, 2007; WaldronLynch and Herold, 2011). Therefore, antigen-specific modulation strategies aiming at re-establishing the self-tolerance of the immune system to $\beta$-cellassociated antigens are highly desired and have shown efficacy in the non-obese diabetic (NOD) mouse and initial human clinical trials (Moody et al., 1995; Waldron-Lynch and Herold, 2011). In fact, patients with a recent onset of T1D demonstrated improved C-peptide responses after vaccination with the glutamic acid decarboxylase 65 (GAD65) protein (Ludvigsson et al., 2008), a well-defined self-antigen involved in T1D development (Kaufman et al., 1993; Nepom et al., 2001; Tisch et al., 1993). Moreover, T cell responses against GAD65 can be detected in NOD mice and T1D patients (Ellis and Atkinson, 1996; Tisch et al., 1993), and prevention of GAD65 expression in pancreatic islets blocked T1D development in NOD mice (Yoon et al., 1999). Several different $C D 4^{+} \mathrm{T}$ cell 
epitopes derived from GAD65 have been further characterized (Chen et al., 2003; Kim et al., 2004; Liu et al., 2000; Tarbell et al., 2002), among which the amino acid sequence 206-220 of GAD65 (p206) is considered a late-stage determinant (Chao et al., 1999). T cells that specifically recognize p206 produced immunoregulatory cytokines IFNy and IL-10 and were able to delay the onset of T1D when co-transferred with diabetogenic T cells (Kim et al., 2004). To effectively present this peptide in vivo and amplify its inhibitory function, we previously inserted the p206 sequence on an immunoglobulin (Ig) molecule (Jain et al., 2008). The resulting Ig-GAD206-220, referred to as Ig-GAD2, halted progression of T1D when given to NOD mice that began to develop hyperglycemia (blood glucose levels (BGL), 160 250 mg/dl) (Jain et al., 2008). The disease suppression in these hyperglycemic mice is manifested by eradication of islet infiltration, stimulation of $\beta$-cell division, and generation of healthy islets (Jain et al., 2008). However, the effectiveness of lg-GAD2 treatment in reversal of overt T1D is yet to be defined.

To this end, we administered Ig-GAD2 to mice with a BGL $\geq 300 \mathrm{mg} / \mathrm{dl}$ for two consecutive measurements. While the regimen was effective at the hyperglycemic stage (BGL, 160 250 mg/dl), it did not reverse the course of the disease in the diabetic mice (BGL $\geq 300 \mathrm{mg} / \mathrm{dl}$ ). Intriguingly, we observed curtailed islet infiltration and diminished pathogenic Th1 and Th17 cells in the diabetic mice given Ig-GAD2. These results suggest that a single antigen-specific regimen may lack sustainable disease remission and should be applied in combination with other agents that could promote $\beta$-cell survival and growth. In 
fact, it has been shown that adult $\beta$-cells are formed mainly by self-duplication in healthy or pancreatectomized mice (Dor et al., 2004). Therefore, the lack of recovery from T1D may be related to an inability of the residual $\beta$-cells to replicate. Since BM transplantation in the absence of inflammation induced regeneration of endogenous $\beta$-cells and restored normoglycemia in mice with streptozotocin (STZ)-induced pancreatic injury (Hess et al., 2003; Mathews et al., 2004), we sought to determine whether enrichment with BM cells during suppression of inflammation with Ig-GAD2 would counter overt diabetes.

Our results demonstrate that sustainable reversal of overt T1D can be achieved by transferring $\mathrm{BM}$ cells during treatment with Ig-GAD2. The recovered mice displayed a concomitant restoration of the insulin-producing $\beta$ and endothelial cells (ECs) in the pancreatic islets. Interestingly, while the restored $\beta$-cells were of host origin, there was a marked pancreatic engraftment of the donor BMderived endothelial cells in the diabetes-free mice. Furthermore, transfer of purified BM endothelial progenitors (EPCs) instead of the whole BM was able to support the protection against T1D along with Ig-GAD2 treatment. Because islet endothelial cells are critical for fine-tuning of $\beta$-cell development and function (Cleaver and Melton, 2003; Johansson et al., 2006; Kaido et al., 2004; Lammert et al., 2001; Nikolova et al., 2006), and diabetes course leads to dysfunction of both EPCs and mature ECs (Caballero et al., 2007; Khoo et al., 2009; Loomans et al., 2004; Schatteman et al., 2000; Thum et al., 2007), our findings have clinical implications by emphasizing the need for repair of islet endothelial cells along with control of immune inflammation in order to overcome overt T1D. 


\section{RESEARCH DESIGN AND METHODS}

\section{Mice}

NOD and NOD.GFP mice expressing the green fluorescence protein under the $\beta$ actin promoter were previously described (Wallet et al., 2009) were maintained in the Animal Facility at the Medical Sciences Building under barrier conditions. All animals were used according to the guidelines of the University of Missouri Animal Care and Use Committee.

\section{Treatment with Ig-GAD2 and donor BM}

Mice began BGL monitoring at 10 weeks of age, and those who displayed $\geq 300$ $\mathrm{mg} / \mathrm{dl}$ for 2 consecutive weeks were enrolled in the treatment regimen. The mice were first given 2 sustained release insulin implants (LinShin, Toronto, Ontario, Canada) inserted subcutaneously in the abdomen to temporarily maintain normoglycemia for 2-3 weeks. The mice were then given $300 \mu \mathrm{g}$ Ig-GAD2 intraperitoneal (i.p.) 3 times weekly for 5 weeks and then once a week for another 5 weeks. Donor BM cells were isolated from the femur and tibia, and 10 x $10^{6}$ whole BM cells were transferred intravenously (i.v) weekly on week 2, 3, and 4 post diagnosis. The mice were monitored for BGL until day 120. 


\section{Treatment with Ig-GAD2 and donor EPCs}

This regimen was similar to treatment with Ig-GAD2 and donor BM except that EPCs substituted for whole BM cells. FLK-1 ${ }^{+}$EPCs were given at $5 \times 10^{4}$ per injection while FLK-1 ${ }^{-}$EPCs were given at $3 \times 10^{6}$ cells per injection.

\section{Purification of EPCs}

BM cells were harvested from healthy or diabetic (sick) mice and depleted of lineage $^{+}\left(\operatorname{Lin}^{+}\right)$cells using the lineage cell depletion kit according to manufacturer's instruction (Miltenyi Biotec). The Lin ${ }^{-}$cells were stained with antic-Kit, and anti-FLK-1 antibodies as well as with 7-amino-actinomycin D (7-AAD)

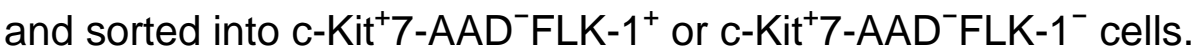

\section{Cell surface staining}

For detection of PECAM1, FLK-1, c-Kit and CD45 the cells were stained with marker-specific antibodies, including phycoerythrin (PE)-cy7-conjugated antiPECAM1 (390), allophycocyanin (APC)-conjugated anti-FLK1 (Avas12a1) (both from eBiosciences), PE-cy7-conjugated anti-c-Kit (2B8) and APC-cy7-conjugated

anti-CD45 (2D1) (both from BD Pharmingen) antibodies. For detection of apoptotic cells, cells were stained with 7-AAD (EMD Biosciences).

\section{Intracellular staining}

For detection of intracellular IFNy, IL-10 and IL-17 in CD4 ${ }^{+} \mathrm{T}$ cells, the cultures were stimulated with PMA $(50 \mathrm{ng} / \mathrm{ml})$ and ionomycin $(500 \mathrm{ng} / \mathrm{ml})$ for $4 \mathrm{~h}$ in 
presence of Brefeldin A $(10 \mu \mathrm{g} / \mathrm{ml})$, and then stained with Peridinin-chlorophyllprotein (PerCP)-cy5.5-conjugated anti-CD4 (RM4-5), PE-conjugated antiVß8.1/8.2 (MR5-2) and FITC-conjugated anti-CD8 (RPA-T8) antibodies (all from BD Pharmingen). Subsequently, the cells were fixed with $2 \%$ formaldehyde, permeabilized with $0.2 \%$ saponin and stained with PE-cy7-conjugated anti-IFNy (XMG1.2), APC-conjugated anti-IL-10 (JES5-16E3) or APC-conjugated anti-IL-17 (eBio17B7) antibodies (all from eBiosciences).

\section{Flow cytometry analyses}

The samples were read using a Beckman Coulter CyAn ADP and data were analyzed using Summit V4.3 (Dako). Cell sorting ( $>98 \%$ purity) was performed using a Beckman Coulter MoFlo XDP sorter.

\section{Sample preparation for histological analyses}

Pancreata were frozen in tissue freezing medium (Triangle Biomedical Sciences), and non-serial 8- $\mu \mathrm{m}$ thick sections were cut $150-\mu \mathrm{m}$ apart to avoid over counting of the labeled cells. The sections were fixed in $4 \%$ formaldehyde for $10 \mathrm{~min}$ before histological procedures. For detection of enhanced GFP expression in tissues, pancreata were fixed in $4 \%$ formaldehyde for $4 \mathrm{~h}$ at $4^{\circ} \mathrm{C}$ and immersed in $30 \%$ sucrose overnight before freezing. Analysis of insulitis used H\&E staining as previously described (Jain et al., 2008). Each experiment used 3-6 sections per pancreas. 


\section{Immunohistochemistry}

For detection of $\beta$-cells, pancreatic sections were incubated with HRP-conjugated anti-insulin affibody molecule (Abcam, 1:200) at room temperature (RT) for 45min, and the insulin ${ }^{+}$cells were identified by incubating the slides with DAB chromogen and substrate (ScyTek) for $5 \mathrm{~min}$. The cell nuclei were counterstained with hematoxylin.

\section{Immunofluorescence}

Pancreatic sections were treated with a PBS solution containing 1\% BSA, 10\% goat or donkey serum, and $0.2 \%$ Triton-X100 at RT for $1 \mathrm{~h}$. The sections were then incubated overnight at $4^{\circ} \mathrm{C}$ with primary antibodies, including rabbit antiinsulin (Santa Cruz, 1:200), guinea pig anti-insulin (Abcam, 1:300), rabbit antiPECAM1 (Abcam, 1:100), goat anti-PECAM1 (Santacruz, 1:100), rabbit anti-ki67 (Abcam, 1:300) and goat anti-VEGF (Santa Cruz, 1:200). The slides were washed with 3 changes of $0.02 \%$ Triton-X100 in PBS and then stained for 1 hour at RT with the corresponding secondary antibodies, including Texas Redconjugated goat anti-rabbit $\lg$ (1:200), fluorescein isothiocyanate (FITC)conjugated goat anti-guinea pig IgG (1:200), FITC-conjugated donkey anti-goat IgG (1:200) (all from Santa Cruz), DyLight 405-conjugated donkey anti-rabbit IgG (1:200) and DyLight 549-conjugated donkey anti-goat IgG (1:300) (all from Jackson ImmunoResearch). In some experiments, the cell nuclei were counterstained with DAPI (Santa Cruz). The images were visualized and acquired with a Zeiss fluorescence microscope or an Olympus DSU confocal 
microscope. The number of $\beta$-cells, islets, and endothelial cells was scored with a computer-assisted Image Pro Plus program. $\beta$-cell mass was calculated as described (Sreenan et al., 1999).

\section{Laser capture microdissection}

Pancreatic sections were stained with insulin or PECAM1 and thoroughly dehydrated with the Arcturus dehydration component. The insulin ${ }^{+}$or PECAM1 ${ }^{+}$ cells were dissected with the CapSure HS LCM caps and the Autopix 100 laser capture microdissection system by following the manufacturer's instructions. For each individual mouse, cells were dissected from 3-10 non-serial sections. Genomic DNA was extracted from the dissected cells using the PicoPure DNA extraction kit. All the reagents are from Applied Biosystems.

\section{Detection of Y chromosome by PCR}

Detection of $Y$ chromosome and beta-actin was performed using 20 ng DNA template and Maxima qPCR master mix (Fermentas). The primer sequences are as follows: Y chromosome, Forward, 5'-GGTGAGAGGCACAAG

TTGG-3', Reverse, 5'-ATCTCTGTGCCTCCTGGAAA-3'; Beta-actin, Forward, 5'GCTTCTTTGCAGCTCCTTCGTTGC-3', Reverse, 5 GTGTCCGTTCTGAGTGATCC

TCAG-3'. 


\section{Measurement of $\beta$-cell mass}

The pancreata were isolated and weighted before staining of insulin by immunohistochemistry. The insulin positive area relative to the whole section area was calculated with the Image Pro Plus program over non-serial sections (150 $\mu \mathrm{m}$ apart). The $\beta$-cell mass is expressed in $\mathrm{mg}$ by multiplying the pancreatic weight $(\mathrm{mg})$ with the relative insulin positive area (\%).

\section{Quantitative PCR analysis}

Total RNA was extracted from pancreatic islets using the TRI RNA isolation reagent (Sigma). Quantitative PCR was performed using the Power SYBR Green kit and the StepOnePlus instrument (all from Applied Biosystems). The relative quantity (RQ) was calculated based on the $\Delta \Delta C T$ after normalization with the internal control $18 \mathrm{~S}$ ribosome RNA expression. Primer sequences are as follows: angpt1, Forward, 5'- AGCATCTGGAGCATGTGATGGA-3', Reverse, 5'TATCTCAAGCAT

GGTGGCCGT-3'; angpt2, Forward, 5'- AACACCGAGAAGATGGCAGTGT-3', Reverse, 5'- AGACAAACTCATTGCCCAGCCA-3'; cdh5, Forward, 5'TTCGCACCA

GGTATTCAACGCA-3', Reverse, 5'- TCATCTGCATCCACTGCTGTCA-3'; flt1, Forward, 5'- TGCAGGAAACCACAGCAGGAA-3', Reverse, 5'TTCAATGTTGCAG 
GCGAGCCAT-3'; tie1, Forward, 5'- CAgCATGAAACTTCGCAAGCCA-3', Reverse, 5'- TGGGCACTTCAAACTCTGCTGT-3'; vegfa, Forward, 5'TGCAGGCTGCTGTA

ACGATGAA-3', Reverse, 5'- TGCTGTGCTGTAGGAAGCTCAT-3'; tbx21, Forward, 5'-TCCAAGTTCAACCAGCACCAGA-3', Reverse, 5'TCCACCAAGACCACATCCA

CAA-3'; rorc, Forward, 5'-ACAGCCACTGCATTCCCAGTTT-3', Reverse, 5'TCTCGGAAGGACTTGCAGACAT-3'.

\section{Statistical analyses}

$P$ values associated with all pair wise comparisons were calculated based on Student's t-test for independent groups. 


\section{RESULTS}

\section{Ig-GAD2-driven immune modulation is not sufficient to overcome overt}

T1D.

Our previous work tested the effectiveness of Ig-GAD2 treatment in prevention of mice at the hyperglycemic stage (BGL 160 250 mg/dl) from progressing into the overtly diabetic stage (BGL $\geq 300 \mathrm{mg} / \mathrm{dl}$ ) (Jain et al., 2008). The mechanisms underlying the protection is the induction of $\mathrm{T}$ cell tolerance characterized by increase of the IFNY and IL-10 production by the GAD206-220-specific T cells in the periphery but the diminished IL-17 and IFNy production in the pancreatic islets (Jain et al., 2008). We next aimed to investigate whether the same IgGAD2 treatment regimen was able to reverse the course of the overtly diabetic mice, which would be more relevant to human circumstances. In an initial attempt, we injected Ig-GAD2 chimeras to diabetic mice following the regimen that we used for hyperglycemic mice (Jain et al., 2008). The results show that IgGAD2 treatment was able to restrain the BGL of the hyperglycemic mice and none of the mice had a BGL above the $300 \mathrm{mg} / \mathrm{dl}$ cut-off (Fig. 1A, left panel). In contrast, there was no reduction of BGL for all the enrolled diabetic mice (Fig. $1 A$, right panel). These results are surprising because Ig-GAD2 was able to induce $\mathrm{T}$ cell tolerance in the diabetic mice despite the fact that these mice were not recovered from the disease. Specifically, the Ig-GAD2-treated diabetic mice had increased frequency of $\mathrm{CD} 4^{+} \mathrm{CD} 8^{-} \mathrm{V} \beta 8.1 / 8.2^{+} \mathrm{T}$ cells producing $\mathrm{IFN} \gamma$ and/or IL-10 (Fig. 1B), but diminished IL-17-producing cells in the spleen (SP) and pancreatic lymph nodes (PLN) relative to untreated sick animals (Fig. 1C). 
Moreover, there were reduced Th1 or Th17 cells in the pancreatic islets because the mRNA for their signature transcription factors, T-bet and ROR $\gamma$ t respectively, were significantly diminished (Fig. 1D). These results suggest immune modulation driven by Ig-GAD2 is insufficient to normalize the high level of the blood glucose in overtly diabetic NOD mice. 

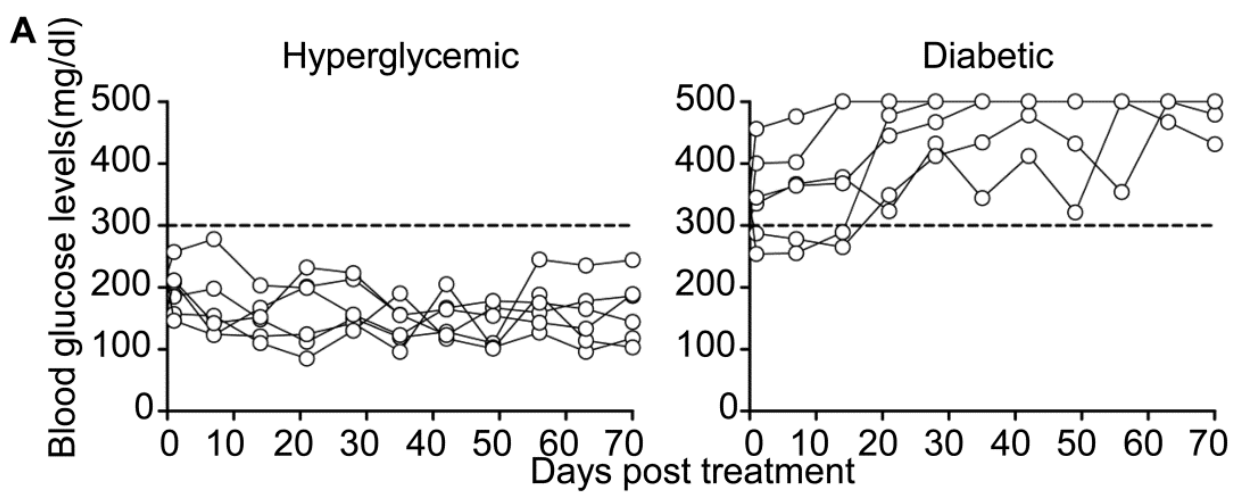

B
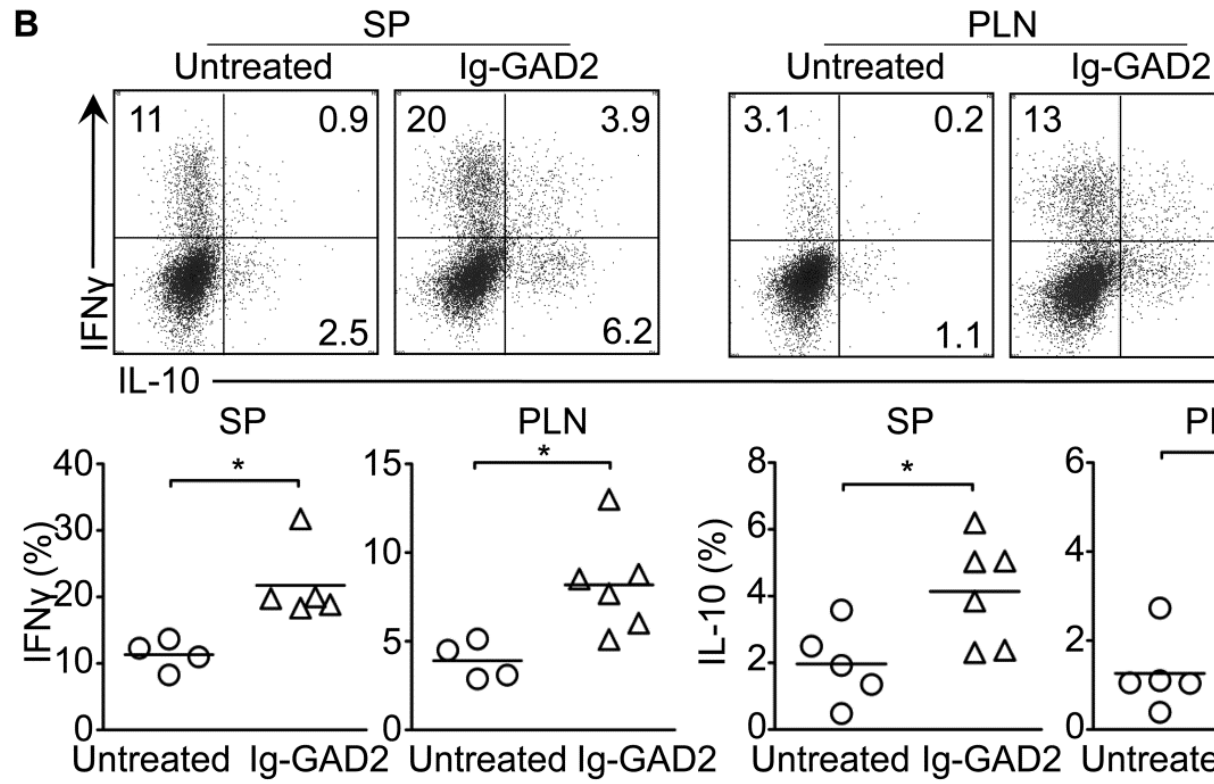

C

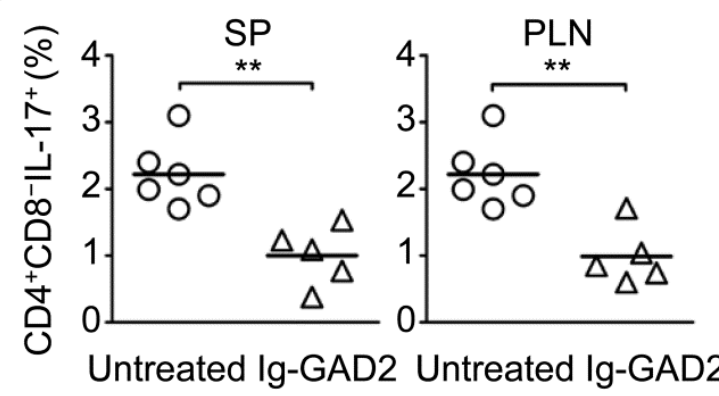

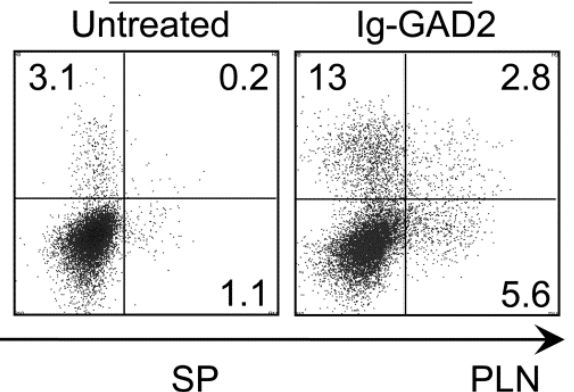

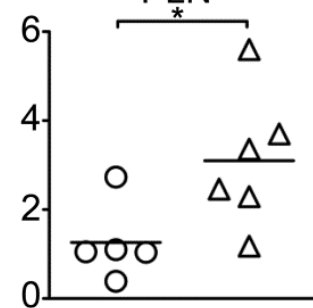

Untreated Ig-GAD2 Untreated Ig-GAD2
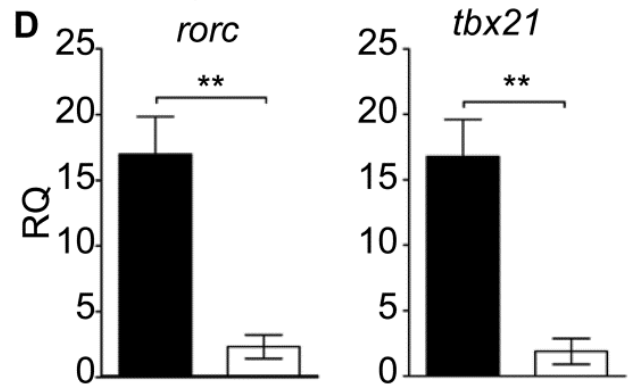

Untreated Ig-GAD2 Untreated Ig-GAD2

Figure. 1. Ig-GAD2 treatment could not overcome overt T1D despite induction of immune tolerance. (A): Hyperglycemic and diabetic NOD mice (6 per group) were given Ig-GAD2 and their blood glucose levels (BGL) were monitored for a period of 70 days. (B-C): The mice of the diabetic group were sacrificed on day 70 and the spleen (SP) and pancreatic lymph node (PLN) cells 
were harvested, stimulated with PMA and ionomycin and stained for surface CD4, CD8 and V $88.1 / 8.2$ as well as intracellular IFNy, IL-10 and IL-17. A group of mice sacrificed upon diagnosis of diabetes (untreated) is used as control. (B) shows representative FACS plots (top) and individual mice (bottom) depicting CD4 ${ }^{+} C D 8^{-} V \beta 8.1 / 8.2^{+}$cells producing IFNY and IL-10. (C) Shows the frequency of $\mathrm{CD}^{+} \mathrm{CD} 8^{-} \mathrm{IL}-17^{+}$cells. (D) Shows the relative quantity (RQ) of mRNA expression for RORyt (rorc) and T-bet (tbx21) in the pancreatic islets of untreated and IgGAD2 treated mice. Each bar represents mean \pm SEM of 3-6 mice. ${ }^{*} \mathrm{P}<0.01$, * $P<0.05$.

\section{Transfer of BM cells alongside Ig-GAD2 treatment overcomes overt T1D.}

Because $\beta$-cells are formed mainly by self-duplication (Dor et al., 2004), and every $\beta$-cell displayed an equal ability to proliferate (Brennand et al., 2007), the lack of disease recovery in diabetic mice may be related to an inability of the very few residual $\beta$-cells to replicate. We reasoned that approaches that may facilitate $\beta$-cell division should be provided as an accessory therapy with Ig-GAD2 treatment. Since BM transplantation in the absence of inflammation led to regeneration of endogenous $\beta$ cells (Hess et al., 2003; Mathews et al., 2004), we sought to determine whether enrichment with BM cells during suppression of inflammation with Ig-GAD2 would counter overt diabetes. We then combined BM cell transfer from healthy donors with Ig-GAD2 injections and devised a 70-day treatment regimen (Figure 2A and Methods). Indeed, the majority of the mice given both Ig-GAD2 and BM (Ig-GAD2+BM) had a BGL $<300 \mathrm{mg} / \mathrm{dl}$ whether the 
BM was from male or female donors (Fig. 2B). No protection was observed in mice given Ig-GAD2 or BM alone (Fig. 2B). These results suggest that both BM transfer and Ig-GAD2 are required to contain the high BGL in overtly diabetic mice. Furthermore, the enrichment with BM cells sustained recovery from disease without impacting Ig-GAD2-mediated immune modulation. Indeed, the diabetic mice treated with the combination (Ig-GAD2+BM) regimen, like those recipient of Ig-GAD2 alone (Fig. 1B-D), had increased frequency of $\mathrm{CD}^{+} \mathrm{CD} 8^{-} \mathrm{V} \beta 8.1 / 8.2^{+} \mathrm{T}$ cells producing IFN $\gamma$ and/or IL-10 (Fig. 2C), but diminished Th17 cells in the SP and PLN (Fig. 2D). In contrast, mice recipient of BM alone which remained sick had no increase in IFN $\gamma$ - and IL-10-producing cells or decrease in Th17 cells (Fig. 2, C and D). Moreover, in the pancreas of IgGAD2+BM groups, the mRNA for T-bet and ROR $\gamma$ t was significantly diminished relative to animals recipient of BM alone (Fig. 2E), indicating that both Th1 and Th17 cells were minimal in this site. Overall, addition of BM transfer to the IgGAD2 regimen sustained recovery from diabetes without impacting immune modulation. 
A

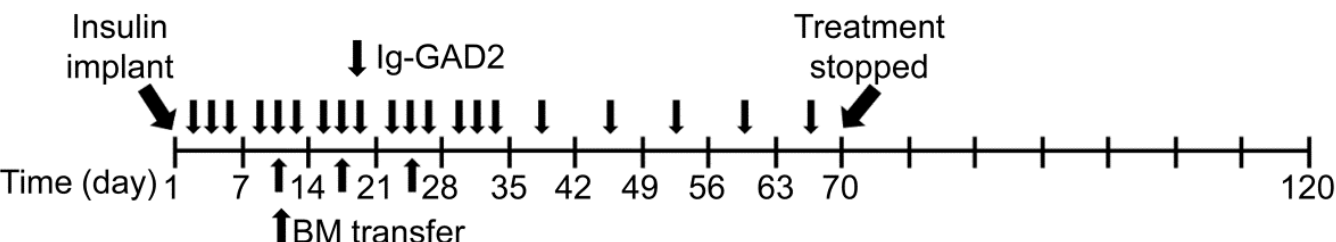

B

IBM transfer

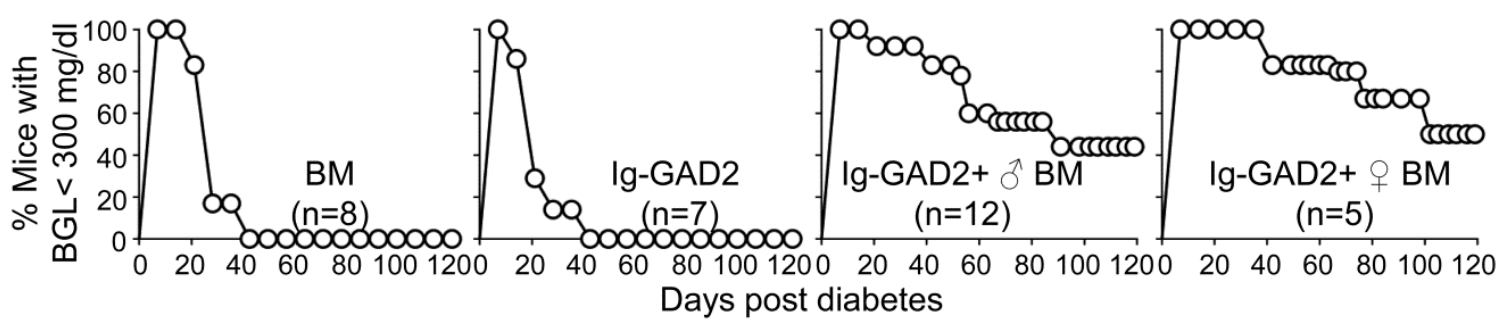

C
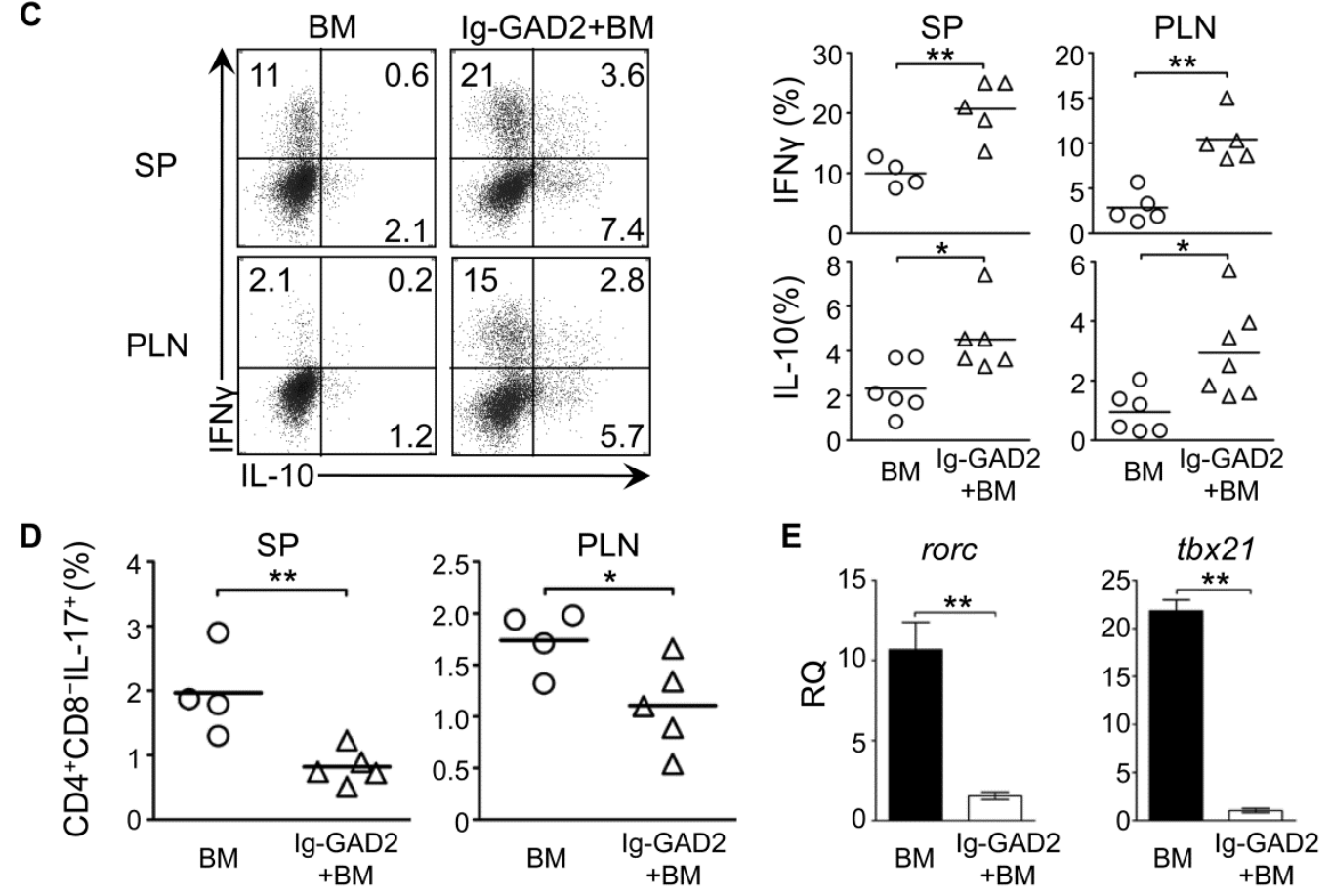

Figure. 2. Healthy donor BM cells transferred during immune modulation restore normoglycemia in diabetic mice. (A) shows a schematic representation of the treatment regimen in which diabetic mice received 2 insulin pellet implants on day 1 of the regimen and Ig-GAD2 and BM transfer as indicated. (B) shows percent of mice with $B G L<300 \mathrm{mg} / \mathrm{dl}$ from groups recipient of BM transfer alone (BM), Ig-GAD2 alone (Ig-GAD2), or Ig-GAD2 plus male or female BM. $\mathrm{n}$ indicates the number of mice. (C-D): The SP and PLN cells of the 
mice recipient of BM or Ig-GAD2 + BM were harvested on day 70 , stimulated with PMA and Ionomycin, and analyzed for cytokine production. (C) shows representative FACS plots (left) and individual mice (right) depicting $\mathrm{CD} 4^{+} \mathrm{CD} 8^{-} \mathrm{V} \beta 8.1 / 8.2^{+}$cells producing IFNy and IL-10. (D) Frequency of IL-17producing $\mathrm{CD}^{+} \mathrm{CD8} 8^{-}$cells. (E) shows the $\mathrm{RQ}$ of mRNA expression for RORyt (rorc) and T-bet (tbx21) in the pancreatic islets of mice recipient of BM or IgGAD2+BM. Each bar represents mean \pm SEM of 4-8 mice. ${ }^{\star *} \mathrm{P}<0.01$, * $\mathrm{P}<$ 0.05 .

\section{BM transfer promotes $\beta$-cell restoration without affecting immune tolerance.}

The protection of the Ig-GAD2+BM treatment regimen against overt T1D is also manifested by measurement of the mean BGL. As is shown in Fig. 3A, the average $B G L$ of all the 17 mice given by $\lg -G A D 2+B M$ is significantly lower throughout the 120-day monitoring period as compared to those given Ig-GAD2 or BM alone. BM transfer from healthy donors may cause innocuous homing of non- $\beta$-cell autoreactive hematopoietic cells into the islet, leading to abrogated immune infiltration and alleviated disease. To test this possibility, we examined the level of pancreatic infiltration in mice recipient of different treatment regimens. The results show that the majority of the islets in mice given BM alone displayed severe insulitis, which was comparable with the control hyperglycemic and diabetic mice (Fig. 3, B and C). In contrast, those given Ig-GAD2 alone or IgGAD2+BM had mostly no insulitis or peri-insulitis (Fig. 3, B and C). Thus, 
treatment with Ig-GAD2 alone was sufficient to suppress the immune infiltration in the pancreas, and BM transfer did not contribute to such modulatory activities. These results are intriguing because the treatment with Ig-GAD2+BM, but not IgGAD2 alone, was able the reverse diabetes. To determine how Ig-GAD2 and IgGAD2+BM eradicated pancreatic infiltration but yielded different clinical outcomes, we compared the effect of the treatments on the pancreatic $\beta$-cell mass. Indeed, while the mice treated with Ig-GAD2+BM had structured islets with abundant insulin-positive cells, those given Ig-GAD2 alone had less islets with fewer $\beta$-cells like those given BM alone (Fig. 3D). Compiled results indicate a significant increase in insulin-producing $\beta$-cells, sizeable islets, and $\beta$-cell mass in Ig-GAD2+BM-treated mice that were not evident in the animals recipient of IgGAD2 or BM alone (Fig. 3, E-G). Overall, these results suggest that that addition of BM transfer sustained increase of functional $\beta$-cells that were able to thrive under minimal inflammation curtailed by Ig-GAD2. 
A

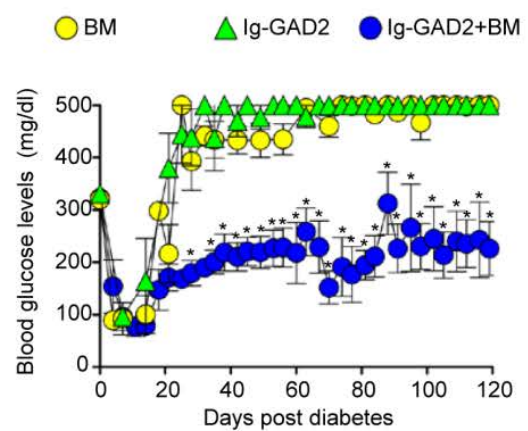

c

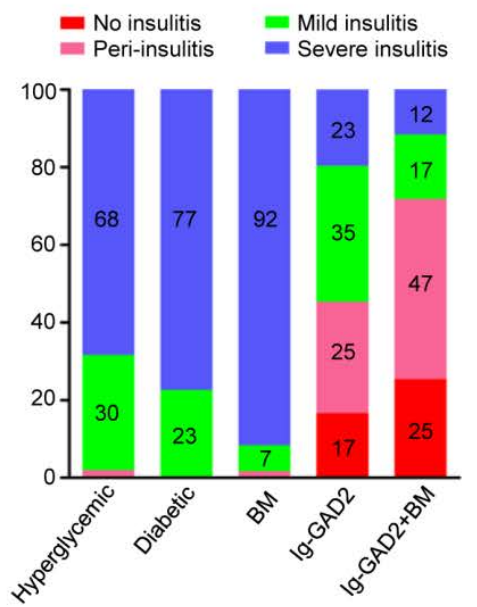

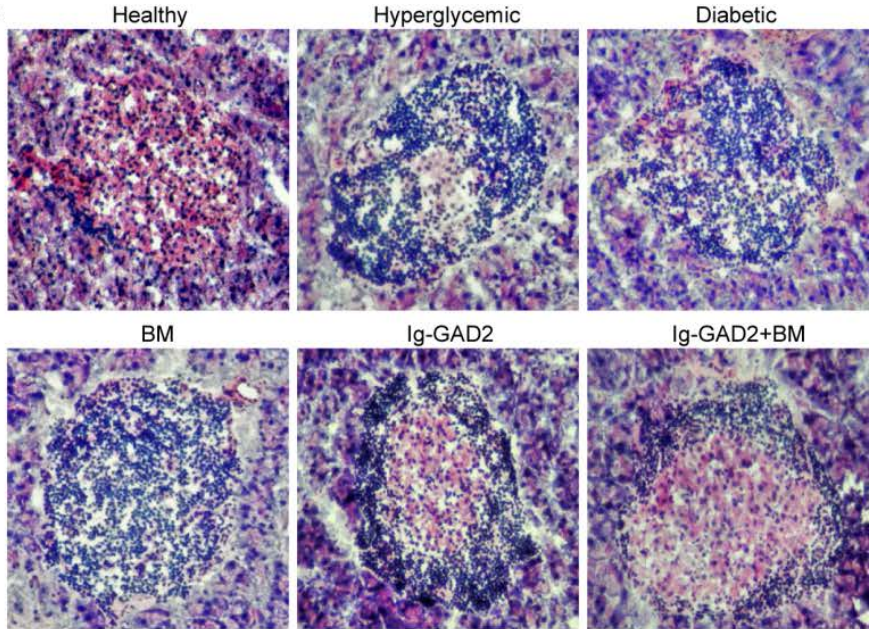

D

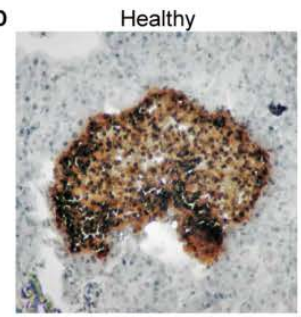

Hyperglycemic

Diabetic

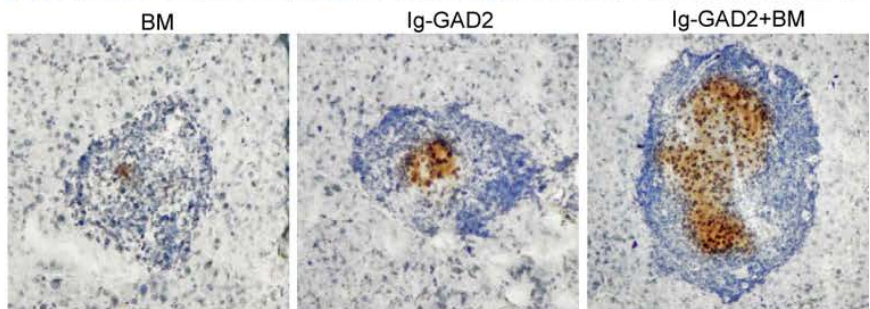

G
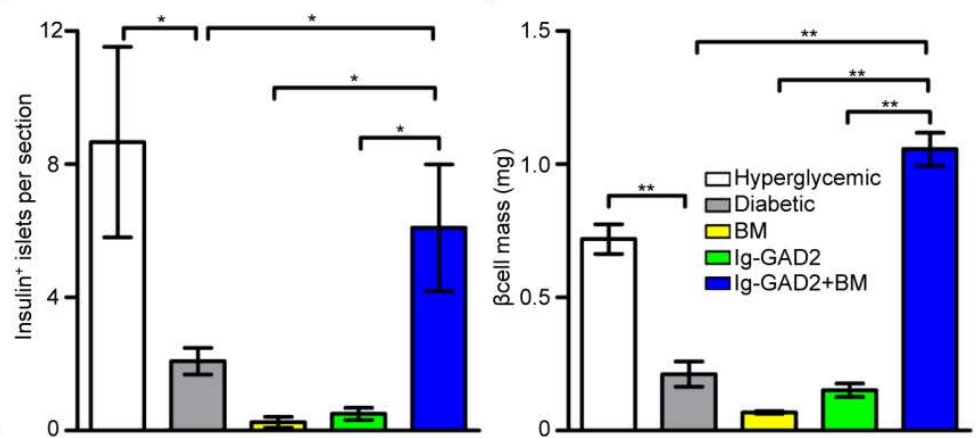

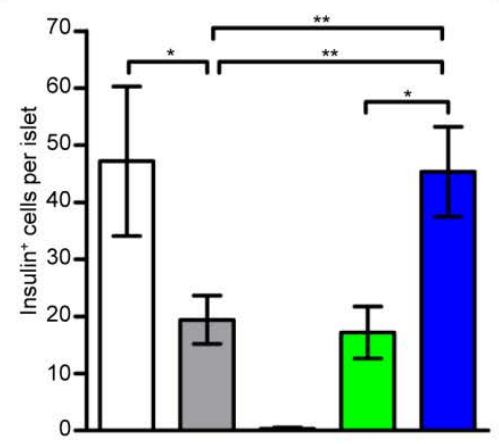

Figure. 3. Mice recipient of $B M$ transfer during treatment with Ig-GAD2 levels (BGL) in mice grafted with insulin pellets and given BM ( $n=8)$, Ig-GAD2 $(n=7)$, or Ig-GAD2 + BM (n=17). (B) Representative H\&E staining (100X) of pancreatic sections from mice recipient of BM, Ig-GAD2 or Ig-GAD2+BM 
(sacrificed on day 70) ( $n=6$ per group). Unmanipulated 4-6 week-old healthy $(B G L \leq 140 \mathrm{mg} / \mathrm{dl})$, hyperglycemic $(B G L=160 \sim 250 \mathrm{mg} / \mathrm{dl})$, and recent onset diabetic (BGL $\geq 300 \mathrm{mg} / \mathrm{dl}$ ) mice are included as control. (C) shows islet infiltration severity scores of the indicated groups. (D) shows representative immunohistochemistry staining (100X) for insulin (brown) with nuclei counterstained with hematoxylin (blue). (E) Quantification of insulin ${ }^{+}$cells per islet. (F) Number of islets that contain more than 10 insulin $^{+}$cells. (G) Mass of $\beta$ cells. Results in (E-G) are based on analysis of 10-50 islets from 3-6 non-serial sections per pancreas for 6 mice in each group. Error bars, mean \pm SEM. * $\mathrm{P}<$ $0.05,{ }^{* *} \mathrm{P}<0.01$.

\section{Donor BM-derived cells contribute to disease remission via indirect} mechanisms. The observations also raise the question as to whether the transferred BM cells serve as a supplemental source of the new $\beta$-cells. To test this premise, we used BM cells from NOD mice expressing enhanced GFP driven by the beta-actin promoter (NOD.GFP) (Wallet et al., 2009) along with IgGAD2 treatment and assessed the insulin-producing $\beta$-cells for GFP expression. Indeed, there was no GFP/insulin colocalization observed at any time point during Ig-GAD2+BM treatment (Fig. 4, left panels). Furthermore, the GFP ${ }^{+}$cells, which were abundant in the diabetes-free mice, were minimal in those animals that received the same regimen but remained diabetic (Fig. 4). Thus, the BM transfer did not appear to serve as a source of insulin-producing $\beta$-cells but yielded engraftment of $\mathrm{GFP}^{+}$cells in the islets of recovering mice. These results 
are in agreement with other reports indicating that BM cells or other cell sources failed to give rise to functional $\beta$-cells during recovery of diabetes (Choi et al., 2003; Chong et al., 2006; Hess et al., 2003; Lechner et al., 2004; Mathews et al., 2004; Nishio et al., 2006; Suri et al., 2006), suggesting that the donor $\mathrm{GFP}^{+}$cells contribute to the formation of healthy islets via indirect mechanisms. 


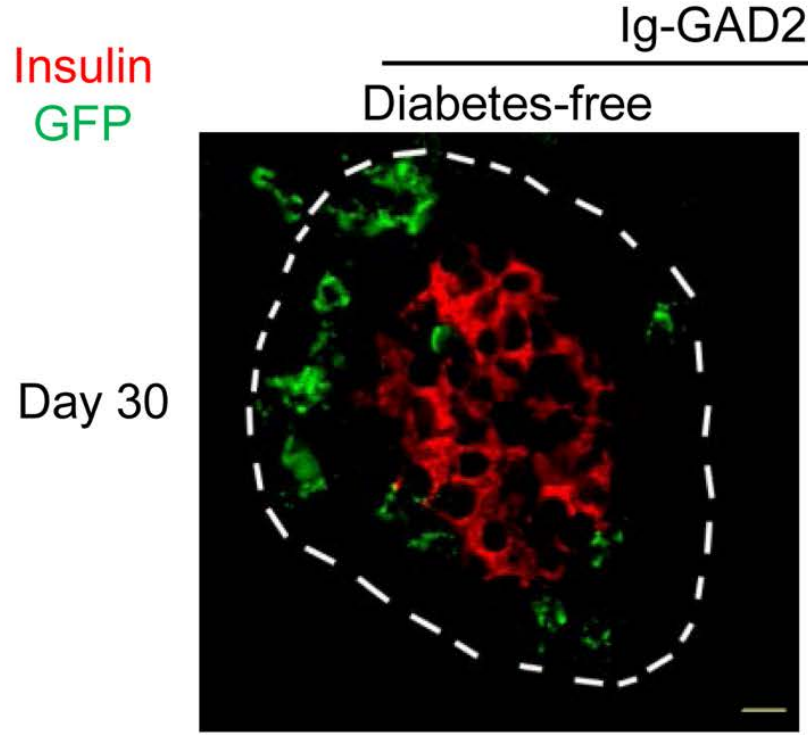

Ig-GAD2+GFP BM
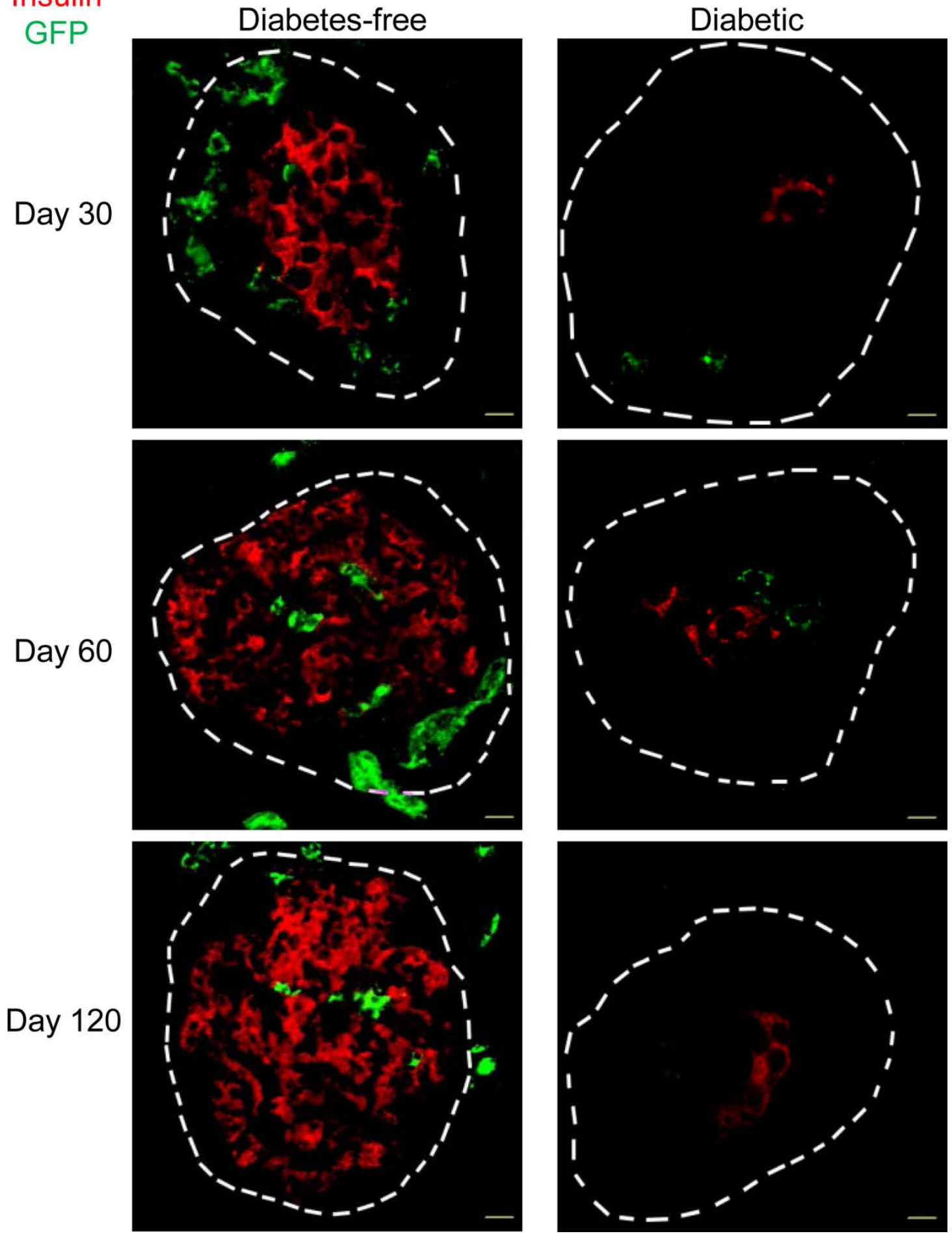

Figure 4. Insulin producing- $\beta$ cells in Ig-GAD2+BM-treated mice are not derived from donor cells. NOD mice given Ig-GAD2 and BM from NOD.GFP 
donors (Ig-GAD2+GFP BM) according to the regimen described in Figure 2 were sacrificed on day 30, 60 and 120 post treatment and pancreatic sections from 3 diabetic or 3 diabetes-free mice were stained for insulin at each time point. Data shows representative confocal microscopy visualizing insulin (red) and GFP (green). The dashed line depicts the boundary of the islet area. Scale bars are $10 \mu \mathrm{m}$.

Treatment with Ig-GAD2+BM results in concomitant restoration of both $\beta$ and endothelial cells in the islet of pancreas.

The question then is whether the GFP ${ }^{+}$engraftment represents cells that could not be provided by the host's BM but are required for maintenance of endogenous $\beta$-cells. It is known that normal islet endothelial network is essential for optimal $\beta$-cell development and function (Cleaver and Melton, 2003; Lammert et al., 2001). For example, $\beta$-cells are in direct contact with the basement membranes of endothelial cells and islet endothelium is able to stimulate $\beta$-cell proliferation by secreting several factors (Johansson et al., 2006; Kaido et al., 2004; Nikolova et al., 2006). Furthermore, the diabetic course is tightly associated with diminished numbers and impaired function of both EPCs in the bone marrow and mature ECs in the islet, leading to poor $\beta$-cell survival and maintenance (Caballero et al., 2007; Khoo et al., 2009; Loomans et al., 2004; Schatteman et al., 2000; Thum et al., 2007). In fact, in our NOD colony we detected a significant decrease in the frequency of both circulating and intra-islet $\mathrm{PECAM}^{+}$endothelial cells in diabetic mice relative to healthy or hyperglycemic 
mice (Fig. 5). These results suggest that supplementation of BM cells provided factors that may correct the dysfunction of ECs in the diabetic NOD mice and generate a suitable microenvironment for optimal regulation of $\beta$-cell functions.

A

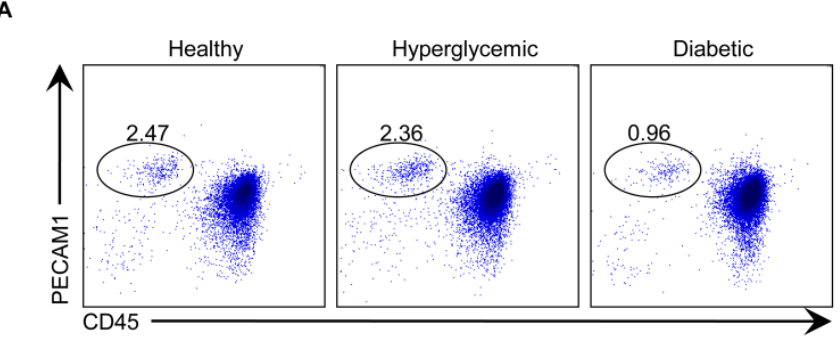

C
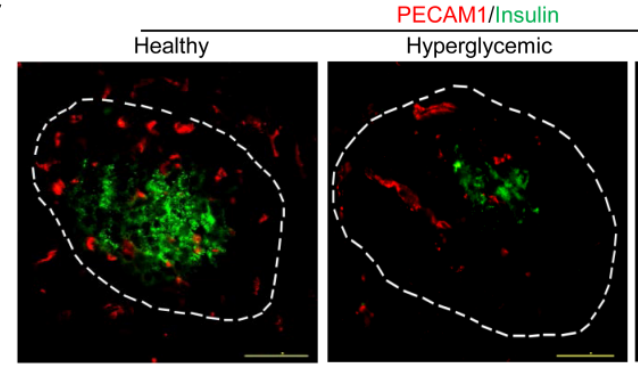

B

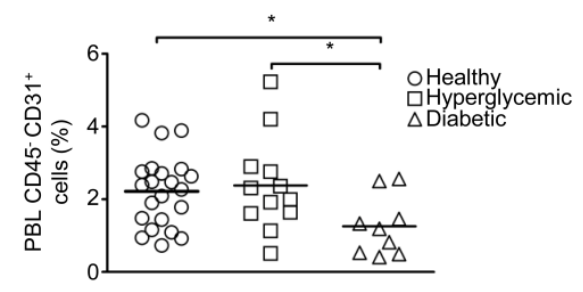

D
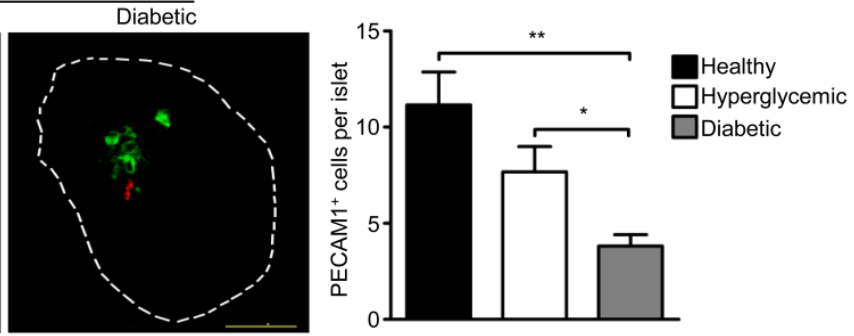

Figure 5. Decline of blood and pancreatic endothelial cells during progression to diabetes. (A-B): Peripheral blood cells from un-manipulated 4-6 week-old healthy ( $n=22), 8-14$ week-old hyperglycemic $(n=12)$ and 15-30 weekold diabetic $(n=9)$ mice were stained with anti-CD45, anti-PECAM1 and 7-AAD, and PECAM1 expression was analyzed on $7-\mathrm{AAD}^{-} \mathrm{CD} 45^{-}$gated cells. (A) shows representative FACS plots and (B) shows results of individually tested mice in each group. (C-D) Non-serial pancreatic sections from the same groups of mice were stained for insulin (green) and PECAM1 (red) and analyzed by immunofluorescence microscopy. (C) shows a representative staining within the 
boundary of an islet area. Scale bars are $50 \mu \mathrm{m}$. (D) shows the number of $\mathrm{PECAM}^{+}$cells per islet. This was determined by nuclear counterstaining with DAPI. At least 40 islets from 3-6 non-serial sections per mouse were analyzed. Each bar represents mean \pm SEM of 5 mice per group. ${ }^{*} \mathrm{P}<0.05,{ }^{*} \mathrm{P}<0.01$.

To investigate the effects of the Ig-GAD2+BM treatment on islet ECs, we measured the amount of these cells in mice of each treatment group. The results show that there was a concomitant restoration of insulin $^{+}$and PECAM1 ${ }^{+}$ECs in the islets of mice recipient of Ig-GAD2+BM but not in those given Ig-GAD2 or BM alone (Fig. 6A). Moreover, the recovering but not the untreated diabetic mice had a significant increase in the expression of genes encoding VE-cadherin (Cdh5), angiopoietin receptor (Tie1) and VEGF receptor 1 (Flt1) (Fig. 6B), which represent functional markers for ECs. These results indicate that during treatment with Ig-GAD2, the transfer of BM cells triggered angiogenic activities. This is supported by the detection of a strong up-regulation of genes encoding angiogenic factors, including VEGFa (vegfa), angiopoietin 1 (angpt1), and angiopoietin 2 (angpt2) in the diabetes-free mice treated by Ig-GAD2+BM (Fig. 7A). Furthermore, the newly-formed $\beta$-cells produced VEGFa (Fig. 7B), which is critical for development of ECs and islet vascularization (Brissova et al., 2006; Lammert et al., 2003). The symbiotic relationship among endothelial and $\beta$ cells is further evidenced by the parallel restoration of $\beta$-cell division in the IgGAD2+BM cell transfer mice (Fig. 6C). Indeed, the $\beta$-cells displayed significant staining for the proliferation marker ki-67 when compared to resting $\beta$-cells in normal mice or to residual $\beta$-cells in untreated diabetic mice (Fig. 6C). Taken 
together, these results suggest that BM transfer during treatment with Ig-GAD2 re-established the functional endothelial network in the islet that ensured efficient regeneration of $\beta$-cells, and the newly-formed $\beta$-cells were able to produce the vital angiogenic factor VEGFa, which could further enhance the symbiotic relationship between the two cell types.
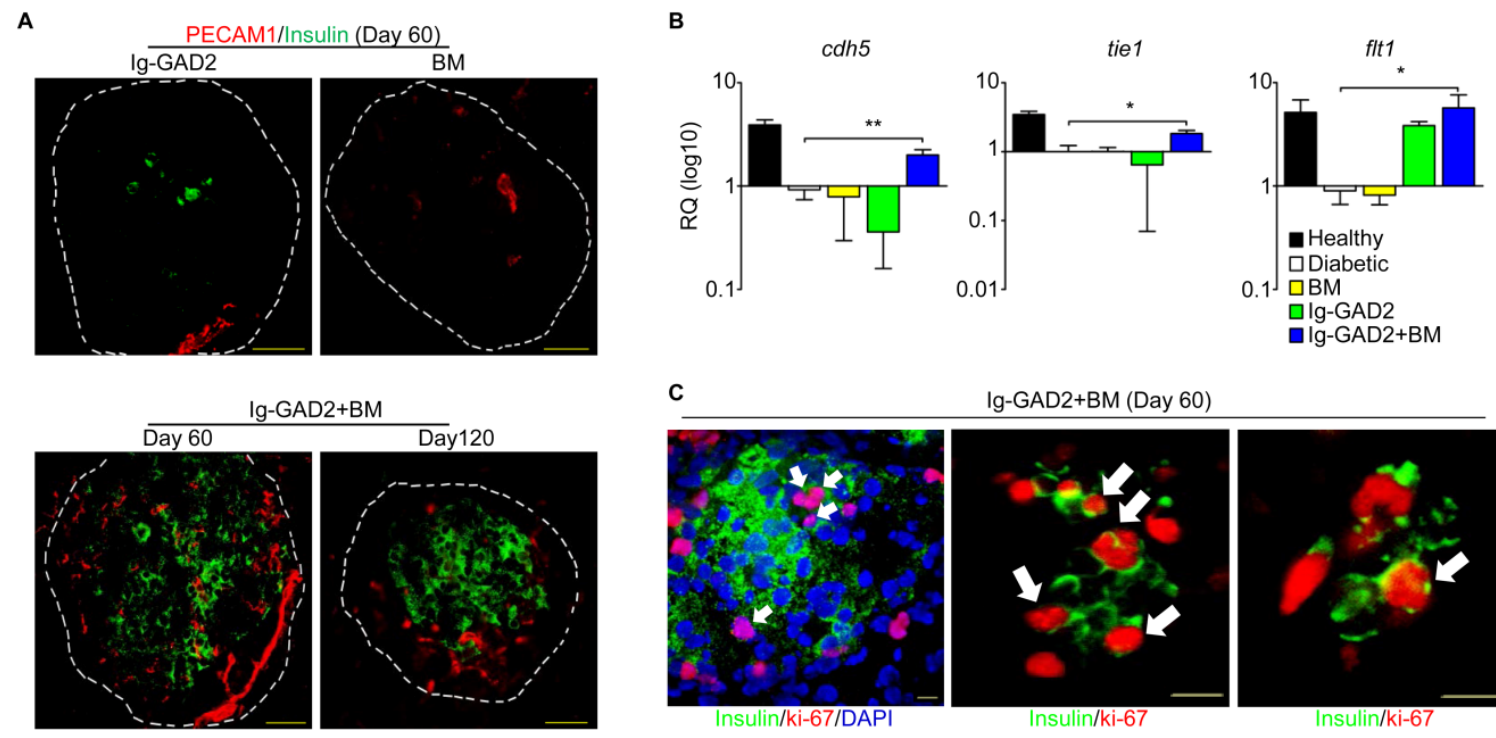

C

Ig-GAD2+BM (Day 60)
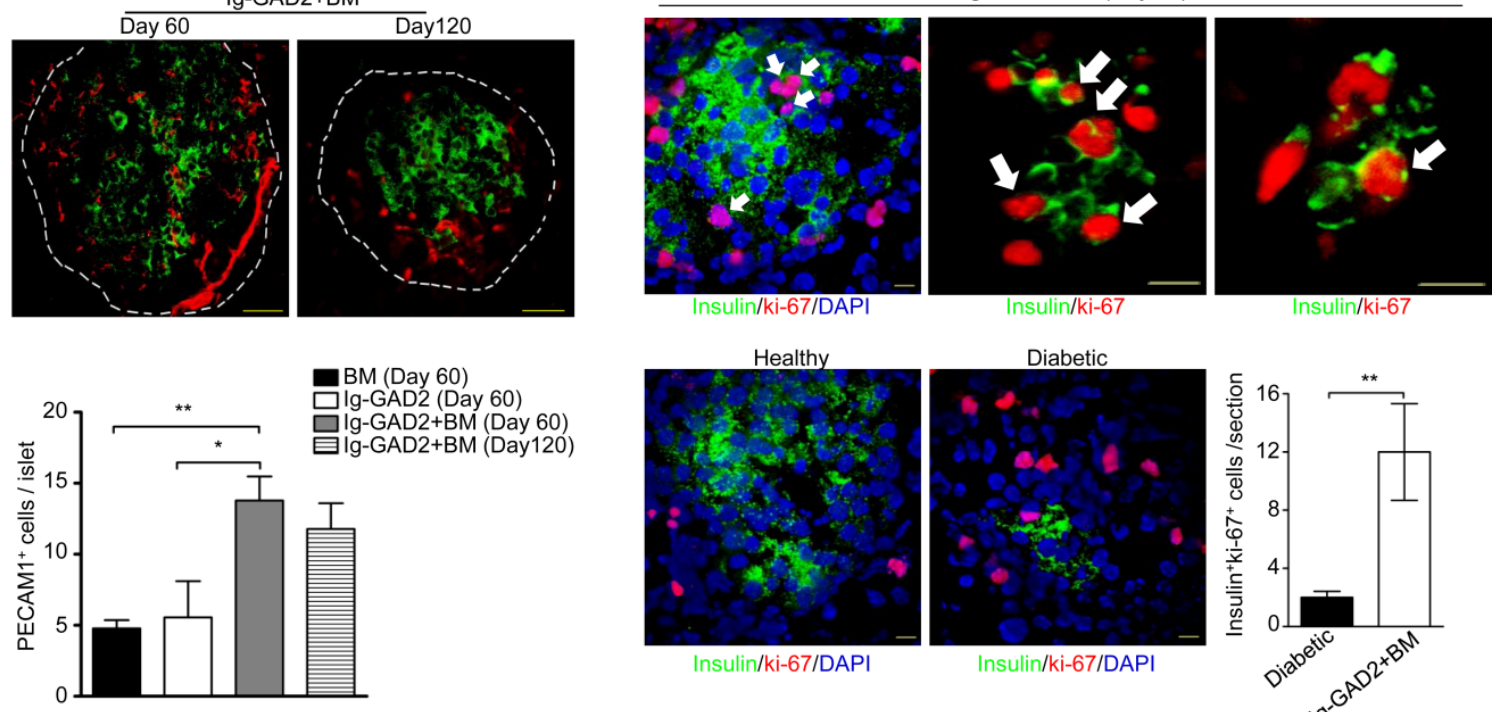

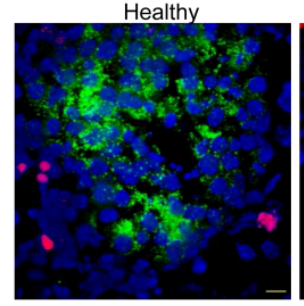

Insulin/ki-67/DAPI

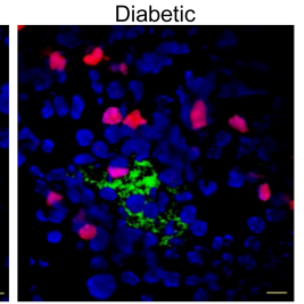

Insulin/ki-67/DAPI

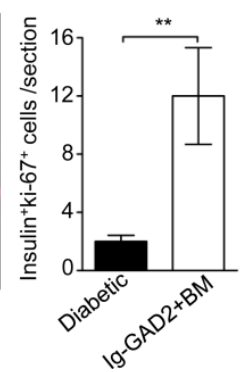

Figure 6. Restoration of endothelial cells parallels with $\beta$-cell regeneration.

(A) shows fluorescence microscopy images of PECAM1 (red) and insulin (green) immunostaining of pancreatic sections from mice given Ig-GAD2, BM or IgGAD2+BM. Islet boundary is depicted by dashed lines. Scale bars are $50 \mu \mathrm{m}$. The bar graph represents quantification of PECAM1 ${ }^{+}$cells per islet $(5$ mice per 
group). 10-30 islets from 3-6 non-serial sections per mouse were examined. (B) Quantitative PCR analysis for cdh5, tie 1 and flt1 expression in pancreatic islets of the mice described in (A) as well as untreated healthy and diabetic controls (4-8 mice per group). (C) shows confocal microscopy images of insulin (green) and ki67 (red) staining of pancreatic sections from Ig-GAD2+BM treated mice (day 60 of treatment), healthy (untreated 4-6 week-old) and diabetic (day 1 of diagnosis) mice. The arrows depict insulin ${ }^{+} k i-67^{+}$cells. Scale bars are $10 \mu \mathrm{m}$. The bar graph represents the number of insulin ${ }^{+} \mathrm{ki}-67^{+}$cells per section. 30-40 non-serial sections from 6 mice per group were analyzed. The bars in the panels represent the mean \pm SEM. ${ }^{*} \mathrm{P}<0.05,{ }^{* *} \mathrm{P}<0.01$. 
A

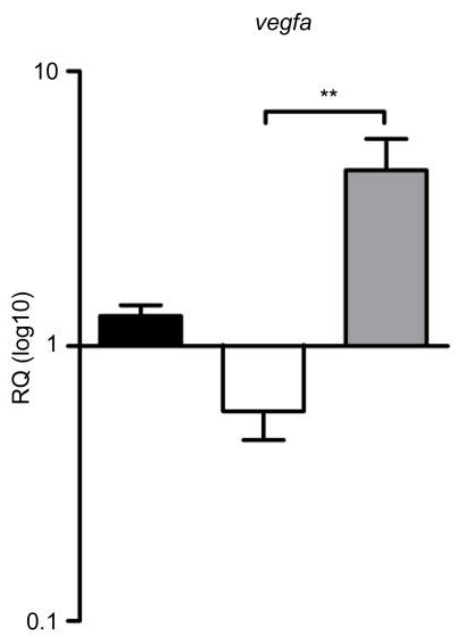

B

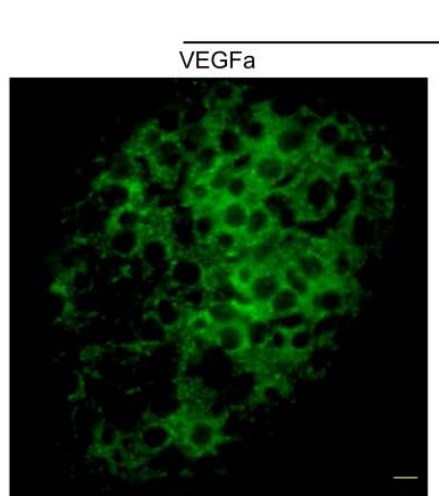

angpt1

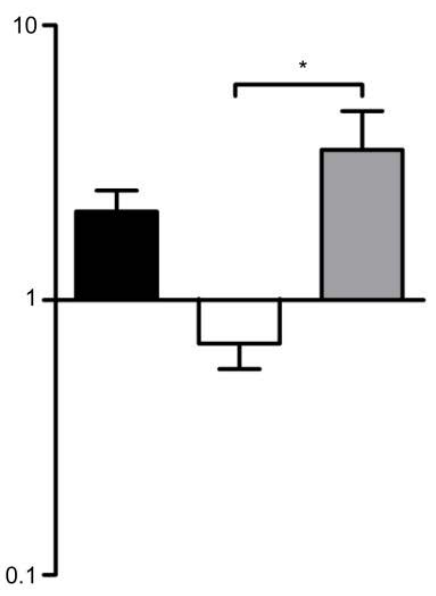

Ig-GAD2+BM

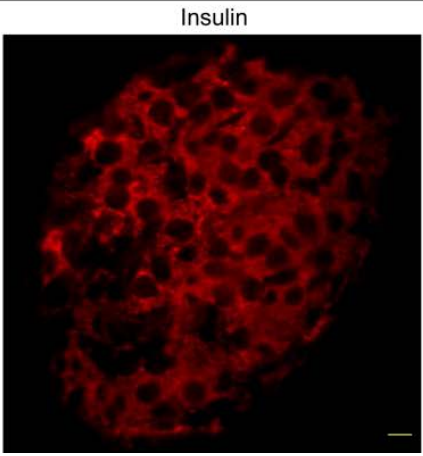

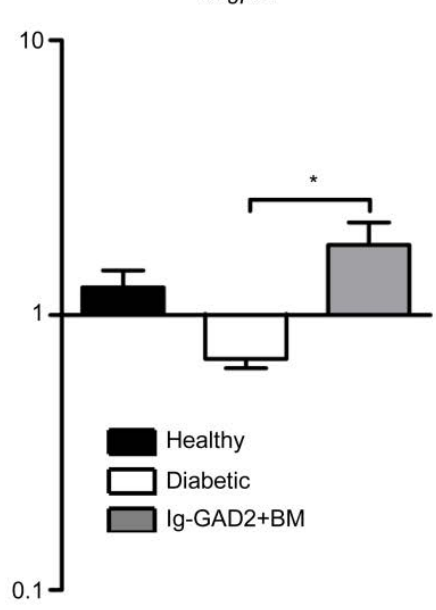

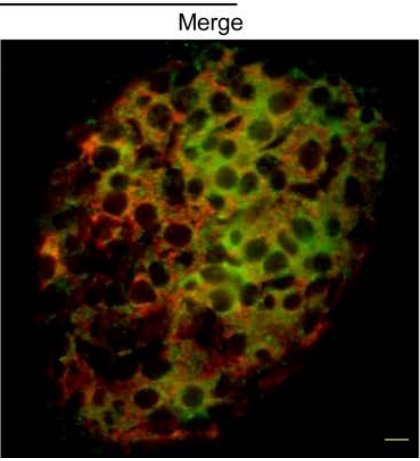

Figure 7. Enhanced production of angiogenic factors during restoration of normoglycemia. (A) Diabetic mice were given Ig-GAD2+BM treatment regimen and RNA was extracted from their pancreata on day 60 and used to analyze expression of vegfa, angpt1 and angpt 2. RNA from the pancreata of healthy and diabetic mice was included for control purposes. Each bar represents relative fold change of gene expression (mean \pm SEM) analyzed by quantitative PCR in 5 mice per experimental group. (B) shows representative confocal microscopy visualizing VEGFa (green) and insulin (red) in pancreatic sections from IgGAD2+BM-treated mice (sacrificed on day $60, n=3$ ). At least 30 islets from 3-4 
non-serial sections per mouse were analyzed. The scale bars are $10 \mu \mathrm{m} .{ }^{*} \mathrm{P}<$ $0.05,{ }^{*} \mathrm{P}<0.01$

\section{Donor BM gave rise to islet endothelial cells.}

To determine whether the ECs in the islets originate from the donor BM, we examined the GFP ${ }^{+}$cells for expression of PECAM1. Indeed, in the diabetes-free mice there were $\mathrm{GFP}^{+}$cells in the islets that expressed PECAM1 as indicated by the colocalization of the two markers at both day 30 and 60 of treatment (Fig. 8A). Such colocalization was not observed in mice recipient of the same regimen but remained diabetic. These observations are supported by the detection of $Y$ chromosome in the endothelial but not $\beta$ cells when BM cells were transferred from male donors. Indeed, Y chromosome was detectable when the DNA was extracted from bulk pancreatic cells in mice recipient of Ig-GAD2+BM (Fig. 8B). More specifically, when PECAM1 ${ }^{+}$and insulin ${ }^{+}$cells were micro-dissected using a laser-capture system (Fig. 9) and their genomic DNA was analyzed by PCR, Y chromosome was readily detecable in $\mathrm{PECAM1}^{+}$but not insulin ${ }^{+}$cells and this was restricted to diabetes-free mice given Ig-GAD2+BM (Fig. 8, C and D). These results indicate that donor BM gives rise to endothelial cells that are required for recovery from diabetes. 


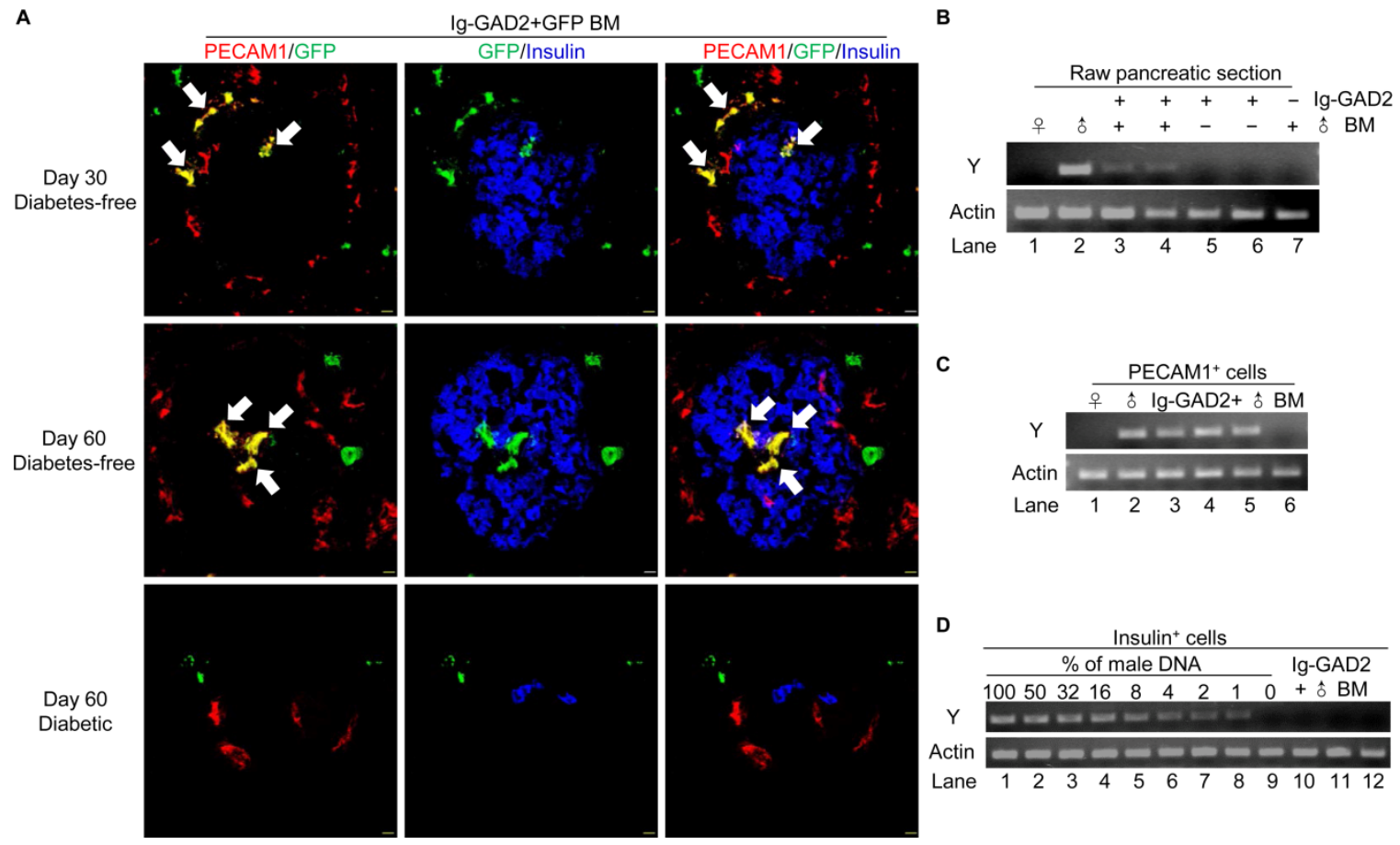

Figure 8. Donor bone marrow gives rise to pancreatic endothelial cells during suppression of diabetes. (A) shows confocal microscopy images for insulin (blue), PECAM1 (red) and GFP (green) from mice given Ig-GAD2 plus NOD.GFP BM (5 mice per time point). The arrows indicate co-localization of

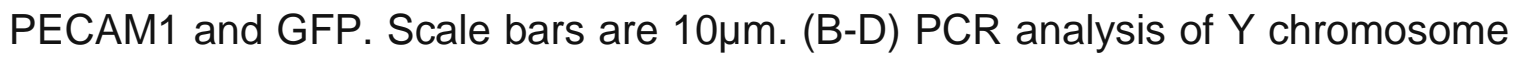
(Y) using genomic DNA extracted from raw pancreatic sections (B), microdissected $\mathrm{PECAM}^{+}(\mathrm{C})$ or insulin ${ }^{+}$cells (D) of mice given Ig-GAD2+male BM (sacrificed on day 60 post treatment). DNA extracted from unmanipulated male $(\lesssim)$ and female $(\uparrow)$ mice was included for control purposes. In (C) lane 6 represents DNA from a Ig-GAD2 + male BM-treated mouse that did not recover from diabetes. In (D) lanes 1-9 represent the percentage of male DNA diluted with female DNA. Lanes 10-12 represent DNA from three individual diabetes-free mice given Ig-GAD2 + male BM. 

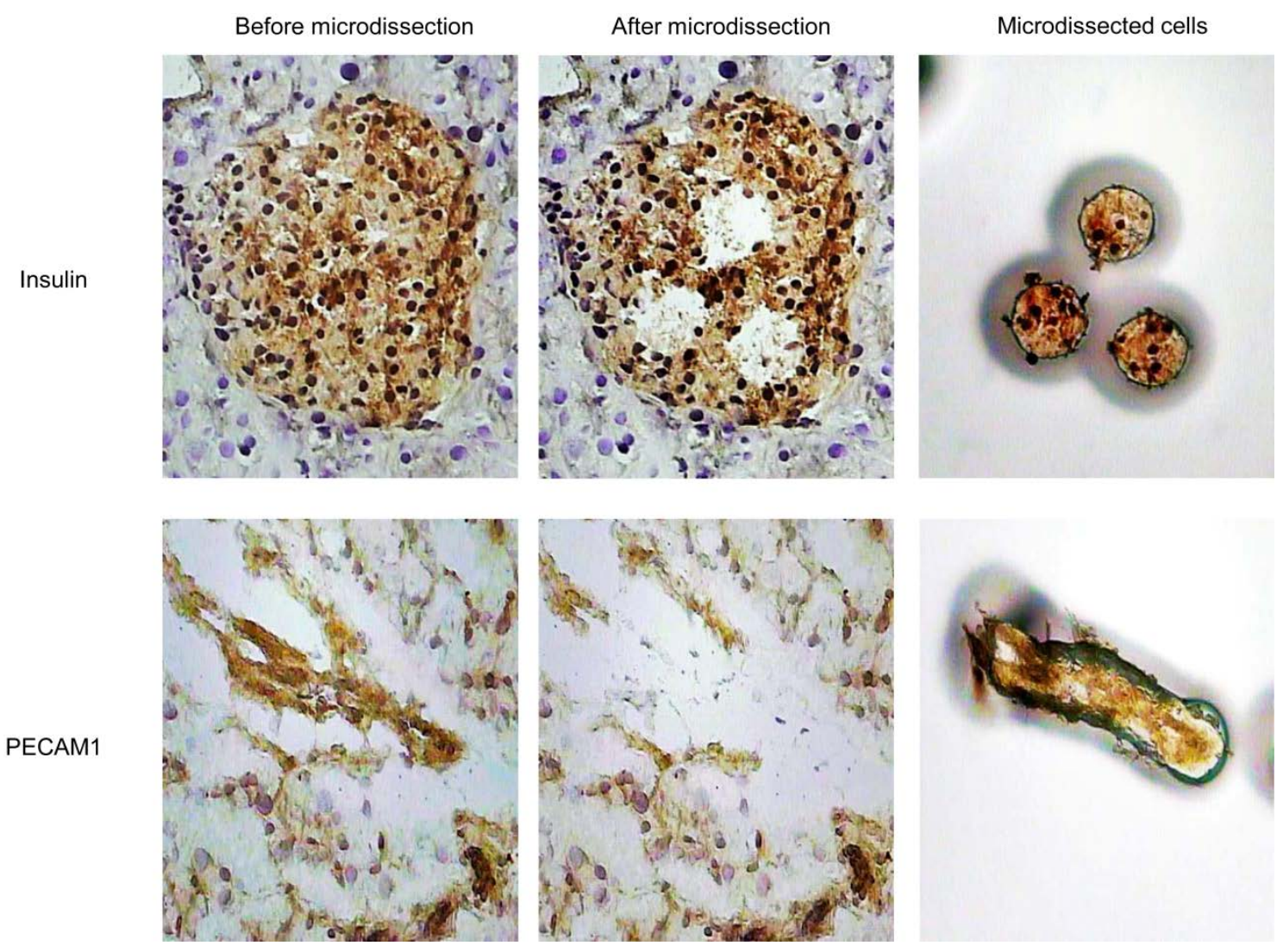

Figure 9. Microdissection of insulin ${ }^{+}$or $\mathrm{PECAM1}^{+}$cells. Pancreatic sections were stained for either insulin or PECAM1 (brown) and the cell nuclei were counterstained with hematoxylin (blue). Data shows representative light microscopy depicting the cell capture area before and after the procedure. The microdissected cells were then used for extraction of genomic DNA and PCR analysis.

\section{Transfer of purified BM EPCs sustained reversal of T1D during treatment with Ig-GAD2.}

The fact that EPCs are diminished in mouse and human diabetic subjects suggests that BM transfer during treatment with Ig-GAD2 serves as a source of 
enrichment with EPCs. To test this premise, we first determined the frequency of EPCs in our NOD colony and found that the BM lineage-negative ( $\operatorname{Lin}^{-}$) population expressing the EPC markers c-Kit (Dentelli et al., 2007) and FLK1(Peichev et al., 2000; Reyes et al., 2002) was significantly reduced in the diabetic versus age-matched healthy mice (Fig. 10, A and B). The Lin $^{-}{ }^{-}-K_{i t}{ }^{+}$FLK$1^{+}$population in healthy mice also expressed CD34 and AC133 (data not shown), further indicating their EPC phenotype (Peichev et al., 2000). We then sorted these EPCs from BM of healthy NOD.GFP mice and evaluated whether these cells can substitute whole BM for reversal of T1D. Importantly, when sorted $\mathrm{GFP}^{+} \mathrm{Lin}^{-} \mathrm{c}-\mathrm{Kit}{ }^{+} \mathrm{FLK}-1^{+}\left(\mathrm{hFLK}-1^{+}\right)$cells from healthy donors replaced whole BM transfer during treatment with Ig-GAD2, most of the mice recovered from the disease while the control group given $\mathrm{Lin}^{-} \mathrm{c}-\mathrm{Kit}^{+} \mathrm{FLK}-1^{-}$(hFLK-1 ${ }^{-}$) cells had a much lower recovery rate despite receiving a 60-times higher cell number (Fig. 10C). In addition, no significant recovery from disease was observed when the FLK $-1^{+}$cells were transferred without Ig-GAD2 (Fig. 10C). Because EPCs in diabetic subjects also displayed impaired ability to differentiate into functional endothelial cells, we next sought to determine whether enrichment of EPCs from diabetic donors would sustain the reversal of T1D during Ig-GAD2 treatment. Indeed, when sorted FLK $-1^{+}$cells from diabetic NOD.GFP mice $\left(\mathrm{sFLK}-1^{+}\right)$were transferred along with Ig-GAD2 treatment, there was minimal recovery of the disease (Fig. 10C). Collectively, these results suggest that enrichment of functional EPCs is essential for reversal of T1D during antigen-specific tolerance. Furthermore, GFP/PECAM1 colocalization was only detected in the islets of mice 
given Ig-GAD2 and $\mathrm{hFLK}-1^{+}$cells (Fig. 10D). The mice that did not recover from diabetes under the Ig-GAD2+hFLK-1 ${ }^{-}$or $\lg -\mathrm{GAD} 2+\mathrm{SFLK}-1^{+}$regimen had very few $\mathrm{GFP}^{+}$and $\mathrm{PECAM}^{+}$cells with no evident colocalization similar to the mice recipient of $\mathrm{hFLK}-1^{+}$cells without Ig-GAD2 (Fig. 10D). These results indicate that EPCs can substitute for BM transfer and give rise to mature ECs that help $\beta$-cells thrive and restore normoglycemia. Furthermore, maturation of the EPCs and increase in ECs occurs only when EPCs originate from healthy donors, which explains the inability of diabetic mice to utilize their own EPCs for repair of the pancreatic endothelial network.
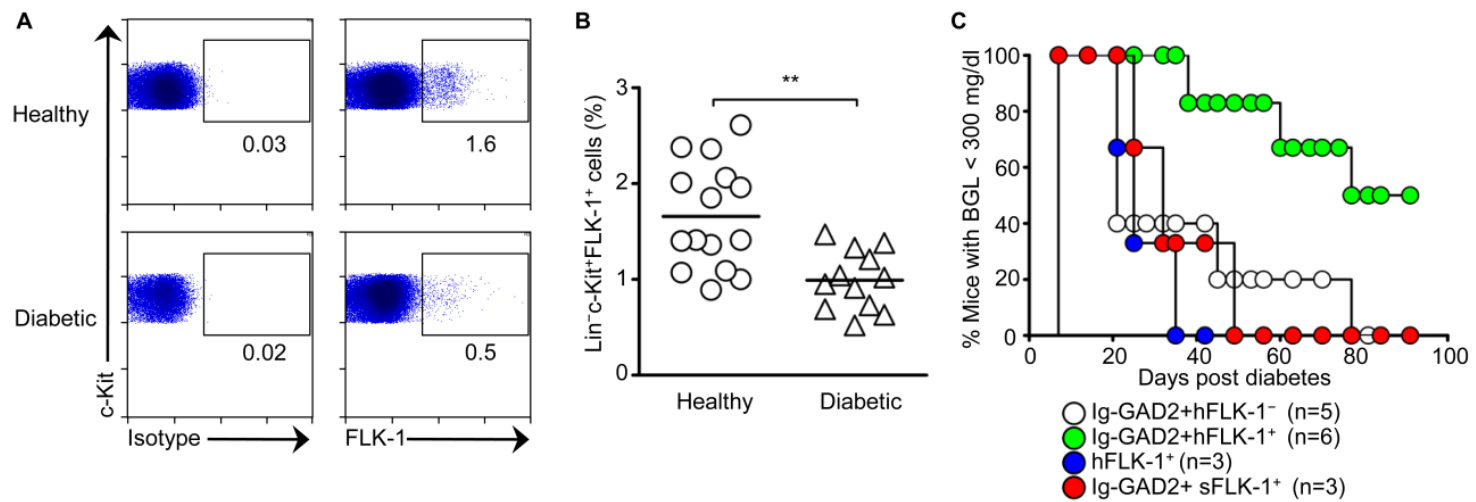

D

PECAM1/GFP/Insulin

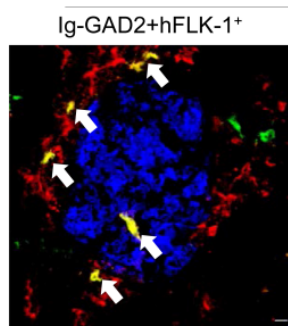
Ig-GAD2+hFLK-1 ${ }^{-}$

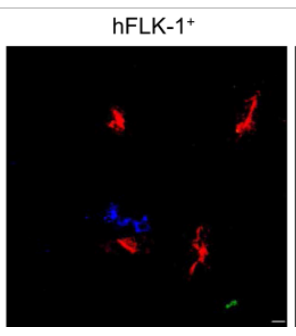
Ig-GAD2+s FLK-1 ${ }^{+}$
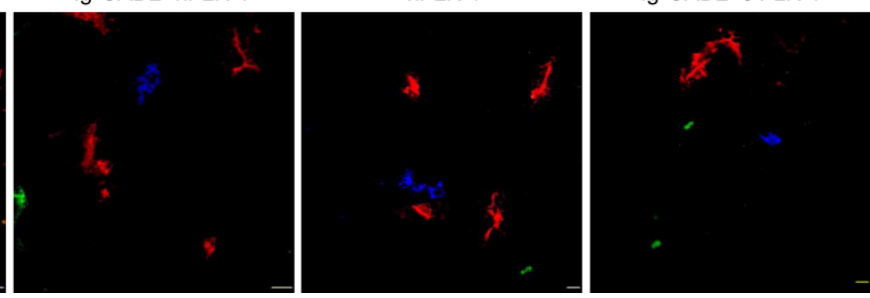

Figure 10. Transfer of endothelial cell progenitors during treatment with IgGAD2 sustains $\beta$ cell regeneration and restores normoglycemia. (A) shows representative FACS plots depicting FLK-1 expression on Lin $^{-} \mathrm{C}-\mathrm{Kit}^{+} 7-\mathrm{AAD}^{-} \mathrm{BM}$ 
cells from age-matched healthy and diabetic mice. (B) shows FLK-1 expression on Lin $^{-}{ }^{-}-\mathrm{Kit}^{+} 7-\mathrm{AAD}^{-} \mathrm{BM}$ cells of individually tested mice described in (A). (C-D) FACS-sorted Lin $^{-} \mathrm{C}-\mathrm{Kit}^{+} \mathrm{FLK}-1^{+}\left(\mathrm{FLK}-1^{+}\right)$or $\mathrm{Lin}^{-} \mathrm{C}-\mathrm{Kit}^{+} \mathrm{FLK}-1^{-}\left(\mathrm{FLK}-1^{-}\right)$BM cells from healthy $\left(\mathrm{hFLK}-1^{+}\right)$or diabetic $\left(\mathrm{sFLK}-1^{+}\right)$NOD.GFP donors were used with or without Ig-GAD2 for treatment of diabetic NOD mice. Some of the mice were monitored for diabetes for 100 days (C), and others (D) were sacrificed on day 60 post treatment and used for visualizing insulin (blue), PECAM1 (red) and GFP by confocal microscopy (at least 20 sections per group). The arrows indicate colocalization of PECAM1 and GFP. Scale bars are $10 \mu \mathrm{m} .{ }^{* *} \mathrm{P}<0.01$. 


\section{DISCUSSION}

Recent advances have shown that treatment with anti-CD3 antibody can reverse overt diabetes (Chatenoud and Bluestone, 2007; Waldron-Lynch and Herold, 2011). However, because of potential interference with the function of the immune system, open-ended treatment regimens are undesirable (Luo et al., 2010). In this context, antigen-specific approaches (Agardh et al., 2005; Gregg et al., 2005; Gregg et al., 2004; Michels and von Herrath, 2011; Tian et al., 1996; Tisch et al., 1998) which target autoreactive T cells and circumvent interference with immunity provide an alternative that could be effective against the disease. We and others have tested cell or protein-based antigen-specific regimens at advanced stages of the disease and promising outcomes were observed (Jain et al., 2008; Li et al., 2009; Tang et al., 2004). In fact, Ig-GAD2 was able to trigger $\beta$-cell regeneration which prevented progress to overt diabetes (Jain et al., 2008). The present study was designed to test Ig-GAD2 for efficacy against overt T1D. However, despite the induction of an immune modulation similar to the hyperglycemic stage, the regimen was not able to trigger $\beta$-cell regeneration or overcome overt T1D. Given that $\beta$-cells are able to self renew (Dor et al., 2004) we thought that either the differentiation of stem cell progenitors into insulinproducing $\beta$-cells is defective at this stage of the disease or there was minimal residual $\beta$-cells to support division and formation of sufficient $\beta$-cell mass. Although the use of BM as a source of $\beta$ cell progenitors is debatable (Choi et al., 2003; Hess et al., 2003; lanus et al., 2003; Lechner et al., 2004; Mathews et al., 2004), repair of injured islet was feasible by BM transplantation (Hess et al., 
2003; Mathews et al., 2004). Thus, we supplemented Ig-GAD2 treatment with BM transfer and found that recovery from disease is attainable. This was intriguing and prompted us to determine the mechanism underlying restoration of normoglycemia. Interestingly, the islets had increased $\beta$-cell mass but the proliferating insulin-producing cells were of endogenous origin rather than donor BM-derived cells. Surprisingly, alongside the newly formed $\beta$-cells there was engraftment of donor BM-derived cells that did not produce insulin or colocalize with the $\beta$ cells.

It has previously been shown in human patients with recent onset of T1D that the number of EPCs is significantly reduced in the peripheral blood compared with sex-matched healthy control subjects (Loomans et al., 2004; Schatteman et al., 2000). More importantly, EPCs in these patients displayed impaired migratory capacity (Thum et al., 2007) and damage repair potential (Caballero et al., 2007), and failed to differentiate into functional vasculatures (Loomans et al., 2004; Schatteman et al., 2000). Given that our NOD mice displayed diminished frequency of EPCs at the onset of diabetes as was observed by others (Khoo et al., 2009; Schatteman et al., 2000), we suspected that the engrafted donor BMderived cells represent mature ECs. This was indeed the case as the BM-derived GFP cells present in the islets of treated diabetes-free mice expressed the EC marker PECAM1. Moreover, PECAM1 expression tightly colocalized with donor GFP but not with newly formed endogenous $\beta$-cells. Since recovery from diabetes occurred only when the treatment is accompanied with BM transfer it is likely that repair of the islet vascular system was required to maintain symbiosis 
among $\beta$ and ECs (Brissova et al., 2006; Cleaver and Melton, 2003; Guney et al., 2011; Johansson et al., 2006; Kaido et al., 2004; Lammert et al., 2001; Nikolova et al., 2006). This could explain the unexpected engraftment of donor BM-derived endothelial cells in the pancreas of STZ mouse models of experimental diabetes (Hess et al., 2003; Mathews et al., 2004) especially since the animals have undergone irradiation prior to BM transplantation which destroys endogenous stem cell precursors. The fact that $\beta$-cells produced VEGFa and the angiogenic activity in the pancreas became evident, it is likely that repair of the islet vascular niche is required for $\beta$-cells to thrive and for insulin delivery into the circulation. Along this line of reasoning we substituted whole BM with EPCs ( Lin $^{-} \mathrm{C}-\mathrm{Kit}^{+} \mathrm{FLK}-$ $1^{+}$) during treatment with Ig-GAD2 and observed formation of donor-derived ECs alongside the generation of endogenous $\beta$-cells in the diabetes-free mice. Again, this suggests that under tight control of the immune inflammatory process, the symbiotic relationship between $\beta$ and ECs ensues and both types of cells contribute to the makeup of an environment suitable for formation of $\beta$-cells, maturation of ECs, and maintenance of healthy islets. Studies with anti-CD3 antibody indicated that despite control of the inflammatory process $\beta$-cell proliferation/regeneration was minimal or at a very slow rate (Ablamunits et al., 2007; Phillips et al., 2007; Takiishi et al., 2012) with evident re-granulation of residual insulin-negative $\beta$ cells (Ablamunits et al., 2007). However, when eradication of inflammation was accompanied with exogenous epidermal growth factor (EGF), $\beta$ cell neogenesis and proliferation ensued and sustained reversal of overt T1D (Wang et al., 2012). The findings in our study suggest that the low 
frequency of EPC and the defective function of residual pancreatic endothelial network in diabetics compromise not only the generation of new $\beta$-cells but also the restoration of optimal function, hence the return of disease observed in human trials upon termination of anti-CD3 antibody treatment (Herold et al., 2005; Herold et al., 2002). In summary, antigen-specific therapy and supplementation with EPCs may overcome the limitation associated with longterm antibody administration and the repair of the islet endothelial niche. Whether effective control of immune inflammation by multiple Ig chimeras and diverse mechanisms (Gregg et al., 2005; Gregg et al., 2004; Jain et al., 2008; Tartar et al., 2010; Wan et al., 2012) upon early diagnosis of disease would overcome the need for stem cell enrichment remains to be determined. 


\section{ACKNOWLEDGEMENTS}

We thank R. Tisch for providing NOD.GFP mice. The study was supported by grants R56AI095235 and R01DK093515 from NIH and by the J. Lavenia Edwards endowment. 


\section{REFERENCES}

Ablamunits, V., N.A. Sherry, J.A. Kushner, and K.C. Herold. 2007. Autoimmunity and beta cell regeneration in mouse and human type 1 diabetes: the peace is not enough. Ann N Y Acad Sci 1103:19-32.

Agardh, C.D., C.M. Cilio, A. Lethagen, K. Lynch, R.D. Leslie, M. Palmer, R.A. Harris, J.A. Robertson, and A. Lernmark. 2005. Clinical evidence for the safety of GAD65 immunomodulation in adult-onset autoimmune diabetes. Journal of diabetes and its complications 19:238-246.

Atkinson, M.A., and G.S. Eisenbarth. 2001. Type 1 diabetes: new perspectives on disease pathogenesis and treatment. Lancet 358:221-229.

Belghith, M., J.A. Bluestone, S. Barriot, J. Megret, J.F. Bach, and L. Chatenoud. 2003. TGF-beta-dependent mechanisms mediate restoration of selftolerance induced by antibodies to CD3 in overt autoimmune diabetes. Nat Med 9:1202-1208.

Bluestone, J.A., K. Herold, and G. Eisenbarth. 2010. Genetics, pathogenesis and clinical interventions in type 1 diabetes. Nature 464:1293-1300.

Brennand, K., D. Huangfu, and D. Melton. 2007. All beta cells contribute equally to islet growth and maintenance. PLoS biology 5:e163.

Brissova, M., A. Shostak, M. Shiota, P.O. Wiebe, G. Poffenberger, J. Kantz, Z. Chen, C. Carr, W.G. Jerome, J. Chen, H.S. Baldwin, W. Nicholson, D.M. Bader, T. Jetton, M. Gannon, and A.C. Powers. 2006. Pancreatic islet production of vascular endothelial growth factor--a is essential for islet vascularization, revascularization, and function. Diabetes 55:2974-2985.

Caballero, S., N. Sengupta, A. Afzal, K.H. Chang, S. Li Calzi, D.L. Guberski, T.S. Kern, and M.B. Grant. 2007. Ischemic vascular damage can be repaired by healthy, but not diabetic, endothelial progenitor cells. Diabetes 56:960967.

Chao, C.C., H.K. Sytwu, E.L. Chen, J. Toma, and H.O. McDevitt. 1999. The role of MHC class II molecules in susceptibility to type I diabetes: identification of peptide epitopes and characterization of the T cell repertoire. Proc Natl Acad Sci U S A 96:9299-9304.

Chatenoud, L., and J.A. Bluestone. 2007. CD3-specific antibodies: a portal to the treatment of autoimmunity. Nat Rev Immunol 7:622-632. 
Chen, C., W.H. Lee, P. Yun, P. Snow, and C.P. Liu. 2003. Induction of autoantigen-specific Th2 and Tr1 regulatory T cells and modulation of autoimmune diabetes. J Immunol 171:733-744.

Choi, J.B., H. Uchino, K. Azuma, N. Iwashita, Y. Tanaka, H. Mochizuki, M. Migita, T. Shimada, R. Kawamori, and H. Watada. 2003. Little evidence of transdifferentiation of bone marrow-derived cells into pancreatic beta cells. Diabetologia 46:1366-1374.

Chong, A.S., J. Shen, J. Tao, D. Yin, A. Kuznetsov, M. Hara, and L.H. Philipson. 2006. Reversal of diabetes in non-obese diabetic mice without spleen cellderived beta cell regeneration. Science 311:1774-1775.

Cleaver, O., and D.A. Melton. 2003. Endothelial signaling during development. Nat Med 9:661-668.

Dentelli, P., A. Rosso, A. Balsamo, S. Colmenares Benedetto, A. Zeoli, M. Pegoraro, G. Camussi, L. Pegoraro, and M.F. Brizzi. 2007. C-KIT, by interacting with the membrane-bound ligand, recruits endothelial progenitor cells to inflamed endothelium. Blood 109:4264-4271.

Dor, Y., J. Brown, O.I. Martinez, and D.A. Melton. 2004. Adult pancreatic betacells are formed by self-duplication rather than stem-cell differentiation. Nature 429:41-46.

Ellis, T.M., and M.A. Atkinson. 1996. The clinical significance of an autoimmune response against glutamic acid decarboxylase. Nat Med 2:148-153.

Gregg, R.K., J.J. Bell, H.H. Lee, R. Jain, S.J. Schoenleber, R. Divekar, and H. Zaghouani. 2005. IL-10 diminishes CTLA-4 expression on islet-resident T cells and sustains their activation rather than tolerance. $\mathrm{J}$ Immunol 174:662-670.

Gregg, R.K., R. Jain, S.J. Schoenleber, R. Divekar, J.J. Bell, H.H. Lee, P. Yu, and $\mathrm{H}$. Zaghouani. 2004. A sudden decline in active membrane-bound TGF-beta impairs both $T$ regulatory cell function and protection against autoimmune diabetes. J Immunol 173:7308-7316.

Guney, M.A., C.P. Petersen, A. Boustani, M.R. Duncan, U. Gunasekaran, R. Menon, C. Warfield, G.R. Grotendorst, A.L. Means, A.N. Economides, and M. Gannon. 2011. Connective tissue growth factor acts within both endothelial cells and beta cells to promote proliferation of developing beta cells. Proc Natl Acad Sci U S A 108:15242-15247.

Herold, K.C., S.E. Gitelman, U. Masharani, W. Hagopian, B. Bisikirska, D. Donaldson, K. Rother, B. Diamond, D.M. Harlan, and J.A. Bluestone. 
2005. A single course of anti-CD3 monoclonal antibody hOKT3gamma1(Ala-Ala) results in improvement in C-peptide responses and clinical parameters for at least 2 years after onset of type 1 diabetes. Diabetes 54:1763-1769.

Herold, K.C., W. Hagopian, J.A. Auger, E. Poumian-Ruiz, L. Taylor, D. Donaldson, S.E. Gitelman, D.M. Harlan, D. Xu, R.A. Zivin, and J.A. Bluestone. 2002. Anti-CD3 monoclonal antibody in new-onset type 1 diabetes mellitus. N Engl J Med 346:1692-1698.

Hess, D., L. Li, M. Martin, S. Sakano, D. Hill, B. Strutt, S. Thyssen, D.A. Gray, and M. Bhatia. 2003. Bone marrow-derived stem cells initiate pancreatic regeneration. Nat Biotechnol 21:763-770.

Ianus, A., G.G. Holz, N.D. Theise, and M.A. Hussain. 2003. In vivo derivation of glucose-competent pancreatic endocrine cells from bone marrow without evidence of cell fusion. J Clin Invest 111:843-850.

Jain, R., D.M. Tartar, R.K. Gregg, R.D. Divekar, J.J. Bell, H.H. Lee, P. Yu, J.S. Ellis, C.M. Hoeman, C.L. Franklin, and H. Zaghouani. 2008. Innocuous IFNgamma induced by adjuvant-free antigen restores normoglycemia in NOD mice through inhibition of IL-17 production. J Exp Med 205:207-218.

Johansson, M., G. Mattsson, A. Andersson, L. Jansson, and P.O. Carlsson. 2006. Islet endothelial cells and pancreatic beta-cell proliferation: studies in vitro and during pregnancy in adult rats. Endocrinology 147:2315-2324.

Kaido, T., M. Yebra, V. Cirulli, and A.M. Montgomery. 2004. Regulation of human beta-cell adhesion, motility, and insulin secretion by collagen IV and its receptor alpha1beta1. J Biol Chem 279:53762-53769.

Kaufman, D.L., M. Clare-Salzler, J. Tian, T. Forsthuber, G.S. Ting, P. Robinson, M.A. Atkinson, E.E. Sercarz, A.J. Tobin, and P.V. Lehmann. 1993. Spontaneous loss of T-cell tolerance to glutamic acid decarboxylase in murine insulin-dependent diabetes. Nature 366:69-72.

Khoo, C.P., M.G. Valorani, M. Brittan, M.R. Alison, G. Warnes, U. Johansson, M. Hawa, and P. Pozzilli. 2009. Characterization of endothelial progenitor cells in the NOD mouse as a source for cell therapies. Diabetes/metabolism research and reviews 25:89-93.

Kim, S.K., K.V. Tarbell, M. Sanna, M. Vadeboncoeur, T. Warganich, M. Lee, M. Davis, and H.O. McDevitt. 2004. Prevention of type I diabetes transfer by glutamic acid decarboxylase 65 peptide 206-220-specific T cells. Proc Natl Acad Sci U S A 101:14204-14209. 
Lammert, E., O. Cleaver, and D. Melton. 2001. Induction of pancreatic differentiation by signals from blood vessels. Science 294:564-567.

Lammert, E., G. Gu, M. McLaughlin, D. Brown, R. Brekken, L.C. Murtaugh, H.P. Gerber, N. Ferrara, and D.A. Melton. 2003. Role of VEGF-A in vascularization of pancreatic islets. Current biology : CB 13:1070-1074.

Lechner, A., Y.G. Yang, R.A. Blacken, L. Wang, A.L. Nolan, and J.F. Habener. 2004. No evidence for significant transdifferentiation of bone marrow into pancreatic beta-cells in vivo. Diabetes 53:616-623.

Li, L., Z. Yi, B. Wang, and R. Tisch. 2009. Suppression of ongoing T cellmediated autoimmunity by peptide-MHC class II dimer vaccination. $J$ Immunol 183:4809-4816.

Liu, C.P., K. Jiang, C.H. Wu, W.H. Lee, and W.J. Lin. 2000. Detection of glutamic acid decarboxylase-activated T cells with I-Ag7 tetramers. Proc Natl Acad Sci U S A 97:14596-14601.

Loomans, C.J., E.J. de Koning, F.J. Staal, M.B. Rookmaaker, C. Verseyden, H.C. de Boer, M.C. Verhaar, B. Braam, T.J. Rabelink, and A.J. van Zonneveld. 2004. Endothelial progenitor cell dysfunction: a novel concept in the pathogenesis of vascular complications of type 1 diabetes. Diabetes 53:195-199.

Ludvigsson, J., M. Faresjo, M. Hjorth, S. Axelsson, M. Cheramy, M. Pihl, O. Vaarala, G. Forsander, S. Ivarsson, C. Johansson, A. Lindh, N.O. Nilsson, J. Aman, E. Ortqvist, P. Zerhouni, and R. Casas. 2008. GAD treatment and insulin secretion in recent-onset type 1 diabetes. $N$ Engl $\mathrm{J}$ Med 359:1909-1920.

Luo, X., K.C. Herold, and S.D. Miller. 2010. Immunotherapy of type 1 diabetes: where are we and where should we be going? Immunity 32:488-499.

Mathews, V., P.T. Hanson, E. Ford, J. Fujita, K.S. Polonsky, and T.A. Graubert. 2004. Recruitment of bone marrow-derived endothelial cells to sites of pancreatic beta-cell injury. Diabetes 53:91-98.

Michels, A.W., and M. von Herrath. 2011. 2011 Update: antigen-specific therapy in type 1 diabetes. Curr Opin Endocrinol Diabetes Obes 18:235-240.

Moody, A.J., K.R. Hejnaes, M.O. Marshall, F.S. Larsen, E. Boel, I. Svendsen, E. Mortensen, and T. Dyrberg. 1995. Isolation by anion-exchange of immunologically and enzymatically active human islet glutamic acid decarboxylase 65 overexpressed in Sf9 insect cells. Diabetologia 38:1423. 
Nepom, G.T., J.D. Lippolis, F.M. White, S. Masewicz, J.A. Marto, A. Herman, C.J. Luckey, B. Falk, J. Shabanowitz, D.F. Hunt, V.H. Engelhard, and B.S. Nepom. 2001. Identification and modulation of a naturally processed $T$ cell epitope from the diabetes-associated autoantigen human glutamic acid decarboxylase 65 (hGAD65). Proc Natl Acad Sci U S A 98:1763-1768.

Nikolova, G., N. Jabs, I. Konstantinova, A. Domogatskaya, K. Tryggvason, L. Sorokin, R. Fassler, G. Gu, H.P. Gerber, N. Ferrara, D.A. Melton, and E. Lammert. 2006. The vascular basement membrane: a niche for insulin gene expression and Beta cell proliferation. Developmental cell 10:397405.

Nishio, J., J.L. Gaglia, S.E. Turvey, C. Campbell, C. Benoist, and D. Mathis. 2006. Islet recovery and reversal of murine type 1 diabetes in the absence of any infused spleen cell contribution. Science 311:1775-1778.

Peichev, M., A.J. Naiyer, D. Pereira, Z. Zhu, W.J. Lane, M. Williams, M.C. Oz, D.J. Hicklin, L. Witte, M.A. Moore, and S. Rafii. 2000. Expression of VEGFR-2 and AC133 by circulating human CD34(+) cells identifies a population of functional endothelial precursors. Blood 95:952-958.

Phillips, J.M., L. O'Reilly, C. Bland, A.K. Foulis, and A. Cooke. 2007. Patients with chronic pancreatitis have islet progenitor cells in their ducts, but reversal of overt diabetes in NOD mice by anti-CD3 shows no evidence for islet regeneration. Diabetes 56:634-640.

Reyes, M., A. Dudek, B. Jahagirdar, L. Koodie, P.H. Marker, and C.M. Verfaillie. 2002. Origin of endothelial progenitors in human postnatal bone marrow. $J$ Clin Invest 109:337-346.

Schatteman, G.C., H.D. Hanlon, C. Jiao, S.G. Dodds, and B.A. Christy. 2000. Blood-derived angioblasts accelerate blood-flow restoration in diabetic mice. J Clin Invest 106:571-578.

Sreenan, S., A.J. Pick, M. Levisetti, A.C. Baldwin, W. Pugh, and K.S. Polonsky. 1999. Increased beta-cell proliferation and reduced mass before diabetes onset in the nonobese diabetic mouse. Diabetes 48:989-996.

Suri, A., B. Calderon, T.J. Esparza, K. Frederick, P. Bittner, and E.R. Unanue. 2006. Immunological reversal of autoimmune diabetes without hematopoietic replacement of beta cells. Science 311:1778-1780.

Takiishi, T., H. Korf, T.L. Van Belle, S. Robert, F.A. Grieco, S. Caluwaerts, L. Galleri, I. Spagnuolo, L. Steidler, K. Van Huynegem, P. Demetter, C. Wasserfall, M.A. Atkinson, F. Dotta, P. Rottiers, C. Gysemans, and C. 
Mathieu. 2012. Reversal of autoimmune diabetes by restoration of antigen-specific tolerance using genetically modified Lactococcus lactis in mice. J Clin Invest 122:1717-1725.

Tang, Q., K.J. Henriksen, M. Bi, E.B. Finger, G. Szot, J. Ye, E.L. Masteller, H. McDevitt, M. Bonyhadi, and J.A. Bluestone. 2004. In vitro-expanded antigen-specific regulatory $\mathrm{T}$ cells suppress autoimmune diabetes. $\mathrm{J}$ Exp Med 199:1455-1465.

Tarbell, K.V., M. Lee, E. Ranheim, C.C. Chao, M. Sanna, S.K. Kim, P. Dickie, L. Teyton, M. Davis, and H. McDevitt. 2002. CD4(+) T cells from glutamic acid decarboxylase (GAD)65-specific $T$ cell receptor transgenic mice are not diabetogenic and can delay diabetes transfer. J Exp Med 196:481492.

Tartar, D.M., A.M. VanMorlan, X. Wan, F.B. Guloglu, R. Jain, C.L. Haymaker, J.S. Ellis, C.M. Hoeman, J.A. Cascio, M. Dhakal, M. Oukka, and H. Zaghouani. 2010. FoxP3+RORgammat+ $T$ helper intermediates display suppressive function against autoimmune diabetes. J Immunol 184:33773385.

Thum, T., D. Fraccarollo, M. Schultheiss, S. Froese, P. Galuppo, J.D. Widder, D. Tsikas, G. Ertl, and J. Bauersachs. 2007. Endothelial nitric oxide synthase uncoupling impairs endothelial progenitor cell mobilization and function in diabetes. Diabetes 56:666-674.

Tian, J., M. Clare-Salzler, A. Herschenfeld, B. Middleton, D. Newman, R. Mueller, S. Arita, C. Evans, M.A. Atkinson, Y. Mullen, N. Sarvetnick, A.J. Tobin, P.V. Lehmann, and D.L. Kaufman. 1996. Modulating autoimmune responses to GAD inhibits disease progression and prolongs islet graft survival in diabetes-prone mice. Nat Med 2:1348-1353.

Tisch, R., R.S. Liblau, X.D. Yang, P. Liblau, and H.O. McDevitt. 1998. Induction of GAD65-specific regulatory T-cells inhibits ongoing autoimmune diabetes in nonobese diabetic mice. Diabetes 47:894-899.

Tisch, R., X.D. Yang, S.M. Singer, R.S. Liblau, L. Fugger, and H.O. McDevitt. 1993. Immune response to glutamic acid decarboxylase correlates with insulitis in non-obese diabetic mice. Nature 366:72-75.

Waldron-Lynch, F., and K.C. Herold. 2011. Immunomodulatory therapy to preserve pancreatic beta-cell function in type 1 diabetes. Nature reviews. Drug discovery 10:439-452.

Wallet, M.A., R.R. Flores, Y. Wang, Z. Yi, C.J. Kroger, C.E. Mathews, H.S. Earp, G. Matsushima, B. Wang, and R. Tisch. 2009. MerTK regulates thymic 
selection of autoreactive T cells. Proc Natl Acad Sci U S A 106:48104815.

Wan, X., F.B. Guloglu, A.M. Vanmorlan, L.M. Rowland, R. Jain, C.L. Haymaker, J.A. Cascio, M. Dhakal, C.M. Hoeman, D.M. Tartar, and H. Zaghouani. 2012. Mechanisms underlying antigen-specific tolerance of stable and convertible th17 cells during suppression of autoimmune diabetes. Diabetes 61:2054-2065.

Wang, M., J.J. Racine, X. Song, X. Li, I. Nair, H. Liu, A. Avakian-Mansoorian, H.F. Johnston, C. Liu, C. Shen, M. Atkinson, I. Todorov, F. Kandeel, S. Forman, B. Wilson, and D. Zeng. 2012. Mixed chimerism and growth factors augment beta cell regeneration and reverse late-stage type 1 diabetes. Sci Transl Med 4:133ra159.

Yoon, J.W., C.S. Yoon, H.W. Lim, Q.Q. Huang, Y. Kang, K.H. Pyun, K. Hirasawa, R.S. Sherwin, and H.S. Jun. 1999. Control of autoimmune diabetes in NOD mice by GAD expression or suppression in beta cells. Science 284:1183-1187. 


\section{VITA}

Xiaoxiao Wan was born December 11, 1980 in Chengdu, Sichuan province in China. He graduated from the West China Medical Center at Sichuan University in 2004 with a Medical Degree. Xiaoxiao graduated from the Shanghai Medical School at Fudan University in 2007 with a Master Degree of Medical Sciences. During the study in medical schools, Xiaoxiao completed his internship as a medical student, residency as a surgeon, and worked as a research assistant in a laboratory.

After graduating from medical school, Xiaoxiao moved to Columbia, MO and joined Dr. Habib Zaghouani's lab to pursue a PhD Degree. His research focuses on antigen-specific tolerance in type 1 diabetes. 